WFPS: TME-79-012

UC-20,20D

\title{
SCOPING AND SENSITIVITY ANALYSES FOR THE \\ DEMONSTRATION TOKAMAK HYBRID REACTOR (DTHR)
}

D. A, SINK

G. GIBSON

MARCH 1979

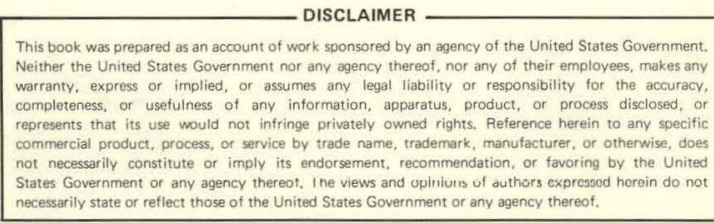

SPONSORED BY

US DEPARTMENT OF ENERGY

CONTRACT EG-77-C-02-4544

\section{fusion power}

\section{susstems department}

(w) Westinghouse Electric Corporation P.O. Box 10864, Pgh. Pa. 15236

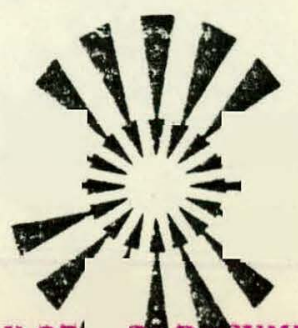




\section{DISCLAIMER}

This report was prepared as an account of work sponsored by an agency of the United States Government. Neither the United States Government nor any agency Thereof, nor any of their employees, makes any warranty, express or implied, or assumes any legal liability or responsibility for the accuracy, completeness, or usefulness of any information, apparatus, product, or process disclosed, or represents that its use would not infringe privately owned rights. Reference herein to any specific commercial product, process, or service by trade name, trademark, manufacturer, or otherwise does not necessarily constitute or imply its endorsement, recommendation, or favoring by the United States Government or any agency thereof. The views and opinions of authors expressed herein do not necessarily state or reflect those of the United States Government or any agency thereof. 


\section{DISCLAIMER}

Portions of this document may be illegible in electronic image products. Images are produced from the best available original document. 
WFPS: TME $-79-012$

MARCH 1979

SCOPING AND SENSITIVITY ANALYSES FOR THE DEMONSTRATION TOKAMAK HYBRID REACTOR (DTHR)
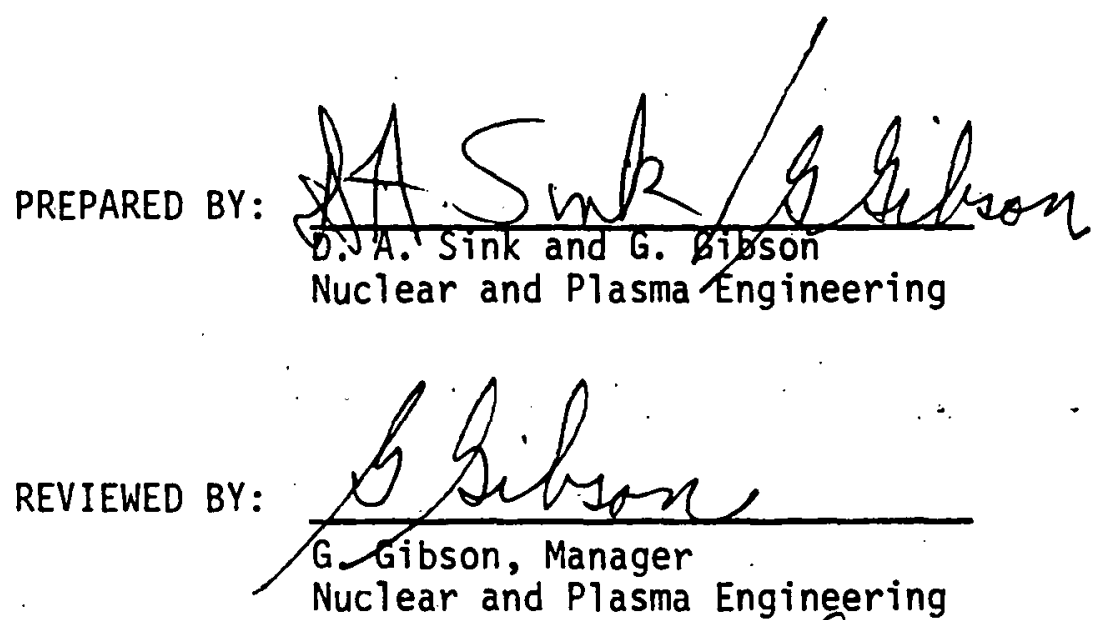

Nuclear and Plasma Engineering

APPROVED BY:
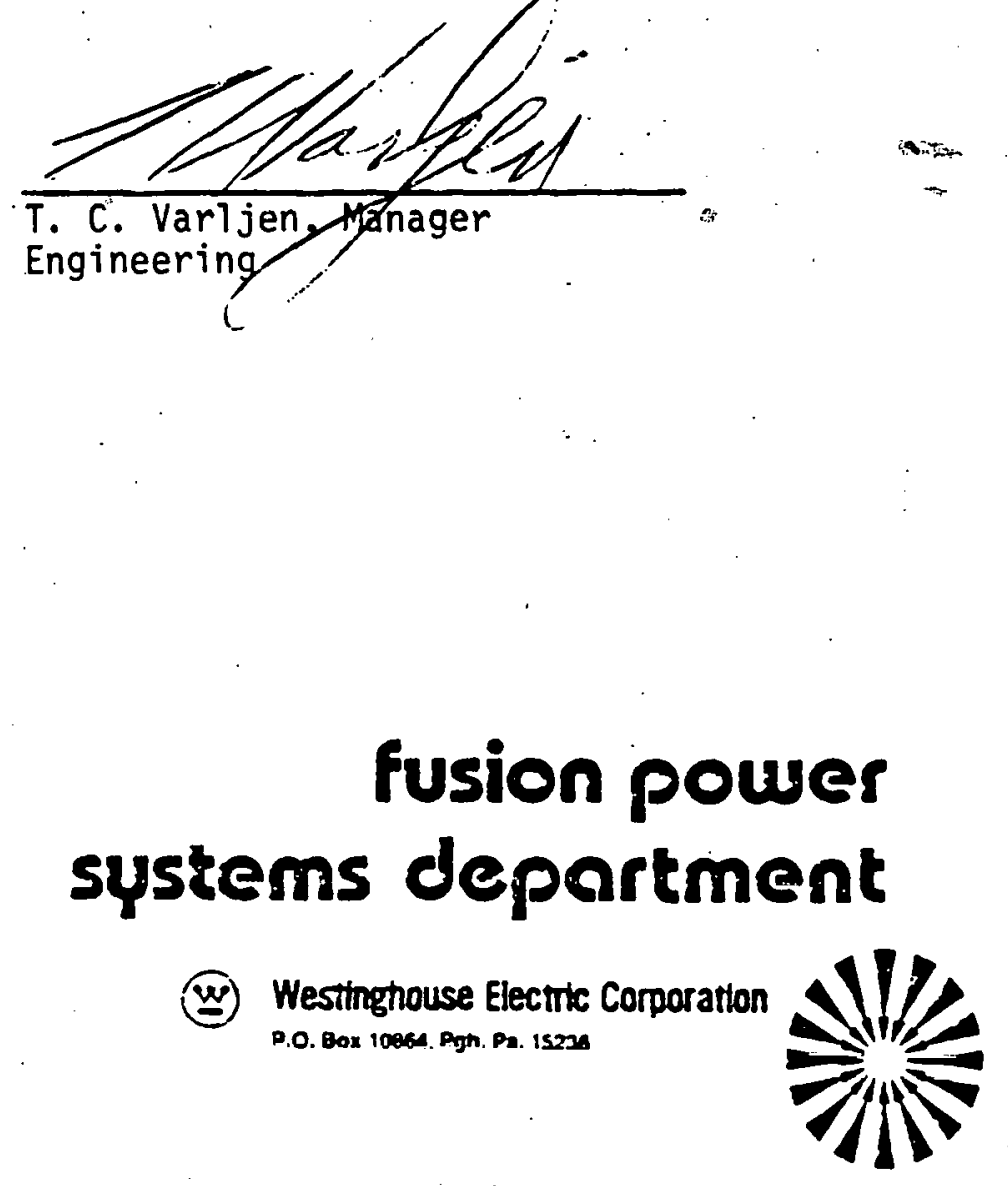


\section{ACKNOWLEDGEMENT}

This work was performed for the Office of Fusion Energy of the U.S. Department of Energy under Contract EG-77-C-02-4544. Reproduction, translation, publication, use and disposal, in whole or in part, by or for the United States Government is permitted.

\section{NOTICE}

This report was prepared as an account of work sponsored by an agency of the United States Government. Neither the United States nor any agency thereof, nor any of their employees, makes any warranty, expressed or implied, or assumes any legal liability or responsibility for any third party's use or the results of such use of any information, apparatus, product or process disclosed in this report, or represents that its use by such third party would not infringe privately owned rights.

Printed in the United States of America

Available from

National Technical Information Service

U.S. Department of Commerce

5285 Port Royal Road

Springfield VA 22161

NTIS price codes

Printed Copy: $\$ 6.00$

Microfiche Copy: A05 


\section{ABSTRACT}

The results of an extensive set of parametric studies are presented which provide analytical data of the effects of various tokamak parameters on the performance and cost of the DTHR (Demonstration Tokamak Hybrid Reactor). The studies were centered on a point design which is described in detail. Variations in the device size, neutron wall loading, and plasma aspect ratio are presented, and the effects on direct hardware costs, fissile fuel production (breeding), fusion power production, electrical power consumption, and thermal power production are shown graphically. The studies considered both ignition and beam-driven operations of DTHR and yielded results based on two empirical scaling laws presently used in reactor studies. Sensitivity studies were also made for variations in the following key parameters: the plasma elongation, the minor radius, the TF coil peak field, the neutral beam injection power; and the $z_{\text {eff }}$ of the plasma.

In general, the results indicate direct capital costs (of device and facility hardware) in the range from $600 \mathrm{M} \$$ to $800 \mathrm{M} \$$, required neutral beam injection energies equal to or greater than $160 \mathrm{keV}$, and TF coil bore dimensions of $6 \mathrm{~m} \times 8.5 \mathrm{~m}$ and larger. For the assumptions used in the study (for example, the product of duty cycle and plant availability equal to 0.2 and a blanket coverage of the outer half of the torus of 0.36 ), all device sizes presented are capable of producing $100 \mathrm{~kg}$ or more of fissile fuel; a major radius, $R_{0}$, of $4.9 \mathrm{~m}$ is the minimum size for which an annual production of $200 \mathrm{~kg}$ of fissile material is predicted, and $R_{0}=5.2 \mathrm{~m}$ is the minimum size for which ignition is achieved. As $R_{0}$ is increased, economy-of-scale cost improvements for fissile production are observed in spite of increases in hardware costs and neutral beam energy requirements. 
TABLE OF CONTENTS

Page No.

1.0 INTRODUCTION

2.0 SCIENTIFIC AND ENGINEERING GROUND RULES

3.0 PERFORMANCE AND COST AS A FUNCTION OF DEVICE SIZE

4.0 PERFORMANCE: AND COST AS A FUNCTION OF NEUTRON WALL LOADING

5.0 PERFORMANCE AND COST AS A FUNCTION OF ASPECT RATIO FOR VARIOUS DEVICE SIZES

6.0 SENSITIVITY STUDIES

7.0 SUMMARY AND CONCLUSIONS

8.0 REFERENCES

APPENDIX A - COAST CODE UPGRADE DESCRIPTION

APPENDIX B - COAST RESULTS FOR TFTR 


\section{LIST OF FIGURES}

Figure No.

Page No.

2-1 Demonstration Tokamak Hybrid Reactor.

3-1 Cost, Annual Fissile Fuel Production and Maximum TF Required as a Function of Major Radius, $R_{0}$, for a Neutron Wall Loading of $2.0 \mathrm{MW} \mathrm{m}^{-2}$.

3-2 Electrical Power Consumed and Peak Fusion Power (17.6 MeV/Event) as a Function of Major Radius, $R_{0}$,

3-3 High-Grade Heat Production and Electrical Energy Consumed Per Year as a Function of Major Radius, $R_{0}$, for a Neutron Wall Loading of $2.0 \mathrm{MW} \mathrm{m}^{-2}$.

3-4 Cost and Annual Fissile Fuel Production as a Function of Major Radius, $R_{0}$, for Ignition Operations and a Neutron Wall Loading of $2.0 \mathrm{MW} \mathrm{m}^{-2}$.

3-5 Electric Power Consumed and Peak Fusion Power (17.6 MeV/Event) as a Function of Major Radius, $R_{0}$, for a Wall Loading of $2.0 \mathrm{MW} \mathrm{m}^{-2}$ and Ignition Operation.

3-6 High-Grade Heat Production and Electrical Energy Consumed Per Year as a Function of Major Radius, $R_{0}$, for a Neutron Wall Loading of $2 \mathrm{MW} \mathrm{m}^{-2}$ and Ignition Operation.

3-7 Cost and Annual Fissile Fuel Production as a Function of Major Radius, $\mathrm{R}_{0}$, for Ignition Operation Assuming Empirical Scaling for $\tau_{E}$ :

3-8 Electric Power Consumed and Peak Fusion Power (17.6 MeV/Event) as a Function of Major Radius, $R_{0}$, for Ignition Operation Assuming Empirical Scaling ${ }^{\circ}$ for $\tau_{E}$.

3-9 High-Grade Heat Production and Electrical Energy Consumed Per Year as a Function of Major Radius, R, for Ignition Operation Assuming Empirical Scaling ${ }^{\circ}$ for $\tau_{E}$. 


\section{LIST OF FIGURES (CONTINUED)}

Figure No.

Page No.

3-1.0 TF Coil Bore Dimensions as a Function of the Plasma

$3-12$

Radii for $A=4.333$ Beam-Driven DTHR.

$3-13$

Plasma Radi $i$ for $A=4.333$, Beam-Driven DTHR.

4-1 Cost, Annual Fissile Fuel Production, and Maximum TF

$4-2$

Required às a Function of Wall Loading for Fixed

Major Radius, $R_{0}=5.2 \mathrm{~m}, \mathrm{a}=1.2 \mathrm{~m}$.

4-2 Electric Power Consumed and Peak Fusion. Power

$4-3$

(17.6 MeV/Event) as a. Function of Wall Loading for

a Fixed Major Radius, $R_{0}=5.2 \mathrm{~m}$.

4-3 High-Grade Heat Production and Electrical Energy

4-4

Consumed Per Year as a Function of Wall Loading

for a Fixed Major Radius, $R_{0 .}=5.2 \mathrm{~m}$.

4-4 Cost, Annual Fissile Fuel Production, and Maximum TF

$4-5$

Required as a Function of Wall Loading for A Fixed

Major Radius $R_{0}=6.93 \mathrm{~m}$, and $a=1.6 \mathrm{~m}$.

4-5 Electrical Power Consumed and Peak Fusion Power

(17.6 MeV/Event) as a Function of Wall Loading for a. Fixed Major Radius, $R_{0}=6.93 \mathrm{~m}, a=1.6 \mathrm{~m}$.

4-6 High-Grade Heat Production and Electrical Energy Consumed. Per Year as a Function of Wall Loading for a. Fixed Major Radius, $R_{0}=6.93 \mathrm{~m}, a=1.6 \mathrm{~m}$.

5-1 Cost as a Function of Aspect Ratio for Various Minor. Radii, a.

5-2. Fissile Fuel Production as a Function of Aspect Ratio 5-4 for Various Minor Radii, a.

5-3 High-Grade Heat Production as a Function of Aspect

5-5 Ratio: for Varinus Minor Radii,. a.

5-4 Peak Fusion Power as a: Function of Aspect Ratio for Various: Minor Radi i, a. 


\section{LIST OF FIGURES (CONTINUED)}

Figure No.

Page No.

5-5 Electrical Power Consumed as a Function of Aspect.

5-6 Electrical Energy Consumption as a Function of Aspect Ratio for Various Minor Radii, a.

5-7 Neutron Wall Loading as a Function of Aspect Ratio for Various Minor Radii.

5-8 Neutral Beam Power Efficiency for Positive Ion Based Injection.

5-9 Cost and Annual Fissile Fuel Production as a Function of Aspect Ratio for $a=1.2 \mathrm{~m}$.

6-1 Cost and Annual Fissile Fuel Production as a Function of Plasma Minor Radius for $R_{0}=6.93 \mathrm{~m}$.

6-2 Cost and Annual Fissile Fuel Production as a Function of Plasma Elongation for $R_{0}=6.93 \mathrm{~m}, E_{b}=185 \mathrm{keV}$, $B_{M}=9.9 \mathrm{~T}$.

6-3 Cost and Annual Fissile Fuel Production as a Function of Maximum Toroidal Field, $B_{M}, R_{0}=6.93 \mathrm{~m}$.

6-4 High-Grade Heat Production and Electrical Energy Consumed Per Year as a Function of Maximum Toroidal Field, $B_{M}, R_{0}=6.93 \mathrm{~m}, a=1.6$.

6-5 Cost and Annual Fissile Fuel Production as a Function of Steady State Neutral Beam Power (PNB $=0 \rightarrow$ Ignition) $a=1.2 \mathrm{~m}$. 


\section{LIST OF TABLES}

Table No.

Page No.

2-1 PLASMA PARAMETERS FOR THE REFERENCE DTHR DESIGN

$2-2$ USED IN TRADE STUDIES

2-2 THE MAIN ENGINEERING FEATURES OF THE REFERENCE DTHR

$2-3$

2-3 NUMERICAL ASSUMPTIONS AND GROUND RULES FOR THE DTHR

$2-5$ DESIGN AND TRADE STUDIES

2-4 PRINCIPLE LIMITS ASSOCIATED WITH THE PLASMA, TF

B-1 ASSUMPTIONS FOR TFTR PLASMA

$B-2$

B-2 CALCULATED RESULTS FOR THE TFTR PLASMA

B-3

B-3 CALCULATED PARAMETERS FOR TF SYSTEMS

$B-5$

B-4. CALCULATED PARAMETERS FOR PF SYSTEMS

B-6

B-5 CALCULATED NB INJECTOR PARAMETERS FOR A SINGLE INJECTOR ARM

B-7

B-6

COSTS IN M\$ OF TFTR HARDWARE FROM COAST-4 AND THE

B-8 


\subsection{INTRODUCTION}

A study has been performed to determine the effects of tokamak parameters such as plasma size, neutron wall loading, neutral beam energy and power, and peak field associated with the magnetic coil assembly on the performance and cost of the DTHR (Demonstration Tokamak Hybrid Reactor) ${ }^{(1)}$. Westinghouse has been developing a point design ${ }^{(2)}$ selected in September 1978 for DTHR under a DOE contract. The DTHR point design was based on a very.limited parametric survey; the objective of the study reported here was to explore the DTHR parameter space and provide the basis for future optimization of the concept. The results presented here are in the nature of a status report and are not intended to be definitive. The technique of first developing a point design with appropriate engineering definition to use as a basis for computer model development was applied during the initial development of COAST and has been used for subsequent upgrades of the code. DTHR has been scoped on the basis that the following principle goals will be achieved during its operation: 1) the demonstration of the production of a significant $(\geq 100 \mathrm{~kg}$ ) quantity of fissile fuel in a nearterm fusion-fission reactor; 2) the demonstration of reactor technology required for future commercial applications; 3 ) the demonstration of long-pulse, highduty-cycle plasma operation; 4) the demonstration of remote handling techniques for future plants; and 5) to serve as an engineering and materials test facility. Although DTHR does not have as goals the production of electrical power or tritium, test modules could be located in designated areas to demons lrate the potential of these functions.

In conducting the performance and cost evaluation of DTHR, the computer code COAST was extensively used. This code provides a generalized description of a D-T burning tokamak and models in a self-consistent manner approximately 50 subsystems. The sizing, costing, and performance of devices ranging from TFTR to a commercial reactor, including a hybrid reactor, can be quantitatively evaluated using COAST. A description of the present version of COAST is given in 
Appendix A. Earlier descriptions and applications of COAST are given in References 3 through 6.

A number of scientific and engineering ground rules were established in order to perform the trade study. These ground rules allow the hybrid tokamak device, i.e., DTHR, to be defined and set limits on the parameter space considered in the study. Even though $100 \mathrm{~kg} / \mathrm{yr}$ of fissile fuel production was assumed as providing the required demonstration of fissile breeding, the value of $200 \mathrm{~kg} /$ yr was considered as a nominal performance rating for DTHR. Section 2.0 is a presentation of the various ground rules assumed.

In Section 3.0, the device size, as parameterized by the major radius of the plasma and TF coil assembly, is varied, and the effects on fusion power, electrical power and energy consumed, high-grade heat production and fissile fuel production are described. Since DTHR was not designed to utilize electric power obtained from the conversion of thermal energy, the operation of the device will result in the consumption of externally supplied electrical power. In Section 4.0, the variation of neutron wall loading is considered. The effects of varying the aspect ratio (A) are discussed in Section 5.0. The impact on plasma and reactor performance and the capital cost of the above variations are shown graphically in each of the three sections. The sensitivities of the calculated results to a number of the important ground rules are discussed in Section 6.0. A summary of the results and conclusions are presented in Section 7.0. References are listed in Section 8.0. There is a description of the COAST code in Appendix $A$, and as a point of normalization the results of applying the COAST code to TFTR are presented in Appendix $B$. Comparisons are made between the COAST results, and the TFTR costs given in the Final Conceptual Design Report. In general, good agreement has been found. 


\subsection{SCIENTIFIC AND ENGINEERING GROUND RULES}

The assumptions and ground rules used in conducting the DTHR Scoping Studies related to performance and cost are varied about a point design ${ }^{(2)}$ completed in September 1978. That design has a plasma characterized by a major radius $R_{0}=5.2 \mathrm{~m}$, a minor radius $a=1.2 \mathrm{~m}$ (therefore $A=R_{0} / a=4.333$ ), an elongation $\delta=1.6$, and an average plasma temperature $T=17.3 \mathrm{keV}$. The plasma density, the magnetic field-on-axis, and the total plasma beta were established such that the neutron wall loading is $2.0 \mathrm{MW} / \mathrm{m}^{2}$, the maximum field at the TF coil inner leg is $\leq 12 \mathrm{~T}$, the neutral beam energy required is $\leq 200 \mathrm{keV}$, and the poloidal beta is $\leq A$. In calculating the above parameters (using COAST), effects due to an assumed parabolic profile in both plasma temperature and plasma density and due to the plasma being operated in a beam-driven mode were taken into account. The DTHR point design ${ }^{(2)}$ was based on 150 MW of neutral beam (NB) power to drive the plasma, but for the studies described in this report a reduced power level has been generally found to be required. The reasons for the assumption on neutral beam power are discussed later in this section.

A 1 ist of plasma parameters is given in Table 2-1 for DTHR. The two time constants shown in Table 2-1 are based on: 1) empirical scaling ( $\tau_{e m p} \propto \bar{n}_{e} a^{2} s^{2}$ $q^{1 / 2}$ where $s=(1+\delta) / 2$ is the shape factor, and $q=2.5$ is the stability factor); and 2) the energy balance equation (Eq. 10) for an equilibrium condition in which a-heating plus NB-heating maintain the plasma temperature against losses due to conduction, transport, and radiation.

The engineering features of the DTHR device are summarized in Table 2-2. A11 magnetic field coil assemblies have $S / C \mathrm{Nb}_{3} S$ conductors with the TF coils having a COMPACT-D $(7)$ shape, and all PF coils located outside the TF coil assembly. The plasma support systems include a compact bundle divertor $(2,8)$, positive-ion based neutral beam injectors ${ }^{(2)}$ with no direct recovery systems, pellet injection for refueling, and a fusile fuel handling system ${ }^{(2)}$ with 
TABLE 2-1

PLASMA PARAMETERS FOR THE REFERENCE DTHR DESIGN USED IN TRADE STUDIES

\begin{tabular}{|c|c|}
\hline PARAMETER (UNITS) & VALUE \\
\hline MAJOR RADIUS, $R_{0}(\mathrm{~m})$ & 5.2 \\
\hline MINOR RADIUS, a (m) & 1.2 \\
\hline ASPECT RATIO, A (-) & 4.333 \\
\hline PLASMA ELONGATION, $\delta(-)$ & 1.6 \\
\hline PLASMA BETA, $B(\%)$ & 6.24 \\
\hline FIELD ON AXIS, $B_{t}(T)$ & 5.45 \\
\hline PLASMA CURRENT, $I_{p}$ (MA) & 5.1 \\
\hline PLASMA FLUX SWING, $v_{s}\left(V_{s}\right)$ & 65 \\
\hline NEUTRAL WALL LOADING, $\mathrm{J}_{W}\left(\mathrm{MW} \mathrm{m}^{-2}\right)$ & 2.0 \\
\hline TOTAL FUSION POWER, $P_{f}(M W)$ & 900 \\
\hline AVERAGE ELECTRON DENSITY, $\bar{n}_{e}\left(m^{-3}\right)$ & $1 \times 10^{20}$ \\
\hline AVERAGE PLASMA TEMPERATURE, $\overline{\mathrm{T}}(\mathrm{keV})$ & 17.3 \\
\hline EMPIRICAL CONFINEMENT TIME, $\tau_{\text {emp }}(s)$ & 1.27 \\
\hline ENERGY BALANCE TIME CONSTANT, $\tau_{E}(s)$ & 0.93 \\
\hline EFFECTIVE CHARGE, $z_{\text {eff }}(-)$ & 1.2 \\
\hline STABILITY FACTOR, q (-) & 2.5 \\
\hline NEUTRAL BEAM POWER, $P_{B}$ (MW) & 52 \\
\hline NEUTRAL BEAM ENERGY, $E_{b}$ (keV) & 180 \\
\hline
\end{tabular}


TABLE 2-2

THE MAIN ENGINEERING FEATURES OF THE REFERENCE DTHR

- ALL MAGNETIC FIELD COILS (TF, EF, OH) HAVE S/C. Nb 3 Sn CONDUCTORS (WITH COPPER STABILIZERS)

- TF COILS hAVE COMPACT-D SHAPES, BOLTED-LAMINATED STRUCTURAL DESIGN, FORCED-FLOW LIQUID-HELIUM COOLANT, CENTRAL BUCKING CYLINDER, AND INDIVIDUAL DEWARS ON OUTER LEGS

- all pF COIls (ef and OH) ARE OUTSide the tF COILS

- THE PLASMA EXHAUST SYSTEM INCLUDES A BUNDLE DIVERTOR WITH A COMPACT MAGNETIC COIL SET WITHIN THE TF COIL BORE AND A COLLECTOR/BURIAL CHAMBER OUTSIDE THE TF COIL BORE WITH SETS OF Zr/AT GETTER COLLECTOR PANELS AND CRYOSORPTION PANELS ENCLOSED.

- THE NEUTRAL BEAM INJECTION SYSTEM FOR PLASMA START-UP AND BEAM-DRIVEN OPERATIONS HAS POSITIVE-ION SOURCES, GAS-CHANNEL NEUTRALIZERS, COMPACT SPACE-CHARGE CONTROLLED CHARGED-ION COLLECTORS, AND LARGEAREA CRYOPANEL GAS COLLECTORS

- DEVICE SHIELDING WHICH LIMITS THE RADIATION HEATING AND DOSE TO FIELD COILS, IS COMPOSED OF $65 . \mathrm{v} / 0$ STAINLESS STEEL AND $35 \mathrm{v} / 0$ WATER LOADED WITH NATURAL BORON (1 BORON ATOM PER 68 MOLECULES OF WATER)

- THE FERTILE BLANKET COVERING SECTIONS OF THE OUTER HALF OF THE TOROIDAL VACUUM VESSEL CONSISTS OF $13 / 10 / 31 / 45$ VOLUME PERCENTS OF STAINLESS STEEL STRUCTURE, ZIRCALOY CLAD, BOILING WATER COOLANT, AND THORIUM OXIDE FUEL, RESPECTIVELY. THE BLANKET IS ARRANGED IN A VERTICAL ROD GEOMETRY WITH $0.35 \mathrm{~m}$ THICK MODULES. THE BLANKET DESIGN INCORPORATES MANY FEATURES OF LIGHT WATER FISSION REACTOR TECHNOLOGY AND IS CAPABLE OF PRODUCING SIGNIFICANT QUANTITIES OF FISSILE ${ }^{233}$ U FUEL. 
continuous load processing capabilities for a once-through operating procedure. Fissile fuel is produced in a zircaloy clad thorium oxide fueled blanket $(2,9)$ with stainless steel structure cooled by two-phase (boiling) water in a crossflow configuration. The plasma and engineering ground rules for the design of DTHR are shown in Table 2-3. A trimetric of the DTHR device is shown in Figure 2-1.

The trade studies were conducted on the DTHR design as described above and for the ground rules listed in Table 2-3 using the COAST code (see Appendix A). The models in COAST allow the results given in the following sections to be consistent with the overall design as well as with each system, e.g., neutral beams, TF coils, blanket, divertor, etc., design.

The ground rules shown in Table 2-3 represent the numerical data used as input into COAST. These input parameters were held fixed in all the code calculations presented in the various figures appearing in this report. In some cases, the ground rule data values were arbitrarily selected in order to begin the study, and in other cases the values were based on engineering calculations (e.g., neutronic calculations for the blanket performance data) as well as engineering judgment and experience.

For purposes of component design, an effective square-wave duty cycle associated with the plasma burn was 0.77 , which is consistent with the plasma conditions given in Table 2-3. The product of duty cycle and the overall plant availability is 0.2 . The value of 0.2 was also assumed for the neutronic model calculations ${ }^{(9)}$, but for those calculations the duty cycle was assumed to be 0.5 and the overall plant availability was 0.4 .

The blanket parameters are based on neutronic model calculations ${ }^{(9)}$ for the $\mathrm{ThO}_{2}$ (zircaloy. clad) fuel elements which are cooled by boiling water. The $F$ and $M$ factors used (see Table 2-3) were selected as representative values. The magnitudes of these factors change slightly during exposure of the blanket and are a function of the scheme for shuffling and replacing individual elements. However, with the low duty cycle and plant availability of the DTHR, the fissile 
TABLE 2-3

NUMERICAL ASSUMPTIONS AND GROUND RULES FOR THE DTHR DESIGN AND TRADE STUDIES

PLASMA CONDITIONS

STABILITY FACTOR, q

2.5

EFFECTIVE CHARGE, $z_{\text {eff }}$

MAXIMUM TF RIPPLE AT PLASMA EDGE

1.2

OHMIC HEATING PERIOD

$2 \mathrm{~s}$

NEUTRAL BEAM HEATING PERIODS

FOR PLASMA START-UP

$5 \mathrm{~s}$

FOR STEADY STATE BURN (IF BEAM DRIVEN)

$63 \mathrm{~s}$

PLASMA TERMINATION PERIOD

$2 \mathrm{~s}$

TIME BETWEEN INITIATION OF SUCCESSIVE PULSES

85 's

DEVICE OPERATION

OPERATING DAYS PER WEEK

5

OPERATING HOURS PER DAY

16

PLANT AVAILABILITY TIMES DUTY CYCLE

0.2

NUMBER OF ANNUAL FULL-POWER PULSES

96,200

TOTAL NUMBER OF FULL-POWER PULSES

$1 \times 10^{6}$

COMPONENT DIMENSIONS AND SPACE ALLOCATIONS

SPACE FOR VACUUM VESSEL WALLS

$0.1 \mathrm{~m}$

SPACE FOR LIMITER/LINERS

$0.2 \mathrm{~m}$

SPACE FOR TF COIL DEWARS

$0.2 \mathrm{~m}$

SPACE FOR DEWARS ON PF AND DIVERTOR COILS

$0.1 \mathrm{~m}$

SPACE FOR HYBRID BLANKET

$1.0 \mathrm{~m}$

SPACE FOR OUTER SHIELD

$0.95 \mathrm{~m}$

SPACE FOR ACCESS AND ASSEMBL.Y

$0.2 \mathrm{~m}$

SPACE BETWEEN NB ARMS AND REACTOR CELL WALLS

$7.5 \mathrm{~m}$

BUNDLE DIVERTER SHIELDING THICKNESSES

$0.6 \mathrm{~m}$

NB ARM LENGTH

$7.5 \mathrm{~m}$ 
TABLE 2-3 (CONTINUED)

NUMERICAL ASSUMPTIONS AND GROUND RULES FOR THE DTHR DESIGN AND TRADE STUDIES

NB SOURCE DIMENSIONS - HORIZONTAL

$0.1 \mathrm{~m}$

- VERTICAL

$0.8 \mathrm{~m}$

NB ARM NEUTRALIZER LENGTH

$2.0 \mathrm{~m}$

NB DUCT SHIELDING THICKNESS

$0.33 \mathrm{~m}$

NB DUCT SCRAPE-OFF THICKNESS

$0.1 \mathrm{~m}$

HYBRID BLANKET DATA

NET NUMBER OF $233 \mathrm{U}$ ATOMS PRODUCED PER INCIDENT

FUSION NEUTRON, $F$

0.6

BLANKET ENERGY MULTIPLICATION FACTOR, $M$

2.0

FRACTION OF FUSION NEUTRONS INTERCEPTING OUTER VACUUM VESSEL WALL

0.67

FRACTION OF OUTER VACUUM VESSEL WALL COVERED BY HYBRID BLANKET MODULES

0.36

FINAL COOLANT TEMPERATURE

$500 \mathrm{~K}$

S/C TF COIL DATA

CURRENT DENSITY IN CONDUCTOR SLOT (CONDUCTOR MATERIAL, INSULATION, AND COOLANT AREA)

TOTAL CURRENT PER TURN

$3.75 \mathrm{kA} / \mathrm{cm}$

LIQUID HELIUM TEMPERATURE

$15 \mathrm{kA}$

TF RIPPLE AT COIL INNER LEG

$4.2 \mathrm{~K}$

STRAIN LIMIT FOR 'STRUCTURAL MEMBER

$4 \%$

SAFETY FACTOR IN STRUCTURAL DESIGN

$408 \mathrm{MPa}$

LIMIT ON TIME-AVERAGED NUCLEAR HEATING

2

LIMIT ON TOTAL DOSE TO COIL INSULATION

$20 \mathrm{~kW}$

$1 \times 10^{9}$ rads 
TABLE 2-3 (CONTINUED)

NUMERICAL ASSUMPTIONS AND GROUND RULES FOR THE DTHR DESIGN AND TRADE STUDIES

NEUTRAL BEAM ARM DATA

CURRENT PER SOURCE

$110 \mathrm{~A}$

ATOMIC FRACTION OF BEAM

0.9

INJECTION ANGLE

$16^{\circ}$

OVERALL TRANSMISSION EFF

$89 \%$

NB POWER SUPPLY EFF

PRESSURE IN NEUTRALIZER

$80 \%$

DRIFT TUBE DISTANCE TO PLASMA

CRYOPANEL AREA PER ION SOURCE

$3.5 \times 10^{-3}$ torr

GAS-TO-ION EFF OF SOURCE

$6.5 \mathrm{~m}$ $30 \mathrm{~m}^{2}$

$40 \%$ 


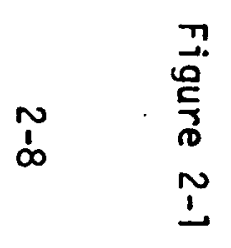

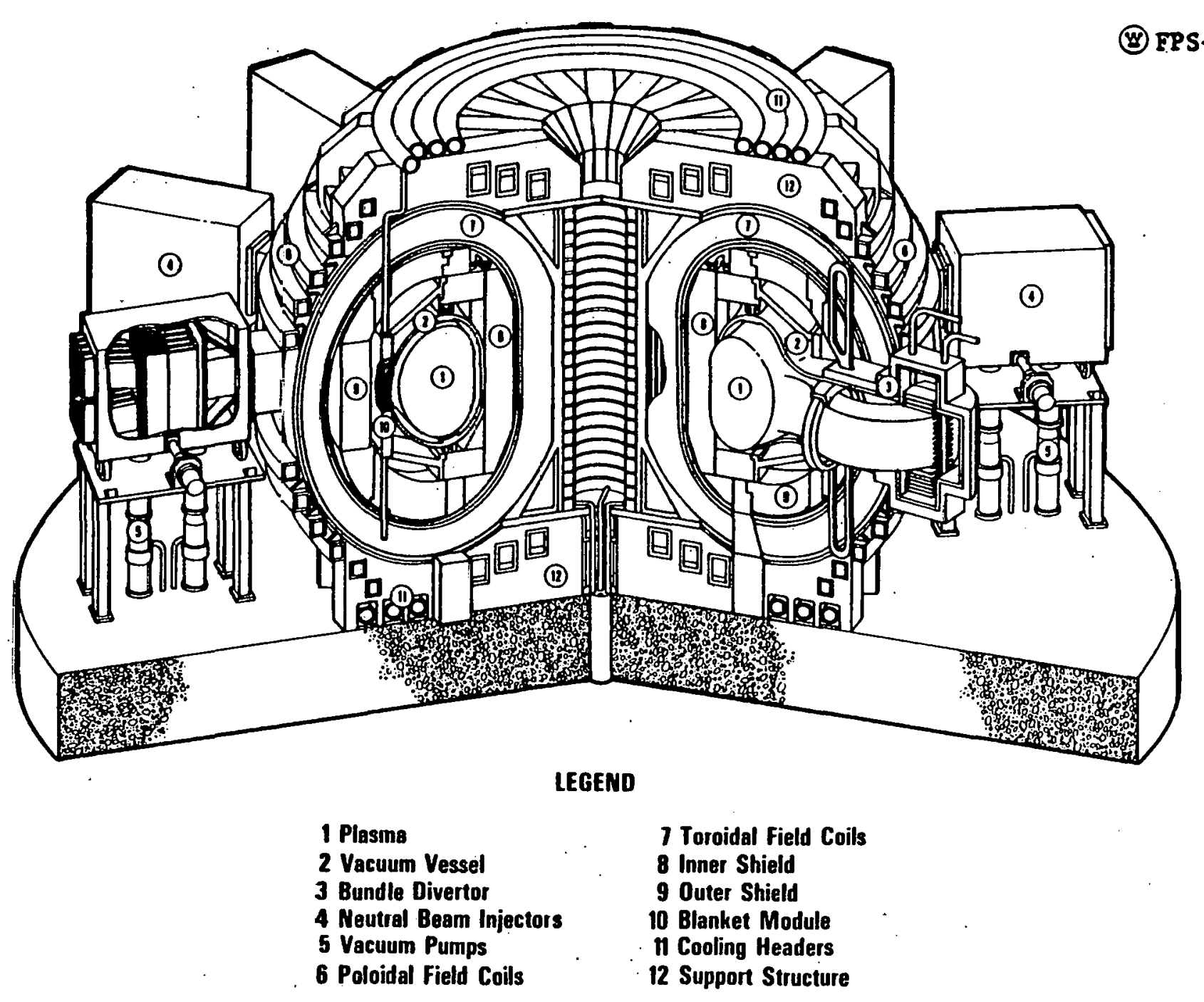

Figure 2-1. Demonstration Tokamak Hybrid Reactor. 
and power production rates in this blanket module remain fairly constant with exposure over a three year period at the values shown in Table 2-3. At the end of this three year exposure in the DTHR, the fissile ${ }^{233} \mathrm{U}$ enrichment has built up to a value of about $0.35 \%$. While tritium breeding was not required in the DTHR, there is sufficient neutron leakage from the blanket to provide a tritium breeding ratio of approximately 0.7 if lithium bearing modules are placed in the inner region of the torus and also in back of the fertile blanket. Also, although electrical power production was not a goal of the DTHR, the blanket module has been designed ${ }^{(9)}$ to operate at fairly high coolant temperatures and pressures. This would provide the potential for demonstrating electricity generation using conventional thermal-to-electrical power conversion systems in a possible upgrade of the DTHR.

The neutral beam injector parameters are based on a positive ion system utilizing sources with long narrow emitting areas which allow for charge particle collection using a space-charge controlled defocusing arrangement of electrodes held at high voltages. In the COAST calculation, various efficiencies for transmission, power supplies, finite neutralizer "thickness," reionization losses, and molecular components in the beam are taken into account. These calculations are particularly important in estimating the electrical power and energy consumption for DTHR operation. For the beam-driven operation of DTHR, the electrical system associated with the NB injectors employs a load smoothing circuit which is used to compensate for the change in load to the DTHR electrical systems during the off-time of the neutral beam injectors.

There are a number of assumptions used in the sizing and performance calculations for the DTHR plasma core which should be kept in mind. First, all confinement times (particle and energy) are assumed to be equal, i.e., $\tau=\tau_{e}=$ $\tau_{i}=\tau_{E}$, and calculated as described below. The density of deuterium ions equals the density of tritium ions. The deuterium population of ions is made up of two components: 1) the "warm" bulk particles; and 2) the "hot" beam injected particles. All the ions associated with the "hot" alphas and the "hot" injected deuterium ions are assumed to remain in the plasma until slowing down processes reduce their velocities to those associated with the bulk plasma. The corresponding slowing down times are calculated and used to cal- 
culate the equilibrium population of "hot" ions. All temperatures are calculated as the same value for each bulk ion species. Finally, both temperature and density are assumed to be parabolic in profile for calculation of particle pressure, plasma beta, and the plasma-plasma fusion reaction rate.

Throughout the DTHR trade studies, the plasma elongation, the maximum field at the TF coil and the energy associated with NB injection have been of particular interest. Calculations were made for a range of magnitudes for these parameters, but in general, upper limits on DTHR were assumed and the criteria for a given size and performance was based on the magnitudes of these parameters relative to the limiting values as given in Table 2-4.

Before discussing the numerical results, a few of the important calculational. steps are shown below to indicate the procedures used in obtaining the results in this study. Limitations in operating and design parameters represent a critical consideration in conducting the study. The maximum field at the inner leg of the TF coil, $B_{M}$, is one limitation, and is calculated as follows:

$$
B_{M}=\frac{B_{t} R_{0}}{R_{M}} \times(1+r)
$$

where $B_{t}$ is the field on axis, $R_{0}$ is the major radius, $R_{M}$ is the radius to the high field side of the TF coil inner leg, and $r$ is the ripple (peak-to-average) at the inner leg. For a given $R_{0}$ and aspect ratio $A$, the value of $R_{M}$ depends on the radiation shield thickness (assuming no blanket on the inboard side of the plasma), and on the space requirements for the vacuum vessel, TF coil dewar, and access/assembly clearances.

The plasma particle densities and temperatures and the alpha and beam heating contributions to the total particle pressure impact the value of $B_{t}$, i.e.,

$$
B_{t}=\left[\frac{\sum \overline{n_{j} T_{j}}+\frac{2}{3} \sum_{k} \overline{n_{k} E_{k}}}{\beta / 2 \mu_{0}}\right]^{1 / 2}
$$


TABLE 2-4

PRINCIPLE LIMITS ASSOCIATED WITH

THE PLASMA, TF COILS, AND NB INJECTION

$$
\begin{aligned}
& \delta \leq 1.6 \\
& B_{M} \leq 12 \mathrm{~T} \\
& E_{B} \leq 200 \mathrm{keV}
\end{aligned}
$$


where $j$ is over the bulk plasma particles (electrons and bulk ions consisting of deuterium, tritium, helium, and impurities) and $k$ is over the "hot" alphas and "hot" beam ions as they slow down and become part of the bulk plasma. The value of. $\beta$ was determined by assuming that the poloidal beta $\beta_{p} \leq A$. Thus,

$$
B \leq \frac{s^{2}}{A^{2} q}
$$

where the equality condition was used throughout the study.

So as to keep the parameter space and the number of variables within reasonable limits, the plasma temperature was arbitrarily fixed throughout most of the study at $T_{p}=\bar{T}_{e}=\bar{T}_{i}=17.3 \mathrm{keV}$ (and any other assumption on $T_{p}$ is indicated). This assumption leads to the result that the annual production of fissile material and the neutron wall loading, $J_{W}$, are functions only of the ion densities and the injected power of the driving neutral beams (for a given geometry and blanket design)

$$
\begin{gathered}
J_{W}=W_{n} \times \frac{a \delta}{\left(1+\delta+\frac{2 \Delta_{s}}{a}\right)} \\
W_{n}=\frac{14.1}{\left.n_{D} n_{T}<\sigma V\right\rangle E_{n}}+\frac{P_{B}}{17.6} Q_{B}
\end{gathered}
$$

where $a$ is the minor radius, $\delta$ the plasma elongation, $\Delta_{s}$ the scrape-off thicknes's, and $w_{n}$ the neutron power density (14.1 MeV per event). The expression for $W_{n}$ has two terms where the first is the volume-integrated average contribution from the plasma bulk, and the second is due to the beam-plasma interaction. The beam power $P_{B}$ to drive the plasma is (for this study) assumed to be the same as that required for plasma start-up. The start-up power is proportional to the major radius $R_{0}$ and the plasma temperature, $T_{p}$, if empirical scaling $\left(\tau_{E} \propto \bar{n}_{e} a^{2} s^{2} q^{1 / 2}\right)$ is used, i.e..

$$
P_{B} \propto R_{0} T_{p}
$$


where $P_{B}=52 \mathrm{MW}$ is assumed for $R_{0}=5.2 \mathrm{~m}$. The neutral beam energy is proportional to the plasma "target thickness," and

$$
E_{B} \propto \overline{n_{e}} a z_{\text {eff }}
$$

An important calculational step in obtaining the trade study results is related to the confinement time calculations associated with particle and energy losses. As indicated in recent experimental result.s $(10)$ the magnitude of the average particle confinement time is approximately equal to the energy confinement time for a plasma operated with a divertor. It was assumed that all confinement times are set equal to each other, and the results $(10)$ indicated add credence to this assumption. The numerical value of the confinement time, $\tau$, is difficult to predict and can be calculated using a variety of scaling laws. In previous studies ${ }^{(11)}$ conducted by Westinghouse, the following empirical formula was used:

$$
\tau_{E}=3.2 \times 10^{-21} \times \overline{n_{e}} \times(a s)^{2} q^{1 / 2}
$$

where $\tau_{E}$ is in $s, \bar{n}_{e}$ in $m^{-3}$, and $a$ in $m$. A more recent formula is given by the Hugell-Sheffeld scaling relationship,

$$
\tau_{E}=1 \times 10^{-13} \bar{n}_{e}^{0.6}(\mathrm{a} \times s)^{1.6} B_{t}^{0.9}
$$

where $B_{t}$ is in $T$. In a very recent analysis ${ }^{(12)}$ of experimental data it was concluded that it is generally not possible to determine confinement time scaling, since it is masked by replacement time scaling, and that substantially different scalings can give comparably good fits. For the OTHR trade studies, the problem of deciding which confinement calculation to use was resolved by assuming a value which allows the following energy balance equation to be satisfied:

$$
\frac{E_{e}+E_{i}}{\tau_{E}}=W_{\alpha}+W_{N B}-W_{L}
$$


where $E_{e}$ is the kinetic energy density of the plasma electron, $E_{i}$ is the kinetic energy density of all the bulk plasma ions, $W_{\alpha}$ is the alpha power density, i.e.,

$$
w_{\alpha}=\frac{3.5}{14.1} w_{n} \text {, }
$$

(see Equation 5 for $\left.W_{n}\right) W_{N B}$ is the NB power density $\left(P_{B} / V_{p}\right)$, and $W_{L}$ are the radiation losses due to bremsstrahlung, synchrotron, line and recombination radiation. Over the range of parameters considered in the OTHR study the value of $\tau_{E}$ calculated was always less than that assuming $n_{e}(a s)^{2} q^{1 / 2}$ scaling and in good agreement with that predicted by Hugell-Sheffield scaling. A large number of calculations were made for the ignition operation of DTHR, i.e., $W_{N B}=0$, and represent a substantial portion of the results presented in Section 3.0. These calculations using COAST were carried out in order to evaluate the sizing and performance of DTHR with respect to the beam-driven operation of a tokamak value. The base system is a beam-driven device ${ }^{(2)}$ and, at this time, the operating mode (ignited or beam-driven) has not been completely analyzed or a final NB system selected.

The results of the DTHR studies presented in the remainder of this report include cost data. When cost data is presented it is the direct capital cost, i.e., the value is that associated with the cost of equipment, hardware, buildings, structures, and land as estimated. The unit costs that have been employed were developed in 1977 for the COAST code. However, in these studies the magnitude of the costs are not important, it is the relative costs that are important for establishing trends. Spare parts, shipping and handling, installation, contingencies, construction costs, taxes, insurance, G\&A, interest, and escalation are not included. Thus, the costs are direct capital costs, as defined in "Fusion Reactor Design Studies - Standard Accounts for Cost Estimates," Batelle Report PNL-2648 (1978), without spare parts, installation, and construction contingencies. Roughly, the total capital costs would be between a factor of 2.0 and 2.5 higher than those listed in the remainder of this report. 


\subsection{PERFORMANCE AND COST AS A FUNCTION OF DEVICE SIZE}

In evaluating the performance and cost of DTHR as a function of the device size, three sets of assumptions were made and three series of data generated. Using COAST in which $T_{e}=17.3 \mathrm{keV}$ and $A=4.333$, the value of $\overline{n_{e}}$ was adjusted in each calculation until $\mathrm{J}_{\mathrm{W}}=2.0 \mathrm{MW} \mathrm{m}^{-2}$ (neutron wall loading), and $\tau_{E}$ was calculated consistent with Equation (10). With this set of assumptions the first series of curves were generated and are shown in Figures 3-1, 3-2, and 3-3. The data ranges from $R_{O}=4.33 \mathrm{~m}$, where both $B_{M}$ and $B_{O H}$ (maximum $O H$ field at $\mathrm{OH}$ windings) exceed $12 \mathrm{~T}$, to $R_{0}=6.93 \mathrm{~m}$. Throughout this range the energybalanced $\tau_{E}$ is less than the value obtained using Equation (8). Thus, confinement does not need to be as good as what "empirical" scaling (Eq. 8) would predict. The data shown in the curves present results related to direct hardware costs, annual fissile fuel production, peak fusion power (17.6 MeV per event), electrical power consumed during pulsing, electrical energy required for a year of operation, and total heat developed within the blanket. For these curves, the plasma is beam-driven. The results are discussed in more detail later on in this section.

The second series of data was generated using COAST in which all the assumptions used in the first data series were again assumed except that the beams were "turned off" during the steady state portion of the pulse. This is equivalent to assuming ignition conditions exist. To maintain the wall loading at $2 \mathrm{MW}$ $\mathrm{m}^{-2}$ the plasma density was adjusted slightly to compensate for the beam-plasma generated neutrons not seen for an ignited plasma. The results are shown in Figures 3-4, 3-5, and 3-6 for the same type of data as in the first set. Again, $\tau_{E}$ is less than that required by Equation (8). Results for radii less than $5.2 \mathrm{~m}$ are not shown because the $\tau_{E}$ required for energy balance is greater than that predicted by Equation (8). Under the assumption that this empirical formula is as optimistic as one can realistically accept, the plasmas at $R_{0}<5.2 \mathrm{~m}$ for the ground rules used in the trade study will not ignite. Tokamak plasmas with radii less than $R_{0}=5.2 \mathrm{~m}$ and $a=1.2 \mathrm{~m}$ and with time constants given by 


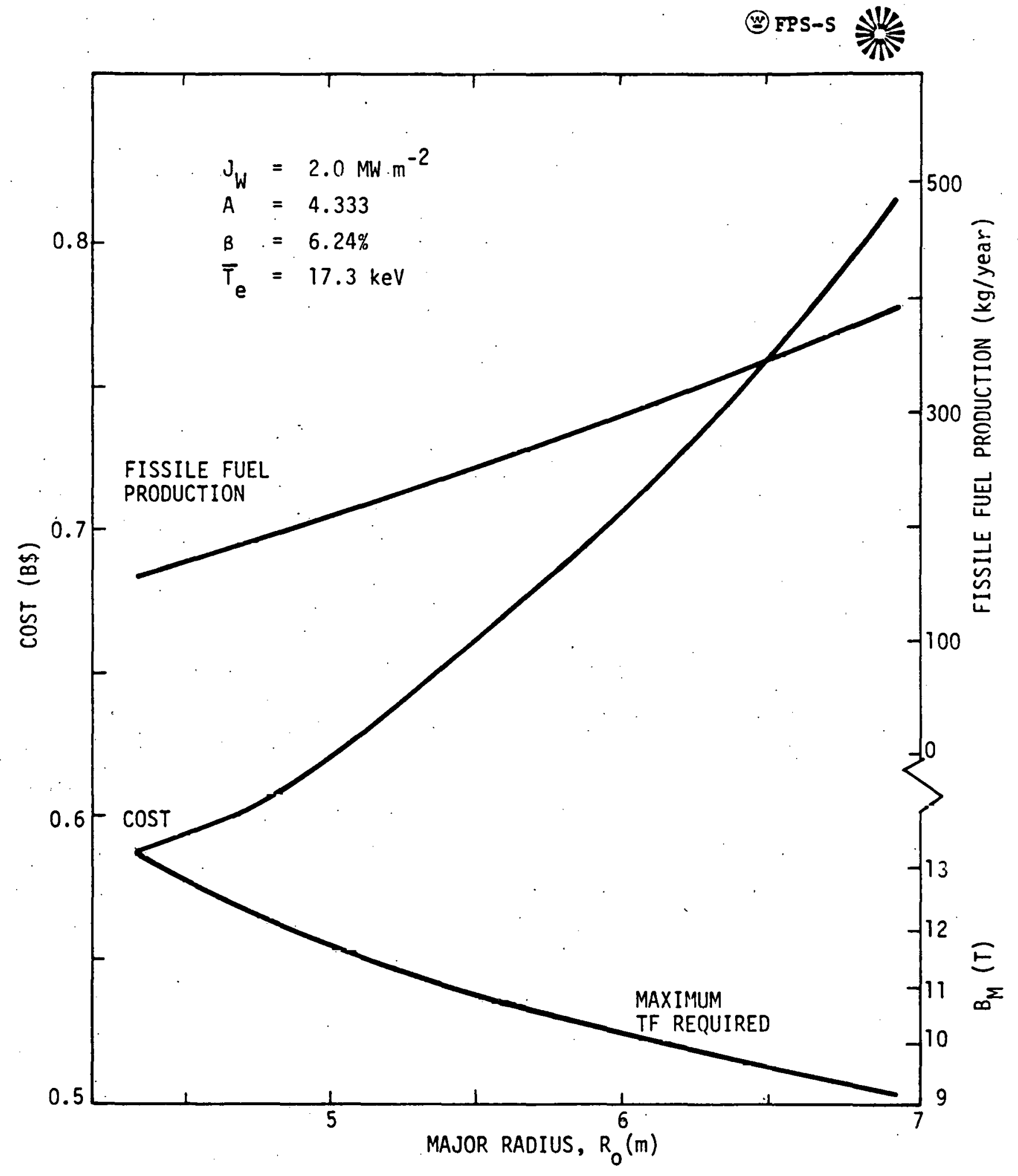

Figure 3-1. Cost, Annual Fissile Fuel Production and Maximum TF Required as a Function of Major Radjus, $\mathrm{R}_{0}$, for
a Neutron Wall Loading of $2.0 \mathrm{MW} \mathrm{m}^{-2}$. 
(알 FPS-s 는

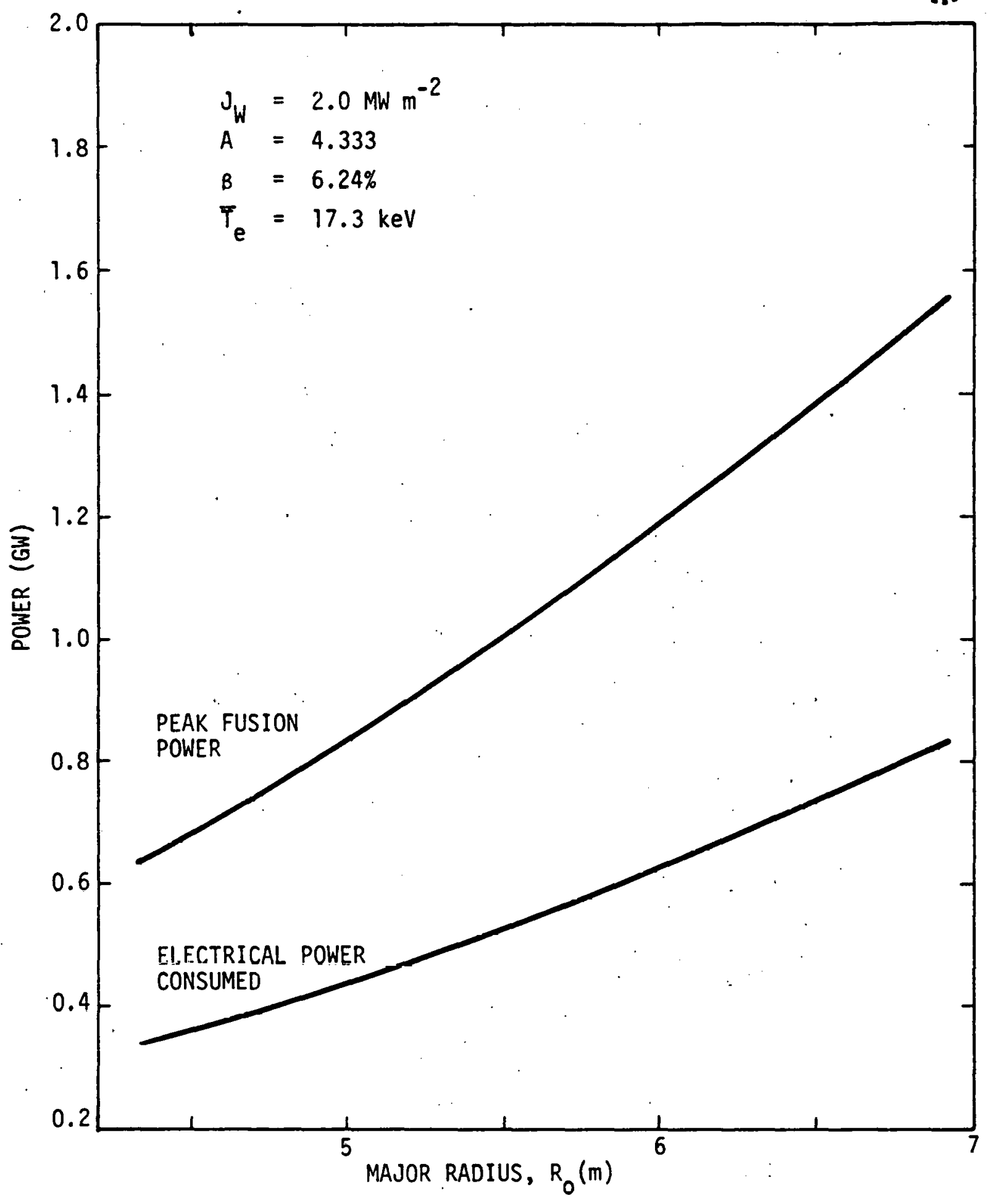

Figure 3-2. Electrical Power Consumed and Peak Fusion Power (17.6 MeV/Event) as a Function of Major Radius, $R_{0}$, for a Neutron Wall Loading of $2.0 \mathrm{MW} \mathrm{m}^{-2}$.

$3-3$ 


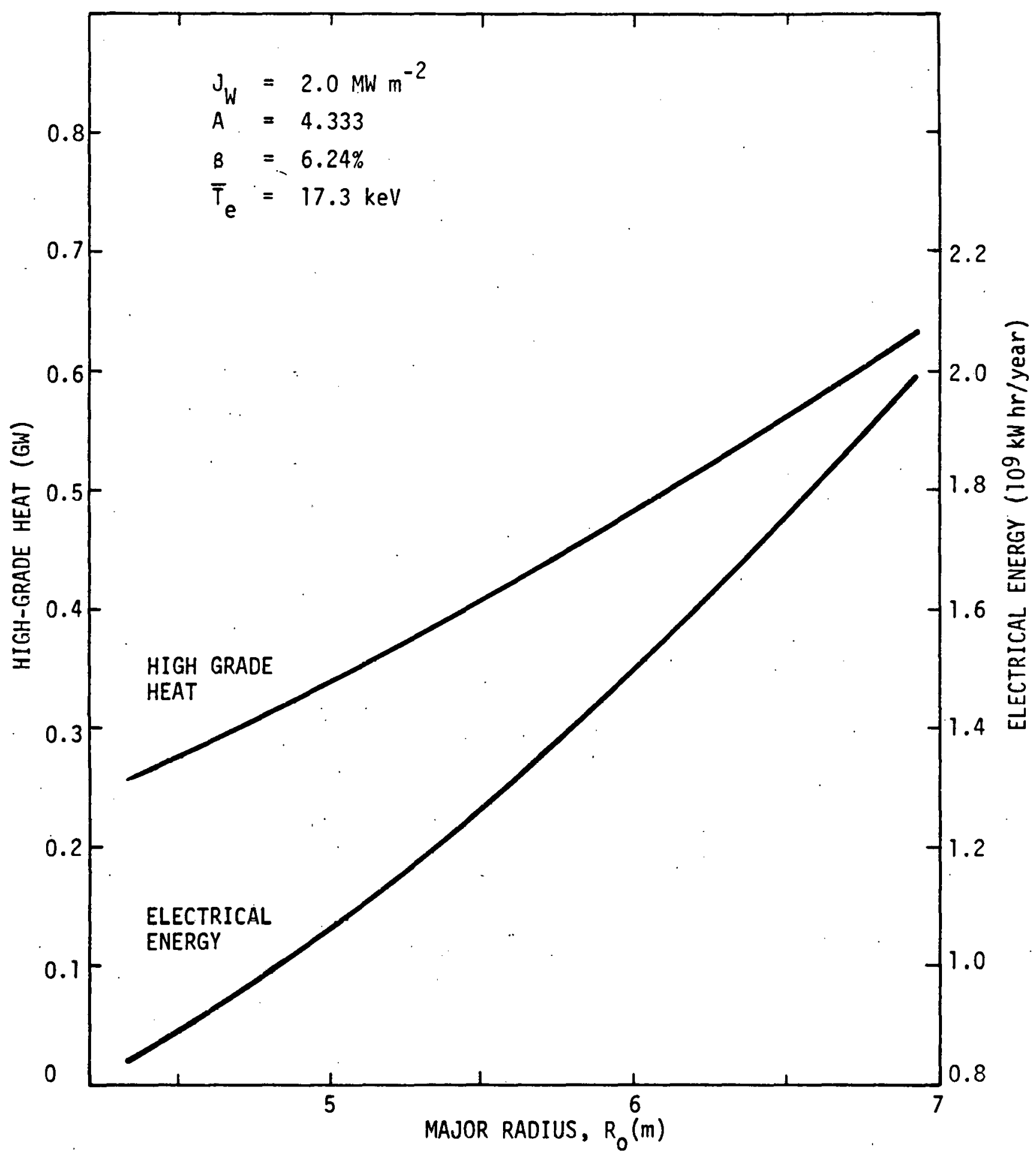

Figure 3-3. High-Grade Heat Production and Electrical Energy Consumed Per Year as a Function of Major Radius, $R_{0}$, for a Neutron Wall Loading of $2.0 \mathrm{MW} \mathrm{m}^{-2}$. 


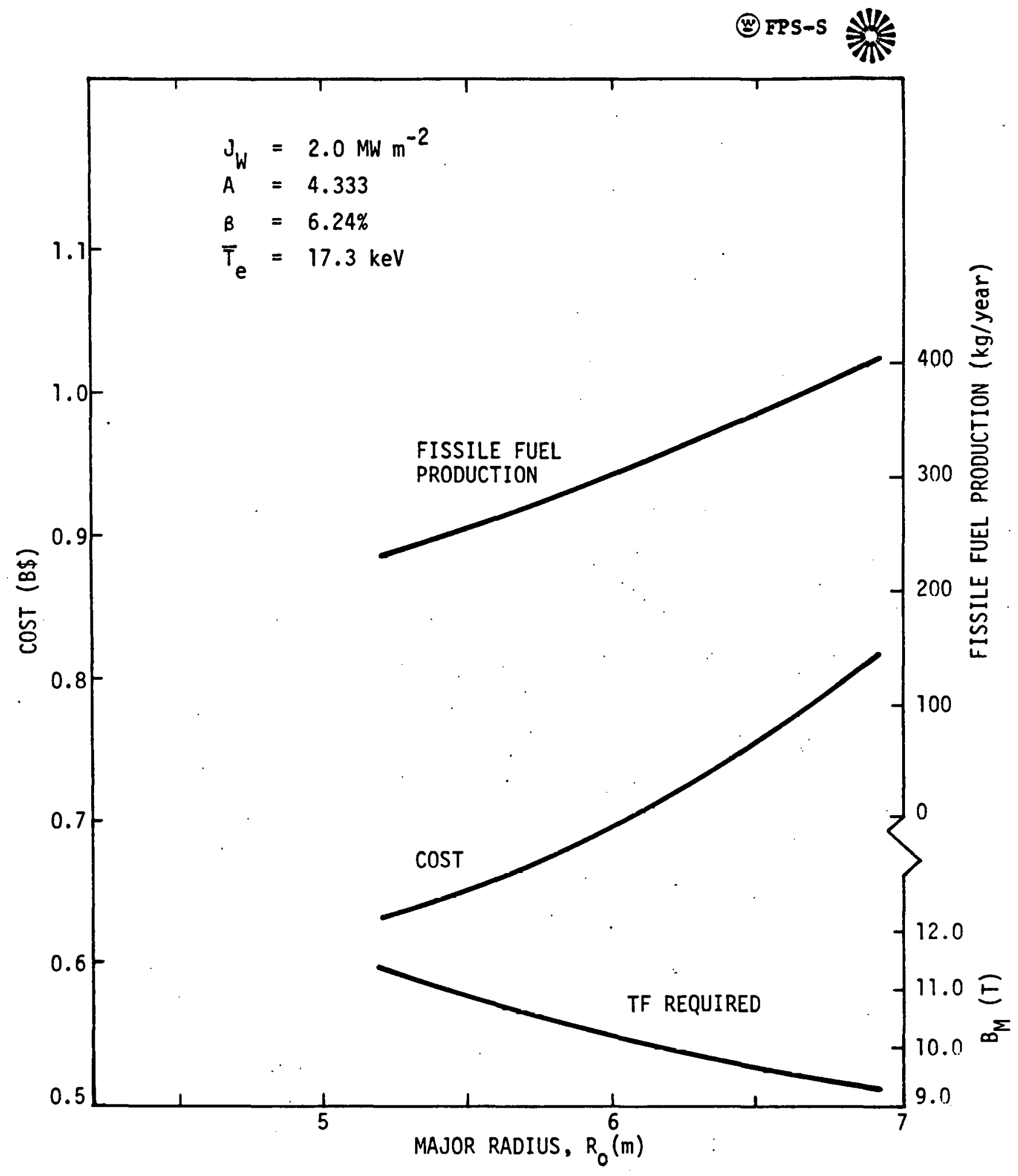

Figure 3-4. Cost and Annual Fissile Fuel Production as a Function of Major Radius, $R_{0}$, for Ignition Operations and a Neutron Wall Loading of $2.0 \mathrm{MW} \mathrm{m}^{-2}$. 


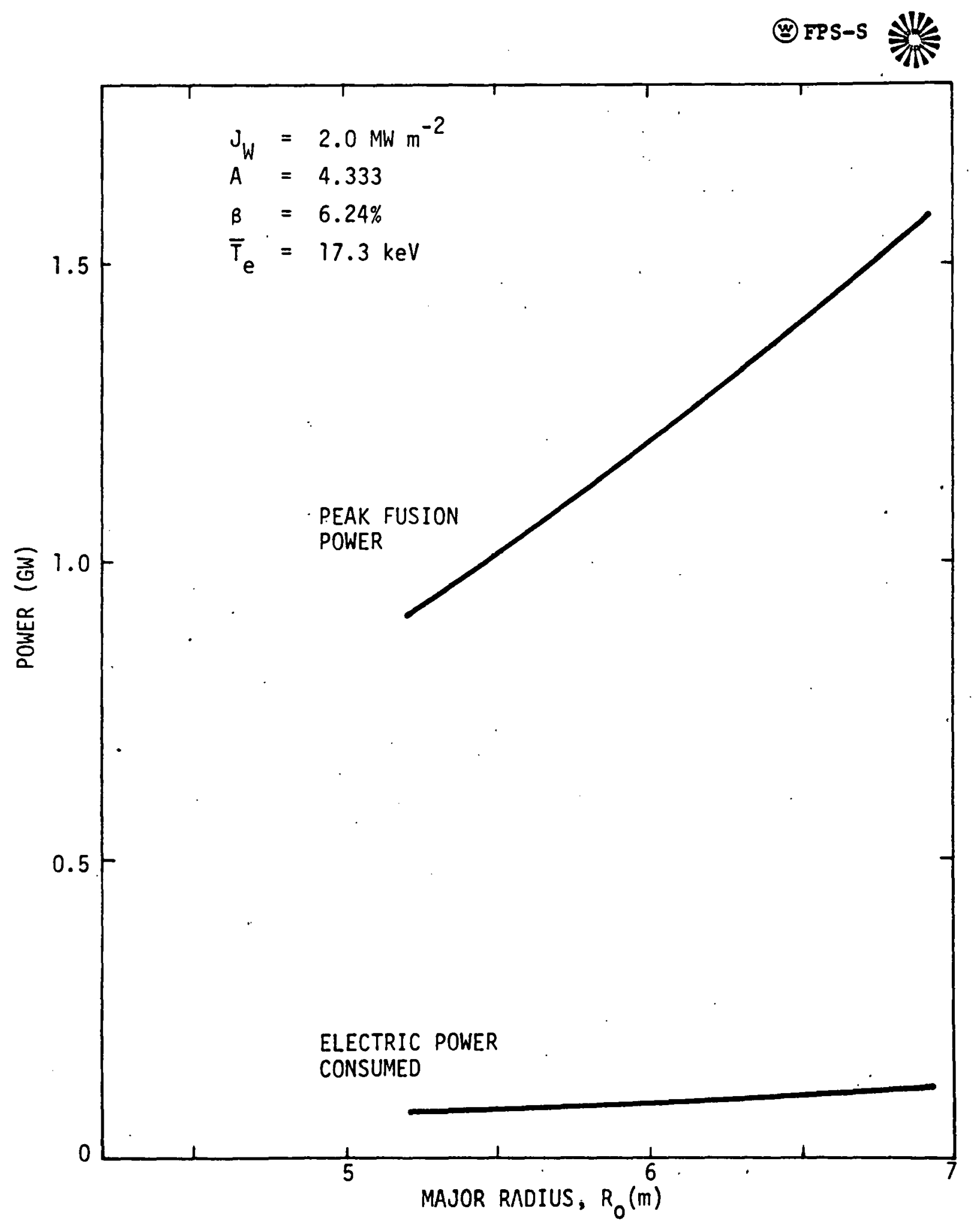

Figure 3-5. Electric Power Consumed and Peak Fusion Power $(17.6 \mathrm{MeV} /$. Event) as a Function of Major Radius, $R_{0}$, for a Wall Loading of $2.0 \mathrm{MW} \mathrm{m} \mathrm{m}^{-2}$ and Ignition Operation. 


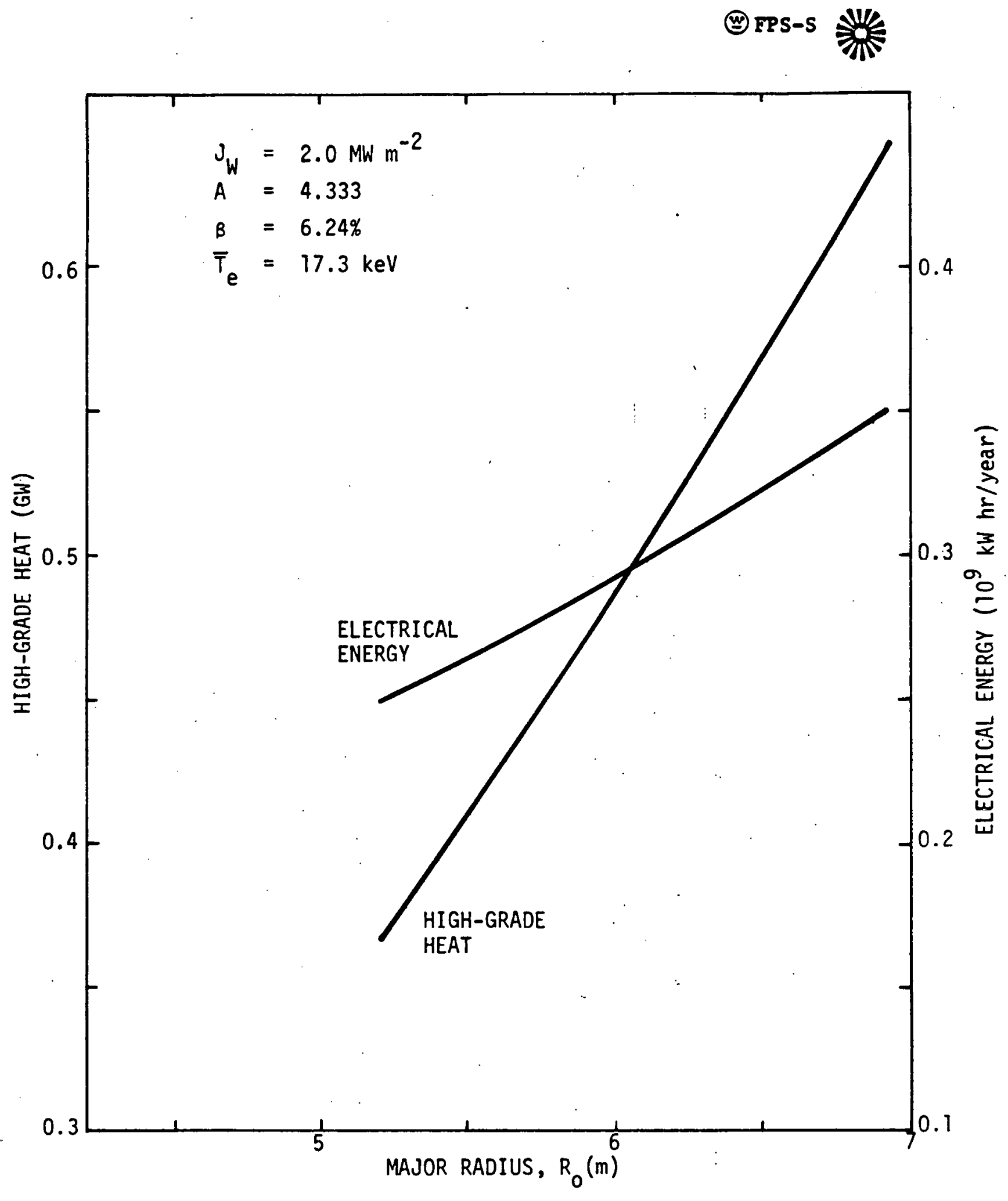

Figure 3-6. High-Grade Heat Production and Electrical Energy Consumed Per Year as a Function of Major Radius, $R_{0}$, for a Neutron Wall Loading of $2 \mathrm{MW} \mathrm{m}^{-2}$ and Ignition Operation. 
Equation (8) can be sized for ignition conditions, but within the engineering constraints and ground rules used for DTHR the possibility is limited. The main limitation is the $B_{M} \leq 12 T$ condition assumed for the engineering of the $\mathrm{Nb}_{3} \mathrm{Sn} \mathrm{S/C} \mathrm{TF} \mathrm{coils.} \mathrm{It} \mathrm{is} \mathrm{important} \mathrm{to} \mathrm{note} \mathrm{that} \mathrm{no} \mathrm{optimization} \mathrm{has} \mathrm{thus} \mathrm{far}$ been performed in the DTHR design, and it is anticipated that such a procedure would result in a reduction in the minimum size device producing an ignition plasma.

In the third series of data generated, it was assumed that empirical scaling, as calculated in Equation ( 8 ), can be realized for DTHR with an ignited plasma. In addition, the plasma density and the plasma temperature were varied in such a manner that $B_{M} \approx 12 T$ and $E_{b} \approx 200 \mathrm{keV}$ (see Equations 1, 2, and 7). The wal1 loading $J_{W}$ was not fixed at $2 \mathrm{MW} \mathrm{m} \mathrm{m}^{-2}$ for this series of calculations. With the above assumptions, DTHR is sized and operated in the limits imposed by an ignited plasma for empirically scaled time constants, 12 T TF coils, and 200 $\mathrm{keV}$ positive-ion neutral beams, as a function of $R_{0}$ and the results are shown in Figures 3-7, 3-8, and 3-9.

As indicated in the introduction, one of the principle goals set for DTHR is the successful demonstration of fissile fuel production in a near-term fusionfission reactor. Assuming that producing $z 100 \mathrm{~kg} / \mathrm{yr}$ of fissile fuel with a final concentration of $233 U$ of $z 0.2 \%$ is a successful demonstration, all the device sizes stated would achleve this goal. A near-term reactor is one in which it is assumed that beam-driven plasma is produced in a device using TF coils operated at or near $12 \mathrm{~T}$ and neutral beam injectors with positive-ion sources and no direct energy recovery and with beam energies $\lesssim 200 \mathrm{keV}$. At $\mathrm{R}_{0} \approx 4.5 \mathrm{~m}$, the fields exceed $13 \mathrm{~T}$, but the value of $E_{B}$ is well below $200 \mathrm{keV}$. At $R_{0} \approx 7 \mathrm{~m}, E_{B}$ begins exceeding the $200 \mathrm{keV}$ limit, while the required fields are low compared to $12 \mathrm{~T}$. The TF bore dimensions over the range of device sizes is shown in Figure 3-10 and the NB powers and particle energies are shown in Figure 3-11,

The annual production of fissile fuel $\left({ }^{233} U\right)$ and the cost of equipment, hardware, facilities, and buildings are shown in Figure 3-1. (Spare Parts, shipping and handling, installation, EDIA, contingencies, construction costs, and 


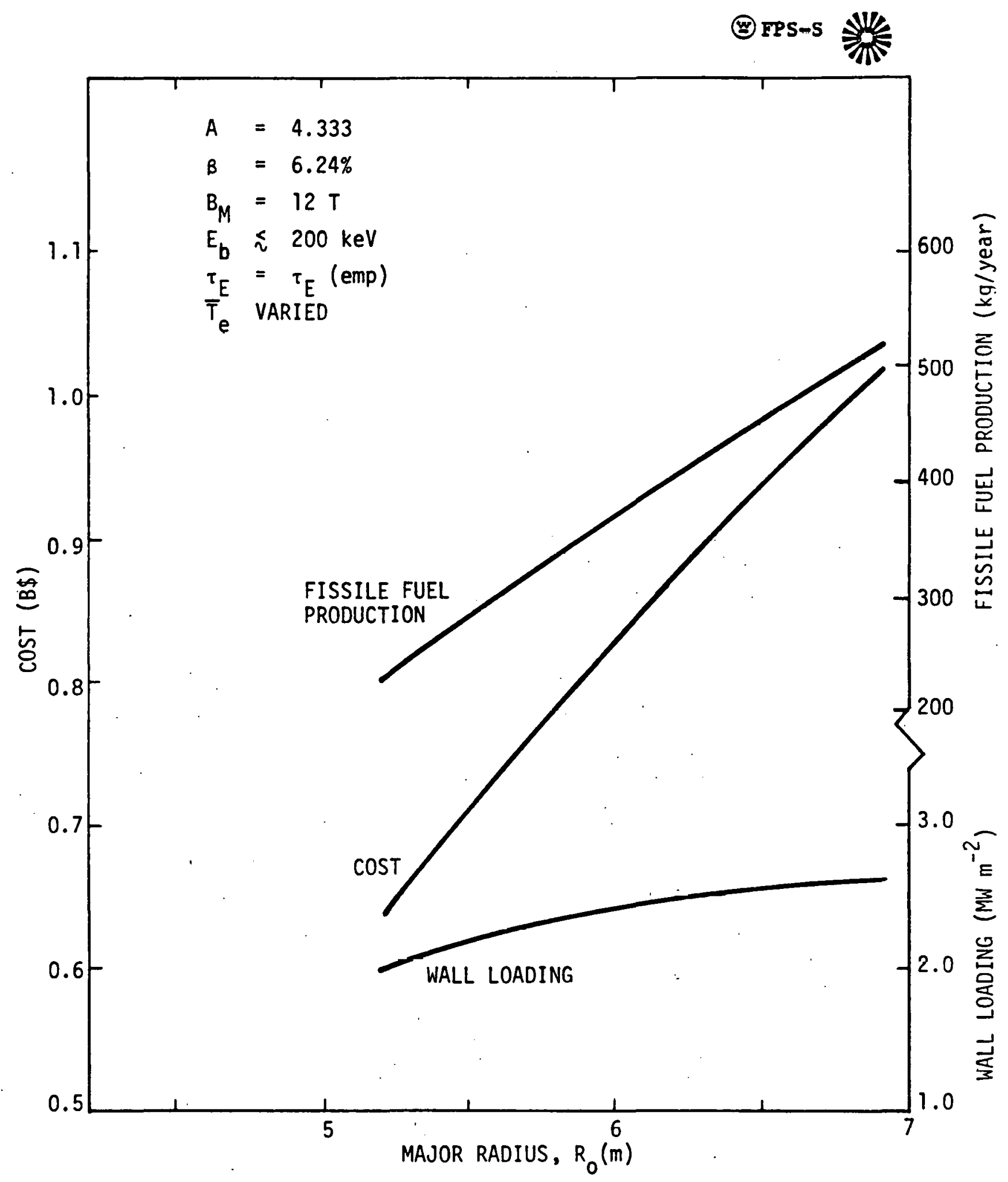

Figure 3-7. Cost and Annual Fissile Fuel Production as a Function of Major Radius, $R_{0}$, for Ignition Operation Assuming Empirical Scaling for ${ }^{\top} E$. 


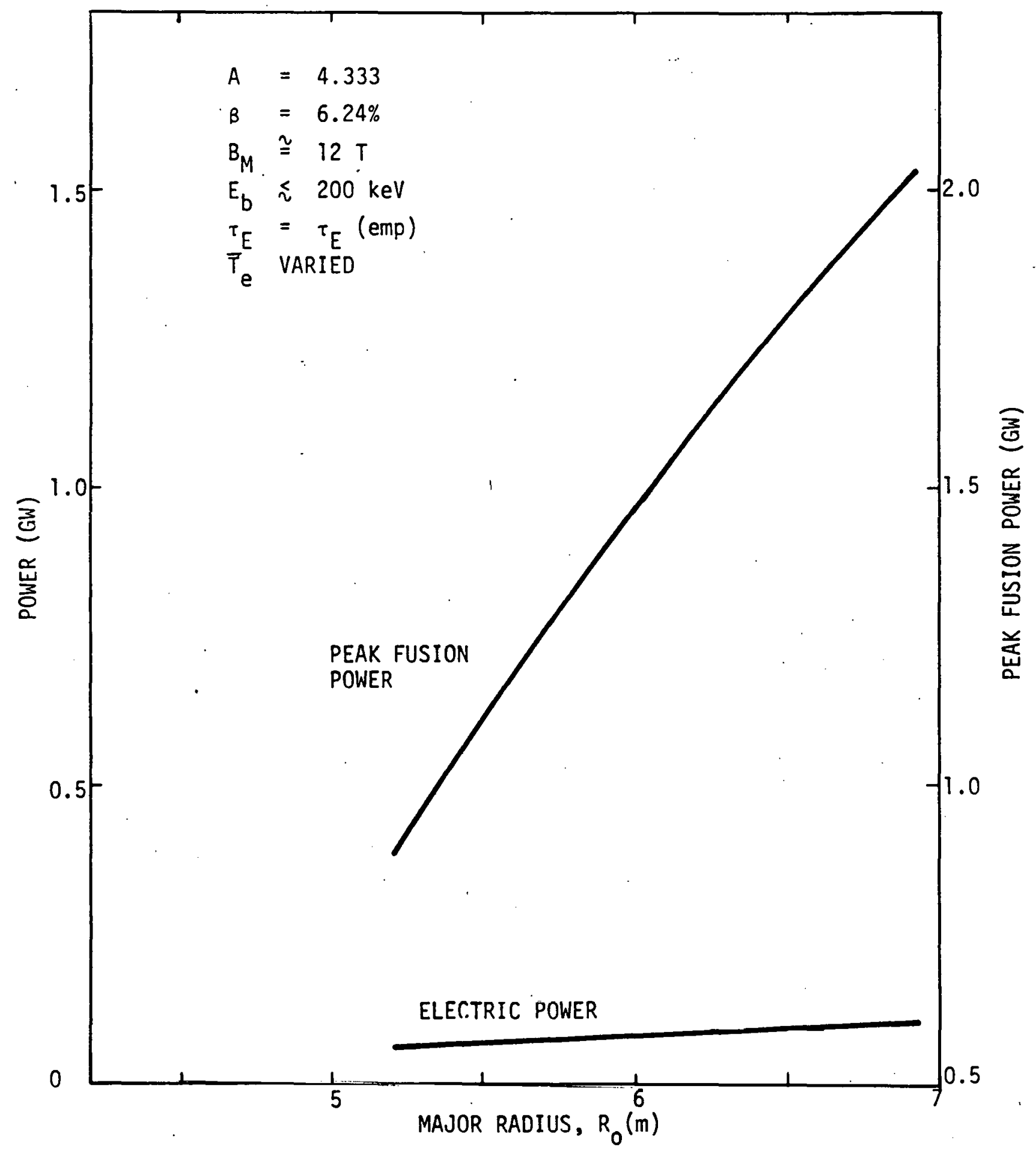

Figure 3-8. Electric Power Consumed and Peak Fusion Power (17.6 MeV/Event) as a Function of Major Radius, $R_{0}$, for Ignition Operation Assuming Empirical Scaling for ${ }^{\top}{ }_{E}$. 


\section{(앙 FPS-S}

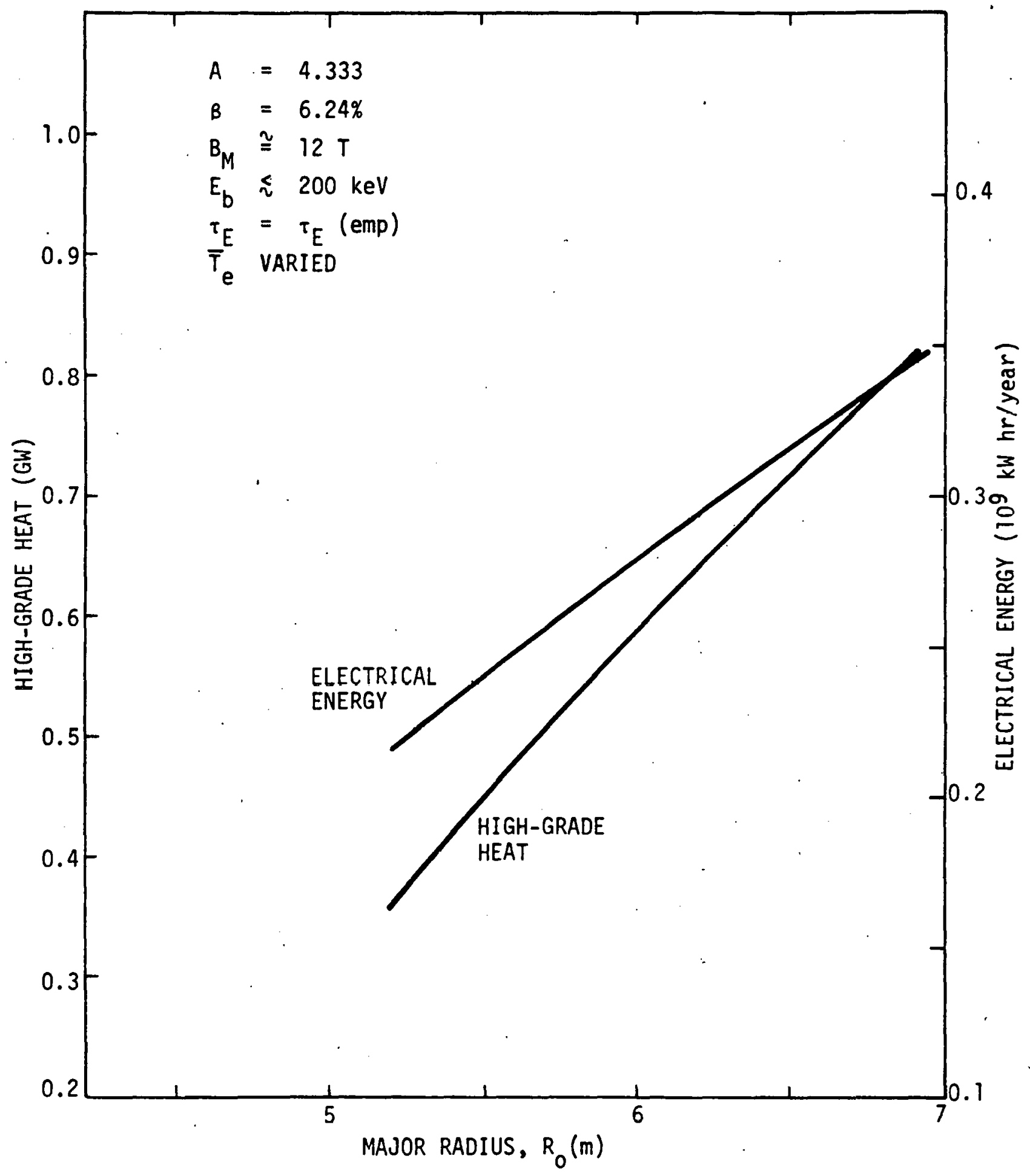

Figure 3-9. High-Grade Heat Production and Electrical Energy Consumed Per Year as a Function of Major Radius, $R_{n}$, for Ignition Operation Assuming Empirical Scaling for ${ }^{\tau} E$. 


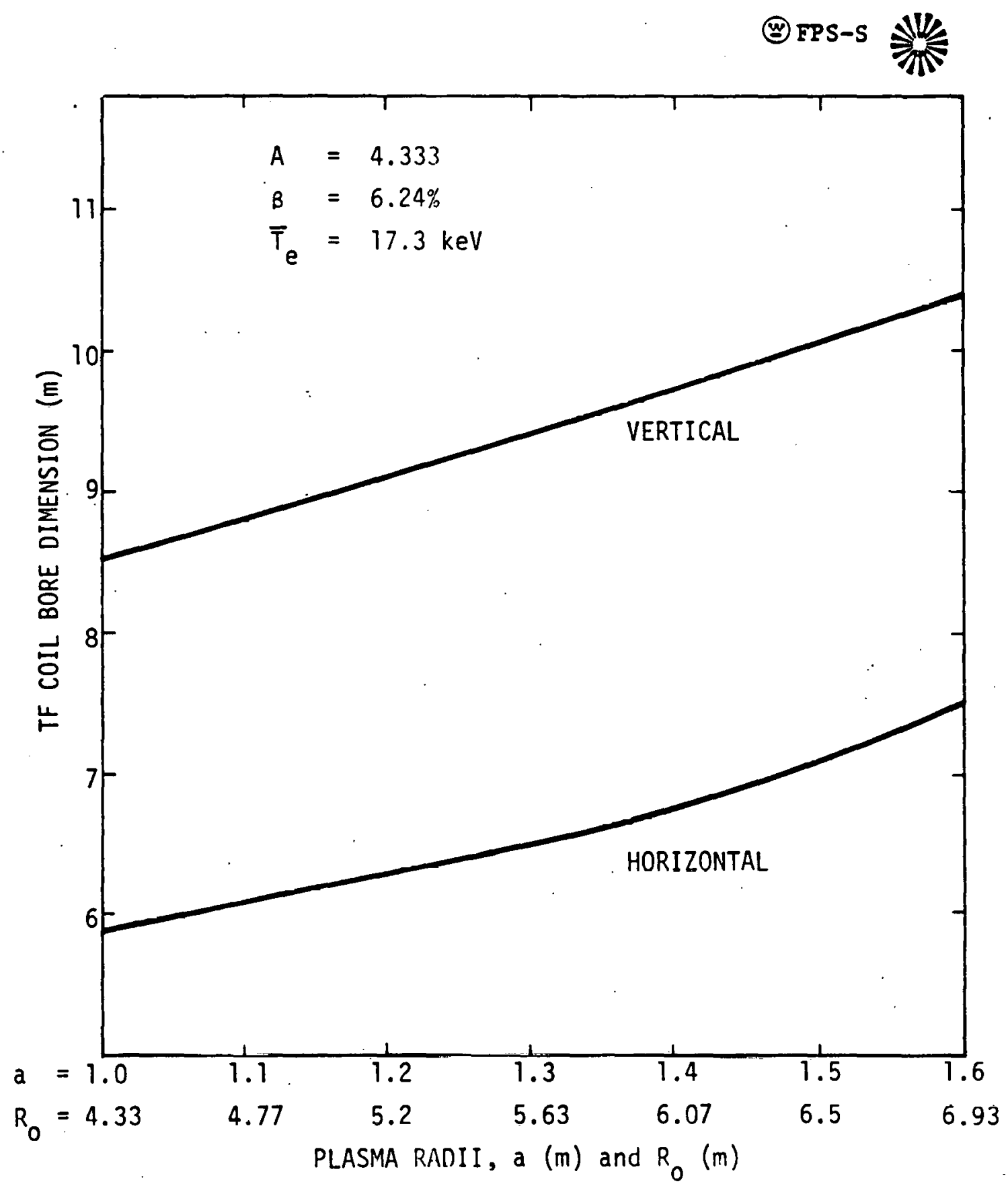

Figure 3-10. TF Coil Bore Dimensions as a Function of the Plasma Radi $i$ for $A=4.333$ Beam-Driven DTHR. 


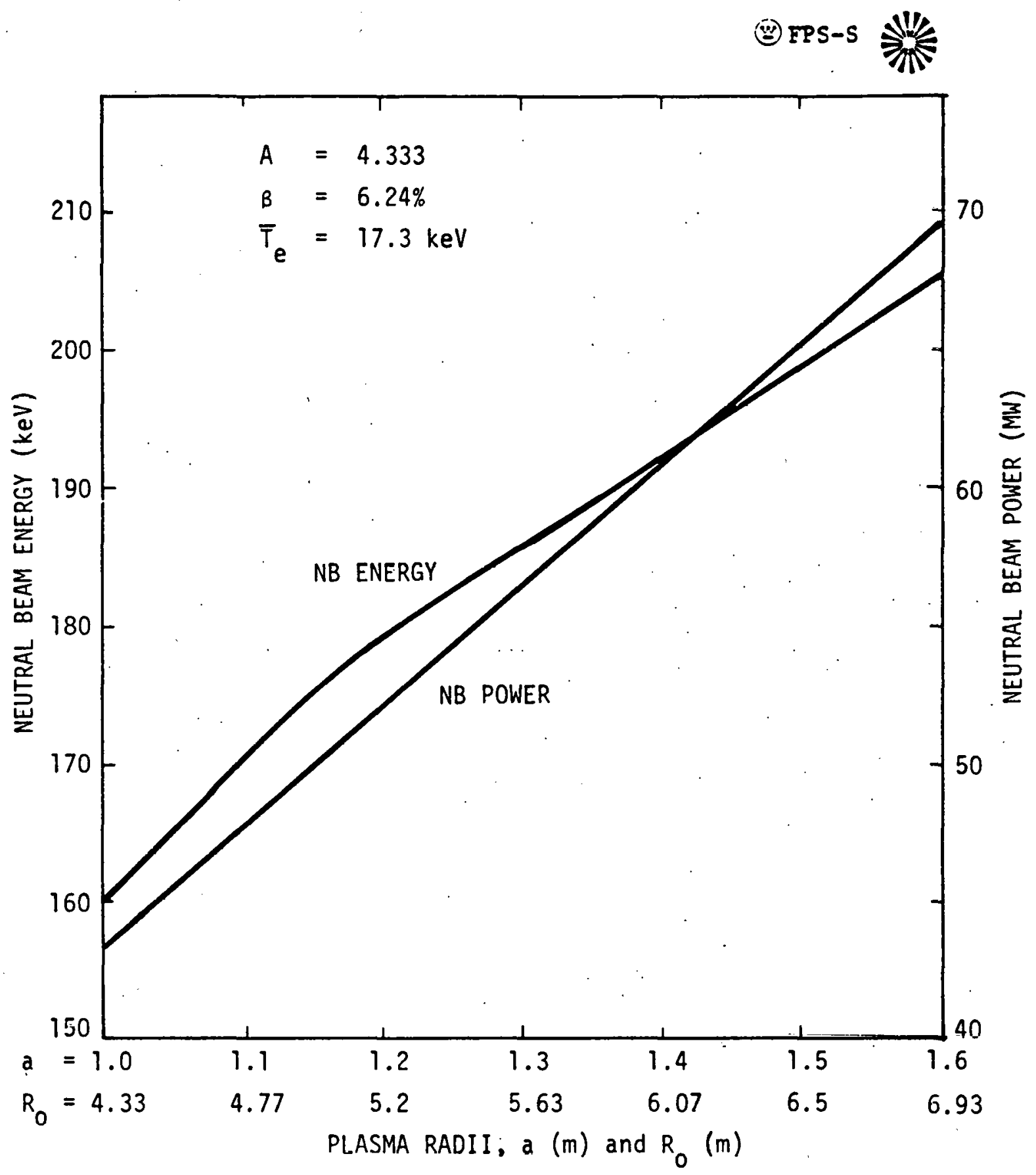

Figure 3-11. Neutral Beam Energy and Power as a Function of the Plasma Radii for $A=4.333$, Beam-Driven DTHR. 
escalation are not included. For a DoE funded project the total PACE costs are approximately twice the values discussed and shown in this study.) The costs range from $\sim 0.6 \mathrm{~B} \$$ to $\sim 0.8 \mathrm{~B} \$$ while the fuel production $\left({ }^{233} \mathrm{U}\right)$ range from $200 \mathrm{~kg} / \mathrm{yr}$ to $400 \mathrm{~kg} / \mathrm{yr}$. Thus, the results indicate an economy-of-scale. Also shown in Figure $3-1$ is the maximum field at the TF coil. This data allows one to select the minimum size for a particular limit assumed in the engineering design. For DTHR, the present assumption is $12 \mathrm{~T}$ which limits the radius to $\geq 4.9 \mathrm{~m}$. At $R_{0}=4.9 \mathrm{~m}$, the device cost is $610 \mathrm{M} \$$ and $200 \mathrm{~kg}$ of $233 \mathrm{U}$ are produced per year.

In Figure 3-2, the magnitudes of the fusion power (17.6 MeV/event) during the pulse and the duty-cycle averaged electrical power consumed are shown for the full range of device sizes. The electrical power consumed in operating the NB injectors makes up roughly $80 \%$ of the consumed power at the small radii and $90 \%$ at the large radii. The remainder is used in operating the pumps associated with the water, nitrogen, and helium cooling systems. The calculated fusion power shown in Figure 3-2 takes profile effects into account. The fusion power density for the average temperatures and densities considered in the DTHR study is approximately $40 \%$ lower for a uniform profile than for a parabolic profile.

The total electrical energy consumption per year and the duty-cycle averaged high grade heat (at $\sim 500 \mathrm{~K}$ ) generated within the blanket modules are shown as a function of $R_{0}$ in Figure 3-3. The electrical energy takes the $26 \%$ full power plant availability into account, whereas the heat generation curve is for the operating cycle, only, during which the duty-cycle is $77 \%$. The heat generation power lies in the range from $250 \mathrm{MW}$ to $650 \mathrm{MW}$. If a thermal-to-electrical conversion plant were considered for DTHR, electrical generation of between $75 \mathrm{MW}$ and $200 \mathrm{MW}$ could be expected. If the blanket coverage fraction were to be increased to more completely cover the outer half of the vacuum vessel, the electrical power generation could be within $\sim 70 \%$ of that associated with the power consumption in operating DTHR in the beam driven mode.

The results shown in Figures $3-1,3-2,3-3,3-10$, and $3-11$ on the sizing, costing and performance of DTHR are based on a beam-driven system. The power level of the beams injected into the plasmas were arbitrarily set equal to that level 
calculated for start-up during which time the plasma is heated from 2-3 keV (ohmically heated prior to NB heating) to the final steady state temperature of $17 \mathrm{keV}$ (average). The Q-value (plasma power divided by NB power) is in the range from 14 to 22 indicating that the plasmas are only weakly driven. Since the energy confinement times are well below the values required using Equation (8), it is anticipated that these weakly driven plasmas can be obtained in a near-term device. If a more strongly driven plasma is actually required, either a reduced plasma performance level would result for the available injection system, or DTHR could be "up graded" to accommodate more beams. The increase in injector arms would not represent any major changes in the tokamak device, which is presently designed ${ }^{(2)}$ for more beam arms than calculated in this trade study. (See Section 7.0 for more discussion on this point.)

For purposes of illustration, consider the $R_{0}=5.2 \mathrm{~m}$ case. If $150 \mathrm{MW}$ of NB power (instead of $52 \mathrm{MW}$ ) were required, the cost would increase by roughly $16 \%$ and the electrical power and energy consumption would increase by a factor of 3. The performance (fissile fuel production and high grade heat production) would remain the same.

On the other hand, if DTHR for $R_{0} \geq 5.2 \mathrm{~m}$ is well within the conditions for ignition assuming values of $\tau_{E}$ as calculated using Equation (10), the performance with respect to the required electrical power and energy consumption is greatly improved. The cost and fissile fuel production, as shown in Figure 3-4, is essentially unchanged from those results shown in figure $3-1$. This is the case since the same facility is required for both types of operation. The neutral beams are used only for start-up, but the same number of injectors are required. There are slight differences in the pumping systems for the thermal loads, but the effects are not felt in the plant costs. A dramatic difference is seen when comparing Figure 3-5 with Figure 3-2. For the same fusion power level (set by the requirement of $2 \mathrm{MW} \mathrm{m}^{-2}$ neutron wall loading and obtained by minor adjustments in the plasma particle densities), the electrical power consumption is in the range from 75 to $100 \mathrm{MW}$ as compared to 500 to $800 \mathrm{MW}$ for the beam-driven case. Of course, the beam-driven case could be improved with the addition of direct recovery systems, but the power requirement would still 
be in the range of from 400 to $700 \mathrm{MW}_{\mathrm{e}}$. This change in operating requirements is also reflected in Figure 3-6 in which the electric energy consumed per year is shown. As indicated earlier in this section, the potential electrical production capabilities for DTHR are in the range from 75 to $200 \mathrm{MW}_{e}$, and for an ignition option, DTHR has the promise of being self-sufficient in the balance between electrical production and consumption.

In a third and final series of calculations as a function of $R_{0}$, data was generated for the case in which $12 \mathrm{~T} \mathrm{Nb}_{3} \mathrm{Sn} \mathrm{S/C} \mathrm{TF} \mathrm{coils,} 200 \mathrm{keV}$ positive-ion produced neutral beams, and an ignited plasma with $\tau_{E}$ given by Equation ( 8 ) were assumed. These assumptions represent a limiting set of DTHR designs as a function of $R_{0}$ and for the plasma and device engineering ground rules used for DTHR represents a potentially achievable performance level. As shown in figure 3-7, the neutron wall loading is between 2.0 and $2.5 \mathrm{MW} \mathrm{m}^{-2}$. Higher values have been reported $(13)$, but the assumptions have allowed for very high fields at the TF coil ${ }^{(13)}$, high beta operation ${ }^{(14)}$, ripple injection of neutral beam power $(15)$, etc. These assumptions indicate a more advanced technology than considered as near-term for the DTHR trade study. The present set of ground rules have not been studied in detail for purposes of optimizing the design in terms of wall loading, and it is anticipated that improvements are possible, but it is difficult to predict the final value.

Figure 3-7 shows fissile fuel production as high $500 \mathrm{~kg} / \mathrm{yr}$ which, with appropriate upgrades in wall coverage and plant availability could result in an annual product greater than $2000 \mathrm{~kg} / \mathrm{yr}$. The higher costs seen in Figure $3-7$ reflect a design in which both the NB's and the TF coils are designed for the assumed highest performance level. The production of fusion power and highgrade heat are shown in Figures $3-8$ and 3-9. Also shown are the electrical consumption in terms of average power and total annual energy. The results show a big return in power produced per unit of power input and indicate the potential of the demonstration of self-sufficiency which is important in working toward an economically viable commercial reactor plant. 


\subsection{PERFORMANCE AND COST AS A FUNCTION OF NEUTRON WALL LOADING}

The magnitude of the neutron wall roading $J_{W}$ generated by the DTHR device impacts the design parameters associated with the TF coils, the neutral beam injectors, and the heat removal system for the blanket. The changes in these design parameters, in turn, effects the required electrical power and energy to operate DTHR, as well as the operating parameters of the plasma. Thus, the wall loading, $J_{W}$, is a key variable and establishes the connection between the sizing and rating of device components, the reactor performance, and the plasma characteristics. In this section, results for $R_{0}=5.2 \mathrm{~m}$ and for $R_{0}=6.93 \mathrm{~m}$ are presented and discussed. The DTHR device is assumed to be beam-driven (first case in Section 3.0) and the wall loading is varied through the adjustment of the plasma density during burn. The results for $R_{0}=5.2 \mathrm{~m}$ are shown in Figures $4-1,4-2$, and $4-3$, and for $R_{0}=6.93 \mathrm{~m}$ in Figures $4-4,4-5$, and 4-6.

Using the device cost, the maximum field at the TF coil, and the NB energy to characterize the sizing and rating results, data for the $R_{0}=5.2 \mathrm{~m}$ case is shown in Figure 4-1. The fissile fuel production per year is also shown so that the data allows one to determine the device characteristics which produces a given rate of fuel production. As shown in the figure, the $200 \mathrm{keV}$ limit on $E_{b}$ and the $12 T$ limit on the TF occur at the same wall loading. The value of $J_{W}$ is $\sim 2.5 \mathrm{MW} \mathrm{m}^{-2}$, and the cost is $680 \mathrm{M} \$$ for a fissile fuel production rate of $\sim 300 \mathrm{~kg} / \mathrm{yr}$. Any higher value of $J_{W}$ would require 1 imits in $E_{b}$ and $B_{M}$ to be readjusted upward in magnitude. If the goal of DTHR were to produce $200 \mathrm{~kg} / \mathrm{yr}$ only, the DTHR, with $J_{W}=1.75 \mathrm{MW} \mathrm{m}^{-2}, E_{b} \approx 175 \mathrm{keV}$, and $B_{M} \approx 11 \mathrm{~T}$ would be sufficient. Thus, a relatively conservative design for DTHR is possible and allows for the demonstration of fissile fuel production at a meaningful level. Figures 4-2 and 4-3 show the electriçal consumption, plasma power levels, and heat production rates as a function of $J_{W}$ at $R_{0}=5.2 \mathrm{~m}$. For the $200 \mathrm{keV}$, $12 \mathrm{~T}$ limit, the fusion power during burn is $1100 \mathrm{MW}$ and the heat generation capacity of the blanket is $\sim 475 \mathrm{MW}_{t}$. The electric power required is $600 \mathrm{MW}_{\mathrm{e}}$ 


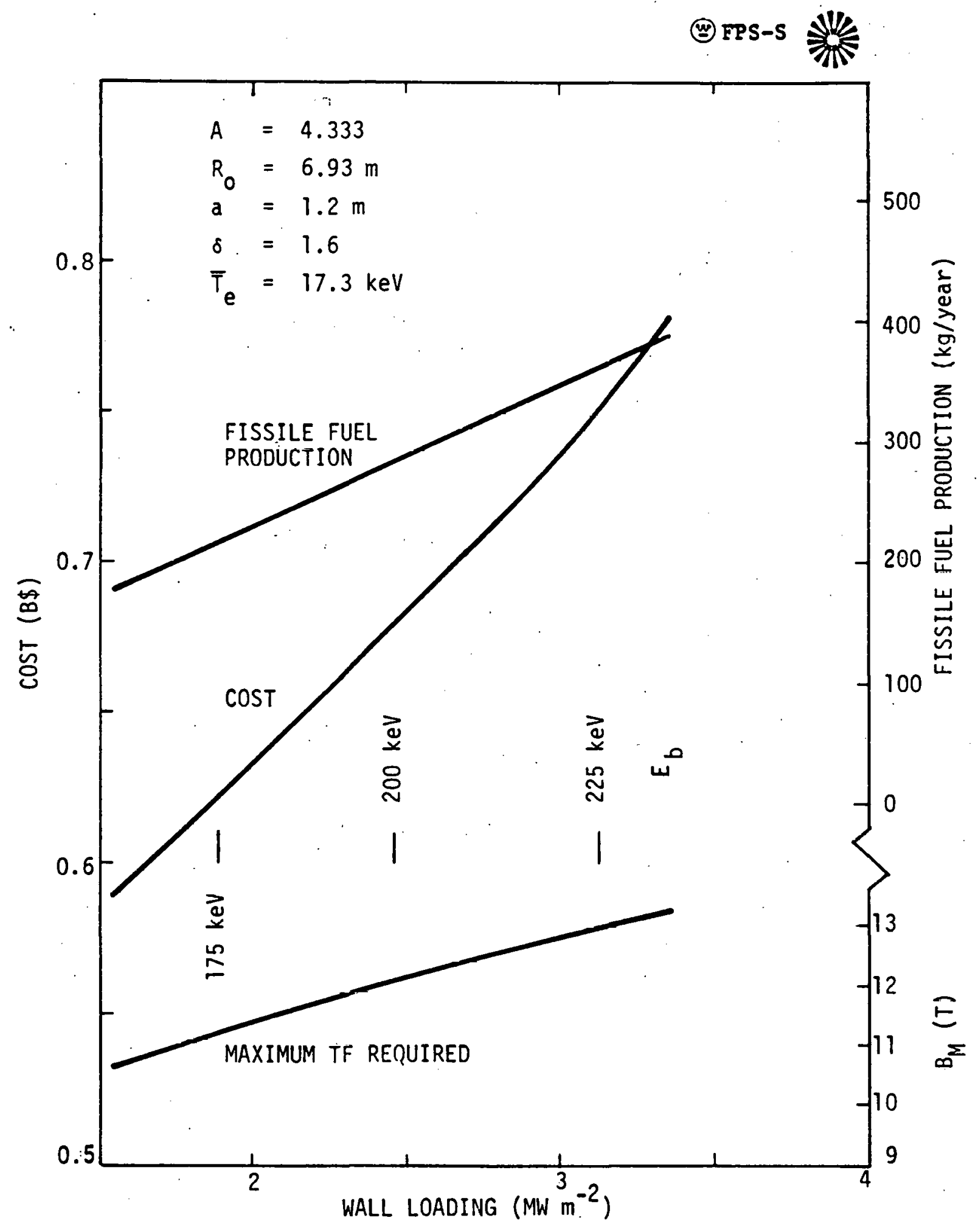

Figure 4-1. Cost, Annual Fissile Fuel Production, and Maximum TF Required as a Function of Wall Loading for Fixed Major Radius, $R_{0}=5.2 \mathrm{~m}, a=1.2 \mathrm{~m}$. 


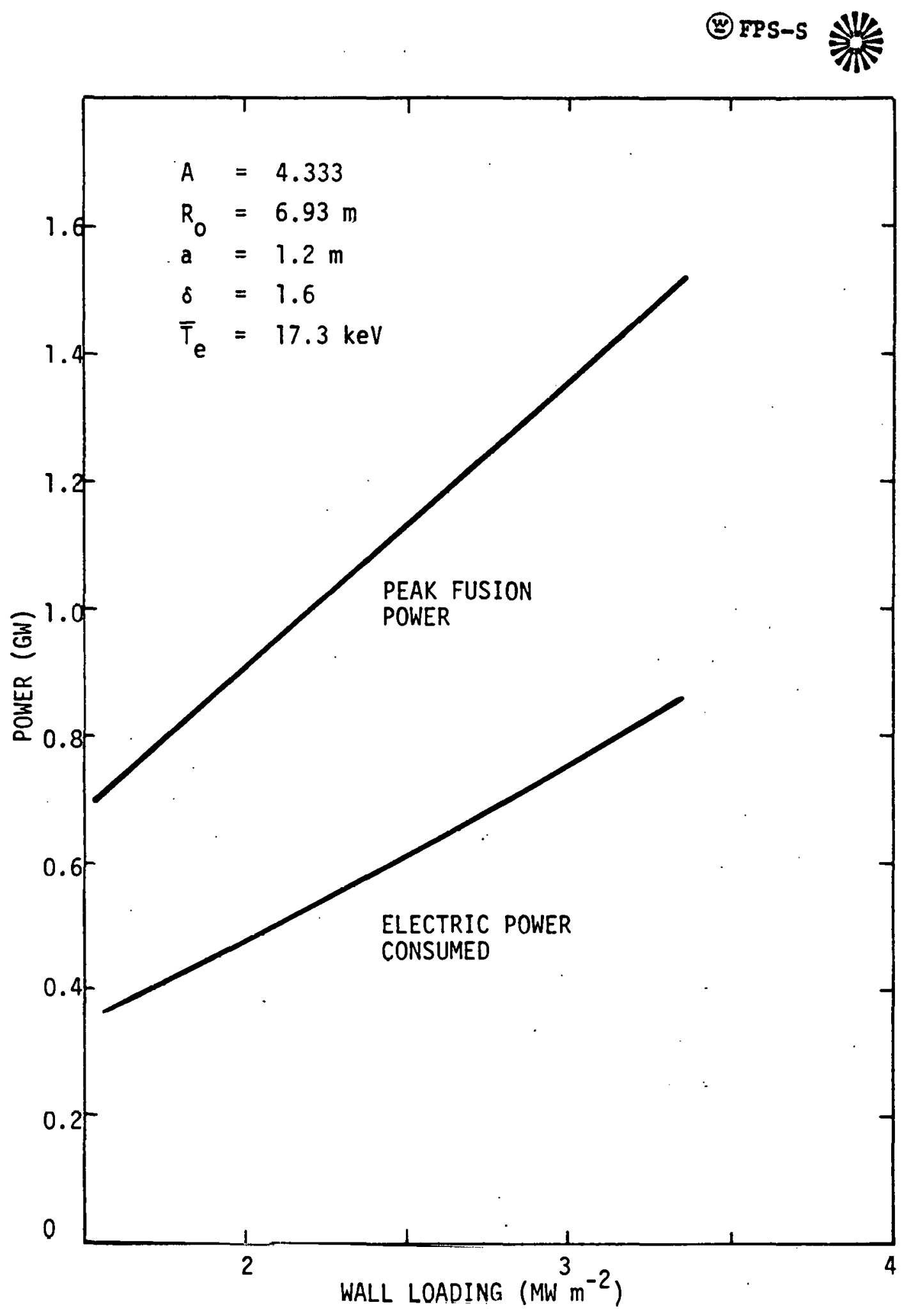

Figure 4-2. Electric Power Consumed and Peak Fusion Power (17.6 MeV/Event) as a Function of Wall Loadina for a Fixed Major Radius, $R_{C_{1}}=5.2 \mathrm{~m}$. 


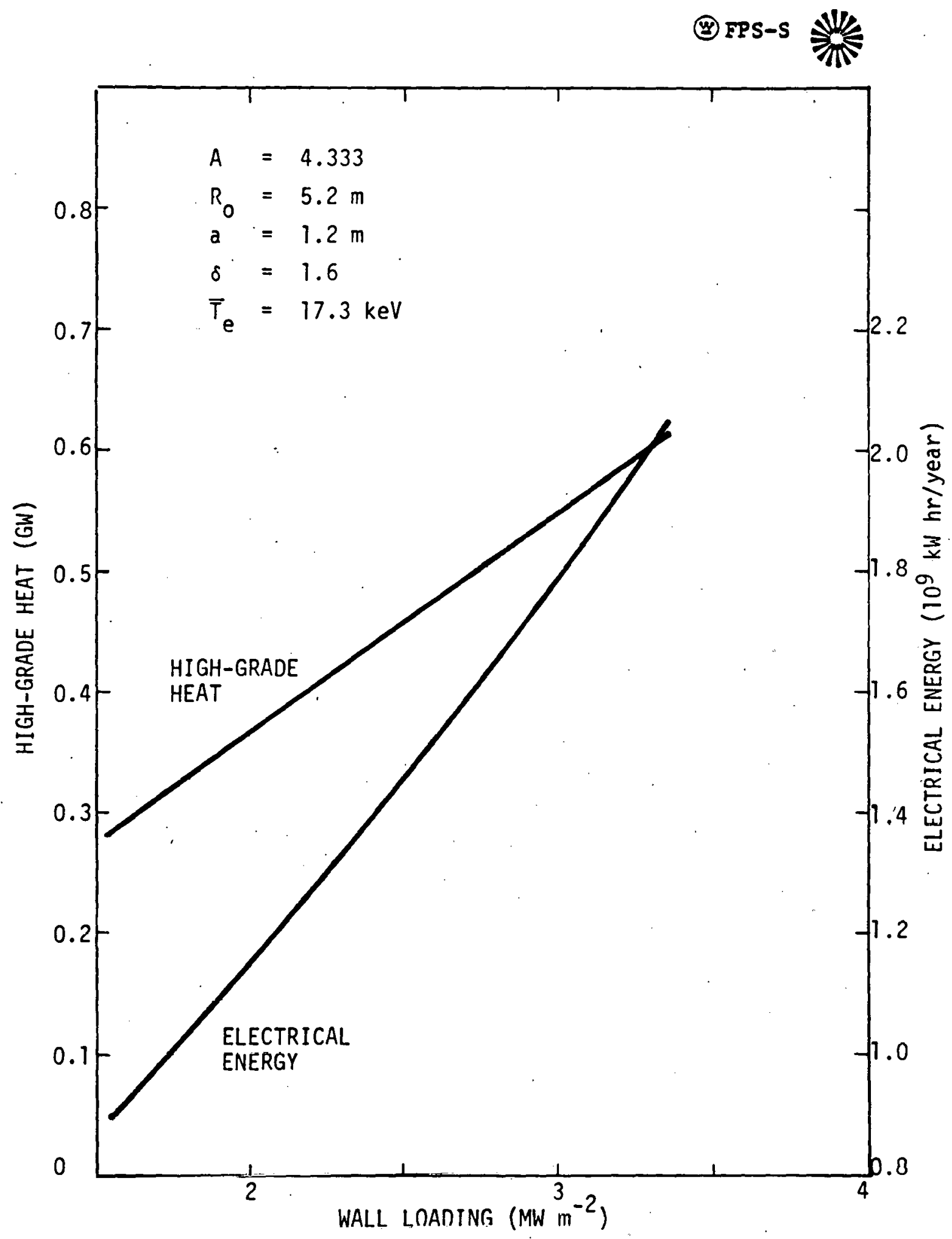

Figure 4-3. High-Grade Heat Production and Electrical Energy Consumed Per Year as a Function of Wall Loading for a Fixed Major Radius, $R_{0}=5.2 \mathrm{~m}$. 


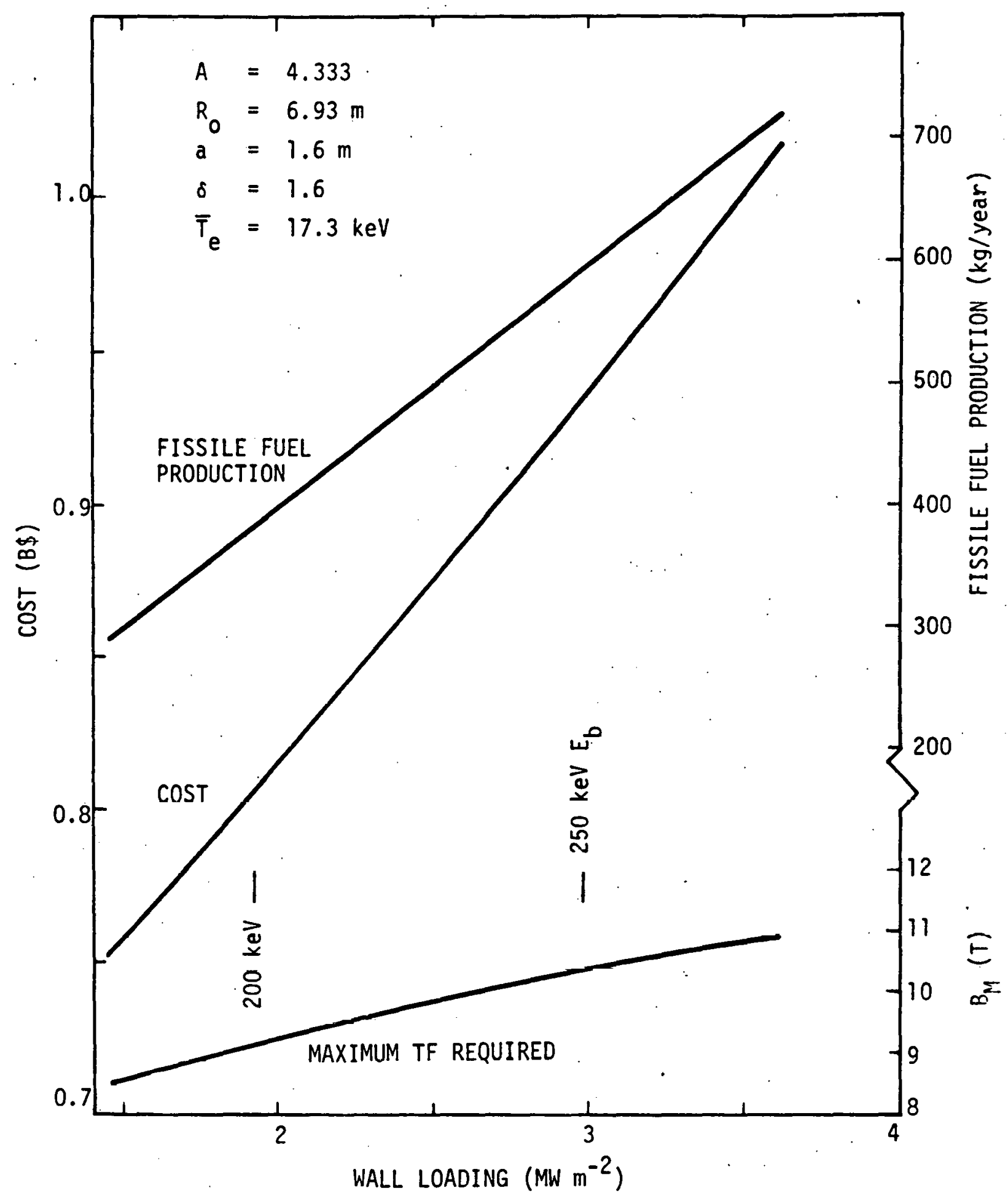

Figure 4-4. Cost, Annual Fisstle Fuel Production, and Maximum TF Required as a Function of Wall Loading for

A Fixed Major Radius $R_{0}=6.93 \mathrm{~m}$, and $a=1.6 \mathrm{~m}$. 


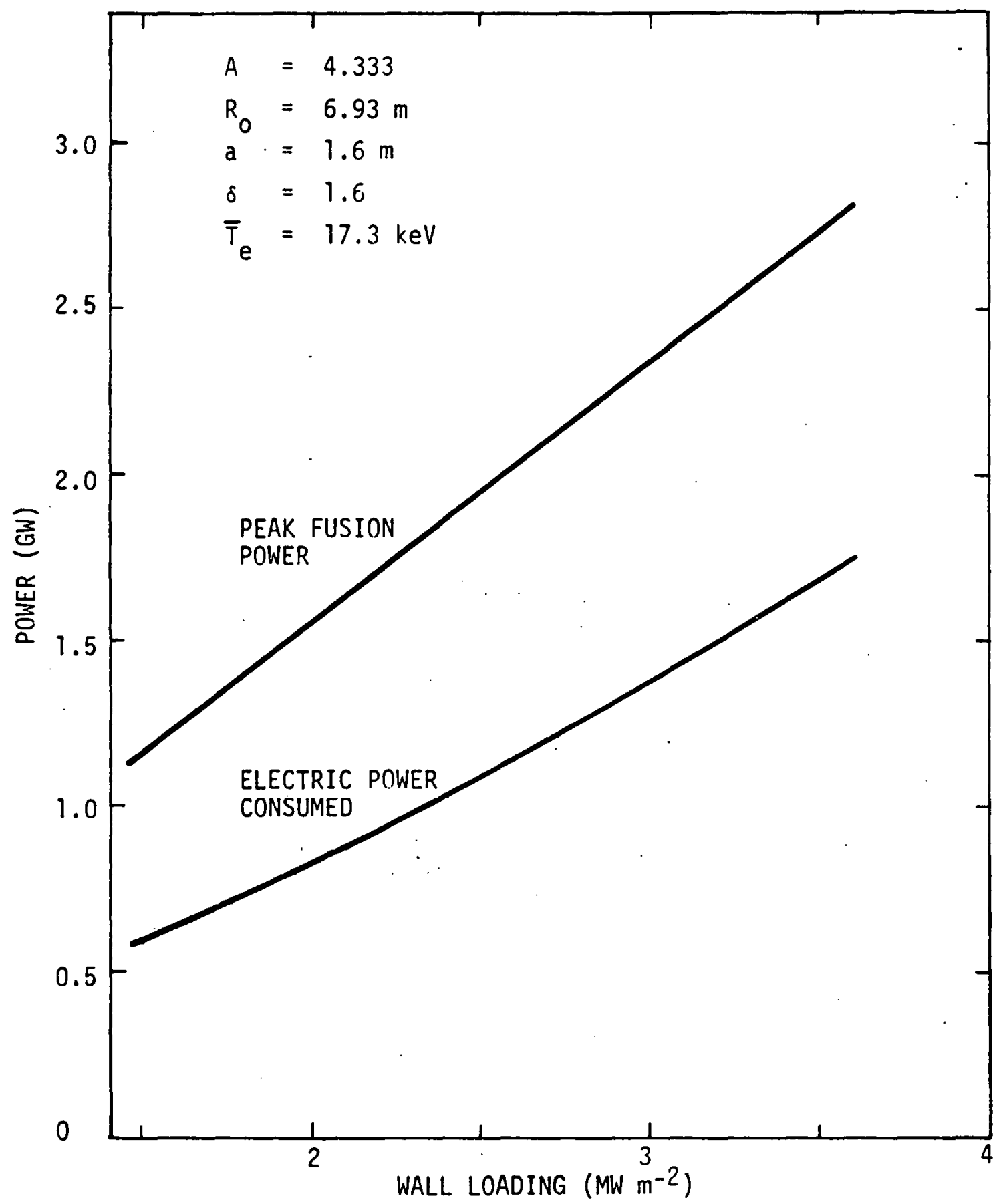

Figure 4-5. Electrical Power Consumed and Peak Fusion Power (17.6 MeV/Event) as a Function of Wall Loading for a Fixed Major Radius, $R_{0}=6.93 \mathrm{~m}, a=1.6 \mathrm{~m}$. 


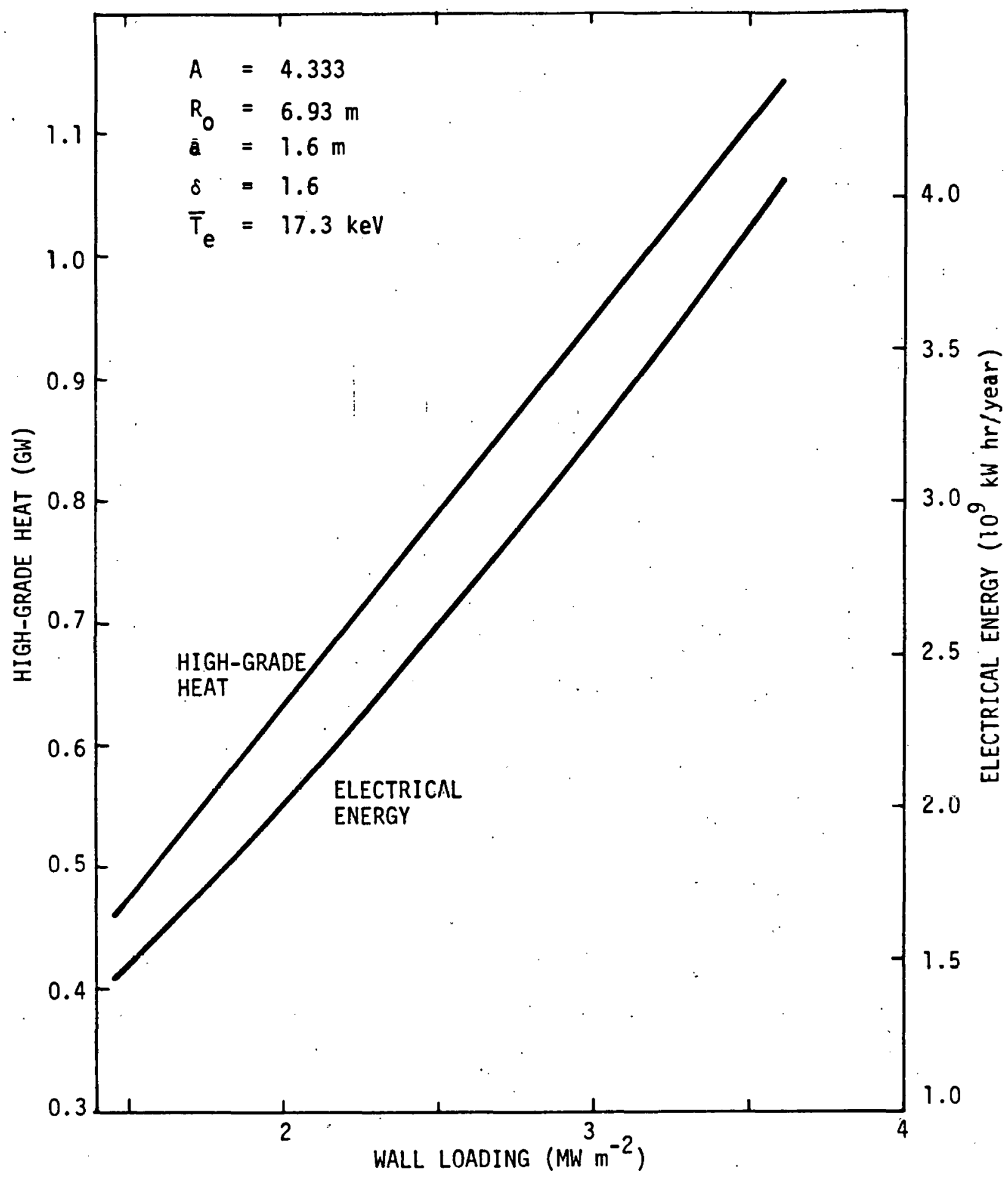

Figure 4-6. High-Girade Heat Production and Electrical Energy Consumed Per Year as a Function of Wall Loading for a Fixed Major Radius, $R_{0}=6.93 \mathrm{~m}$; $a=1.6 \mathrm{~m}$. 
for an annual requirement of $\sim 1.5 \times 10^{9} \mathrm{kWhr}$. For the more conservative design $(200 \mathrm{~kg} / \mathrm{yr}), P_{F} \sim 800 \mathrm{MW}$, heat generation $\sim 300 \mathrm{MW}_{t}$, electrical power $\sim 400 \mathrm{MW}_{e}$, and electrical energy $\sim 1 \times 10^{9} \mathrm{kWhr}$. The cost for the $200 \mathrm{~kg} / \mathrm{yr}$ system is $\sim 600 \mathrm{M} \$$ which is only $12 \%$ less than the system required to operate at the limiting assumptions for $E_{b}$ and $B_{M}$.

In Figure 4-4, the results at $R_{0}=6.93 \mathrm{~m}$ are shown. For the larger sized DTHR, the cost and fissile fuel production show a considerable increase over those for the $R_{0}=5.2 \mathrm{~m}$ case. In terms of cost per unit of fissile production, there is clearly an economy-of-scale, e.g., at $J_{W}=2.5 \mathrm{MW} \mathrm{m}^{-2}$, a direct capital cost of $\$ 2.36$ per $\mathrm{kg} / \mathrm{yr}$ for: $R_{0}=5.2 \mathrm{~m}$ and $\$ 1.75$ per $\mathrm{kg} / \mathrm{yr}$ for $R_{0}=6.93 \mathrm{~m}$. In addition, the requirement on the maximum $T F$ is reduced to the range from $9 T$ to $11 \mathrm{~T}$ throughout the wall loadings considered. Based on these two observations, it looks very promising to examine the larger sized DTHR devices. The larger devices have a serious technology deficiency in that the energy requirements for the neutral beams, as set by the effective "target thickness" of the plasma, is very high. (200 keV $\left.\leqslant E_{b} \leqslant 250 \mathrm{keV}\right)$. For positive ion sources this energy range is very unattractive. For negative ion sources the energies are reasonable, but the technology is new and the source requirements in ion currents are very high ( $I_{B} \sim 300 \mathrm{~A}$ at the plasma, and $I_{S} \lambda 1000 \mathrm{~A}$ at the sources). If a scheme using a form of "programmed start-up" or ripple injection can be developed, the energy requirement could be reduced. The COAST calculations for the DTHR trade studies used $z_{\text {eff }}=1.2$. If; in fact, $z_{\text {eff }} \approx 1$, the energy requirements could be reduced by a factor of $1 / 1.2 \approx 0.8$ which would reduce the $250 \mathrm{keV}$ requirement to roughly $200 \mathrm{keV}$ permitting the $R_{0}=6.93 \mathrm{~m}$ DTHR to have a wall loading of $\sim 3 \mathrm{MW} \mathrm{m}^{-2}$. With respect to the magnitude of the wall loading it should be pointed out that the DTHR design and ground rules have not been optimized and until an optimization is performed the results will indicate important trends, but the magnitudes of the parameters discussed here will be different following an optimization of DTHR.

In Figure 4-5, the values of the peak fusion power for $R_{0}=6.93 \mathrm{~m}$ lie in the range from 1 to $3 \mathrm{GW}$ and the electrical power consumption is centered about $1 \mathrm{GW}$. The high grade heat generation in the DTHR $\left(R_{0}=6.93 \mathrm{~m}\right)$ blanket exceeds $1 \mathrm{GW}$ at the higher wall loadings and the total annual electrical energy required 
is as high as $4 \times 10^{9} \mathrm{~kW} \mathrm{hr}$. Assuming the above calculations are reasonable, a blanket with a high coverage fraction ( 20.85 ) operated at a high duty cycle $x$ plant availability $(\sim 0.6)$, the $6.93 \mathrm{~m}$ device could be operated (with appropriate upgrades) to produce $\sim 3000 \mathrm{~kg} / \mathrm{yr}$ of fissile fuel and $\sim 700 \mathrm{MW}$ of electrical power for $J_{W}=2.5 \mathrm{MW} \mathrm{m}^{-2}$. 


\subsection{PERFORMANCE AND COST AS A FUNCTION OF ASPECT RATIO FOR VARIOUS DEVICE SIZES}

The selection of the aspect ratio $A\left(=R_{0} / a\right)$ associated with the plasma impacts the operating conditions (densities, temperatures, fusion power levels) of the plasma as well as the performance of the reactor (thermal power generation and fissile fuel production). The plasma operating conditions are particularly affected under the assumption used throughout the DTHR study that the total beta is inversely proportional to $A$, i.e., Equation (3). Such a dependence has been found to hold.for theoretical studies of tokamak plasma stability and equilibrium. In the present studies, $B$ has been calculated assuming the poloidal beta is equal to $A$ which results in using the equality condition for Equation (3).

The impact of the value of $A$ on the reactor sizing is felt in two important ways. First, there is a lower limit on $A$ imposed by the machine bore space requirements for the ohmic heating $(\mathrm{OH})$ coil. Secondly, for a given set of plasma conditions on temperature and density (and the profiles for each), the plasma beta establishes the field on axis $B_{t}$, which, in turn, establishes the required maximum field $B_{M}$ at the inner leg of the TF coil. In addition, these two effects are coupled in that the value of $B_{M}$ establishes the radial build of the TF coil. Since the space requirements at the center of the tokamak must be satisfied for both the $\mathrm{OH}$ and TF coils, there is a trade-off between the two coil sets in the alocation of space in the machine bore.

To study the effects of variations in the aspect ratio a series of COAST calculations were made for plasma minor radii $a=1.0,1.1$, and $1.2 \mathrm{~m}$ and 4.333 $\leq A \leq 5.0$. The resulting major radii are in the range from $4.33 \mathrm{~m}$ to $6.0 \mathrm{~m}$. To limit the amount of data generated to a reasonable level, the calculations were based on the beam-driven option (case 1 of Section 3.0) for which $\delta=1.6$, $B_{M}=12 \mathrm{~T}$, and $\bar{T}_{e}=17.3 \mathrm{keV}$. To accomplish these conditions the plasma density was allowed to vary and as a result the wall loading, $J_{W}$, also varied and the neutral beam energy requirements $\left(E_{b} \propto \bar{n}_{e} a Z_{\text {eff }}\right)$ differed over the 
parameter space established for these calculations. The results are shown in Figures 5-1 through 5-7.

The cost data shown in Figure 5-1 reflects the increase in $R_{0}$ as $A$ increases for a given a as well as the difference in a for a given value of $R_{0}$. For example, the cost for $a=1.2 \mathrm{~m}, A=4.333\left(R_{0}=5.2 \mathrm{~m}\right)$ is $670 \mathrm{M} \$$ as compared to $640 \mathrm{M} \$$ for a device with $a=1.1, A=4.727\left(R_{0}=5.2 \mathrm{~m}\right)$. The costs reflect increases in dimensions which result in increases in material volumes and masses as well as the effects of bore space requirements on the $\mathrm{OH}$ coil sizing and power supply rating. Since the device size is a variable in these calculations, the wall coverage (number of $\mathrm{m}^{2}$ of surface of blanket) as well as the blanket volume is a variable. The resulting fissile fuel production per year is shown in Figure 5-2. The production rate is also a function of the wall loading which is a varible as shown in Figure 5-7.

As shown in Figure 5-2, the fissile production rate is centered about $150 \mathrm{~kg} /$ yr at $a=1.0 \mathrm{~m}, 225 \mathrm{~kg} / \mathrm{yr}$ at $\mathrm{a}=1.1 \mathrm{~m}$, and $350 \mathrm{~kg} / \mathrm{yr}$ at $\mathrm{a}=1.2 \mathrm{~m}$. In addition, an economy-of-scale is observed when considering the cost per unit of production as a is increased. The neutral beam energy requirements for the $a=1.0 \mathrm{~m}$ device size is $145 \pm 10 \mathrm{keV}$ over the range of A shown, and for $a=$ $1.2 \mathrm{~m}$, is $209 \pm 13 \mathrm{keV}$. Thus, the favorable economy-of-scale at a $=1.2$ does not look attractive for the NB injector system requirements. These results for NB requirements are based on $Z_{\text {eff }}=1.2$ and $E_{b} \propto \bar{n}_{e}$ a $Z_{e f f}$. If $Z_{\text {eff }}$ could be reduced to $\approx 1, E_{b} \approx 174 \mathrm{keV}$ at $a=1.2 \mathrm{~m}$.

One further point should be made in examining the data in Figures 5-1 and 5-2. The cost for the larger devices at $a=1.2$ is approaching $750 M \$$ and more, and after adding indirect costs, contingencies, etc., the total cost will be $\sim 1.5$ $B \$$ or more. Even though an economy-of-scale in cost of fuel production is exhibited in the data, the total capital costs are likely to be more important in the determination of device size for a near-term demonstration device.

The production of high-grade heat in the blanket and of fusion power (17.6 MeV) event) in the plasma are shown in Figures 5-3 and 5-4. These results are 


\section{(상 FPS-S}
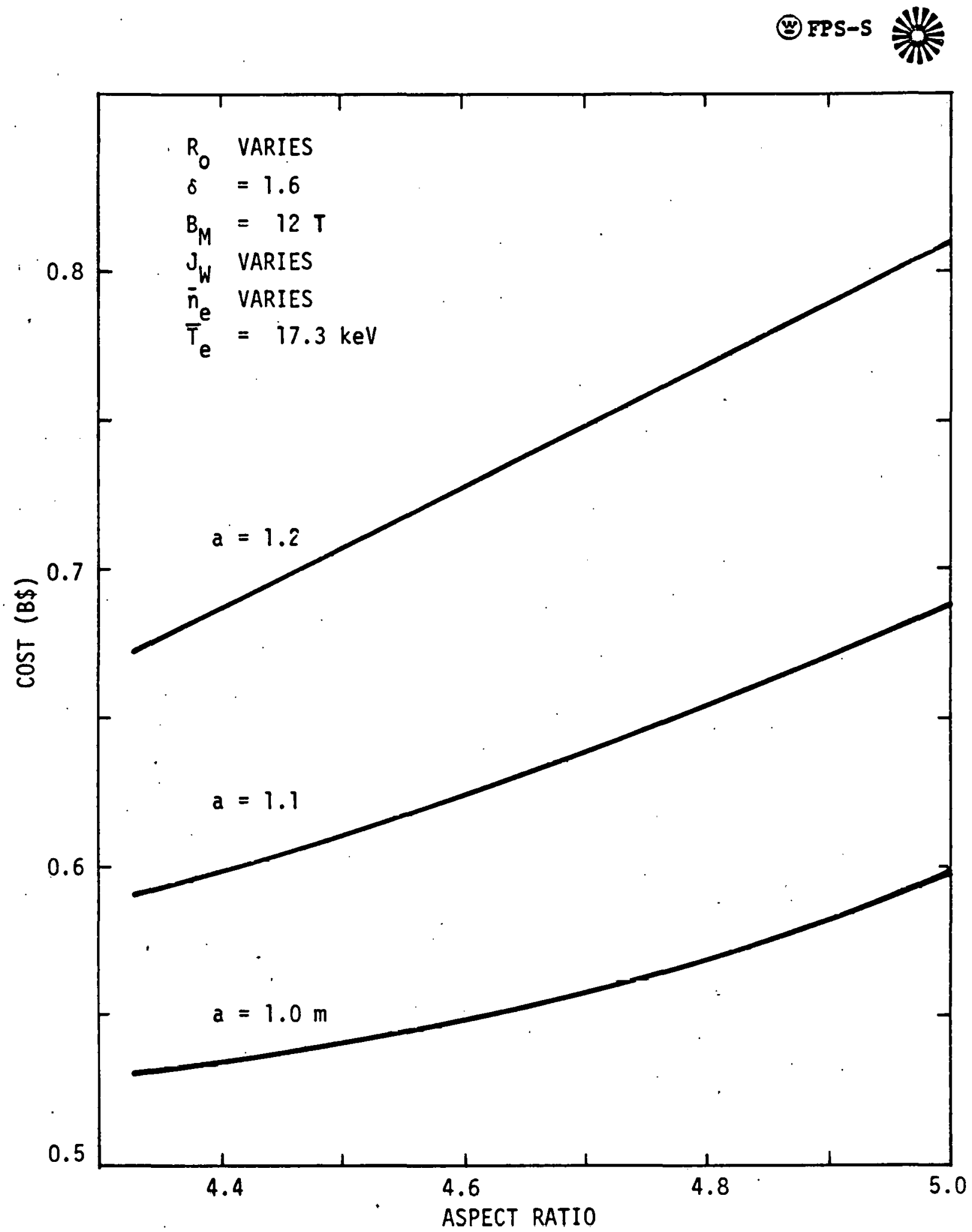

Figure 5-1. Cost as a Function of Aspect Ratio for Various Minor Radii, a. 
(앙 FPS-S

Hi

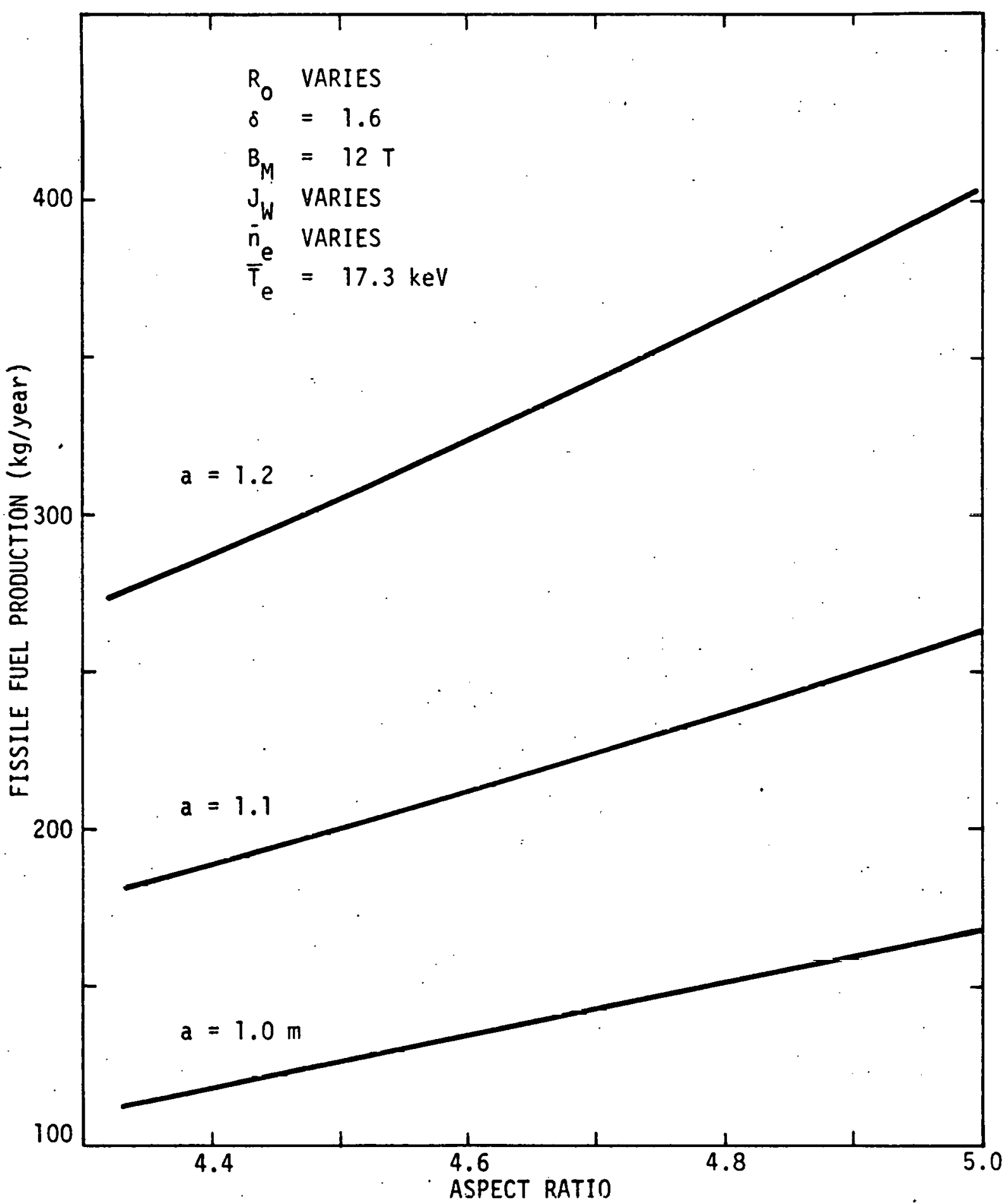

Figure 5-2. Fissile Fuel Production as a Function of Aspect Ratio for Various Minor Radii, a. 


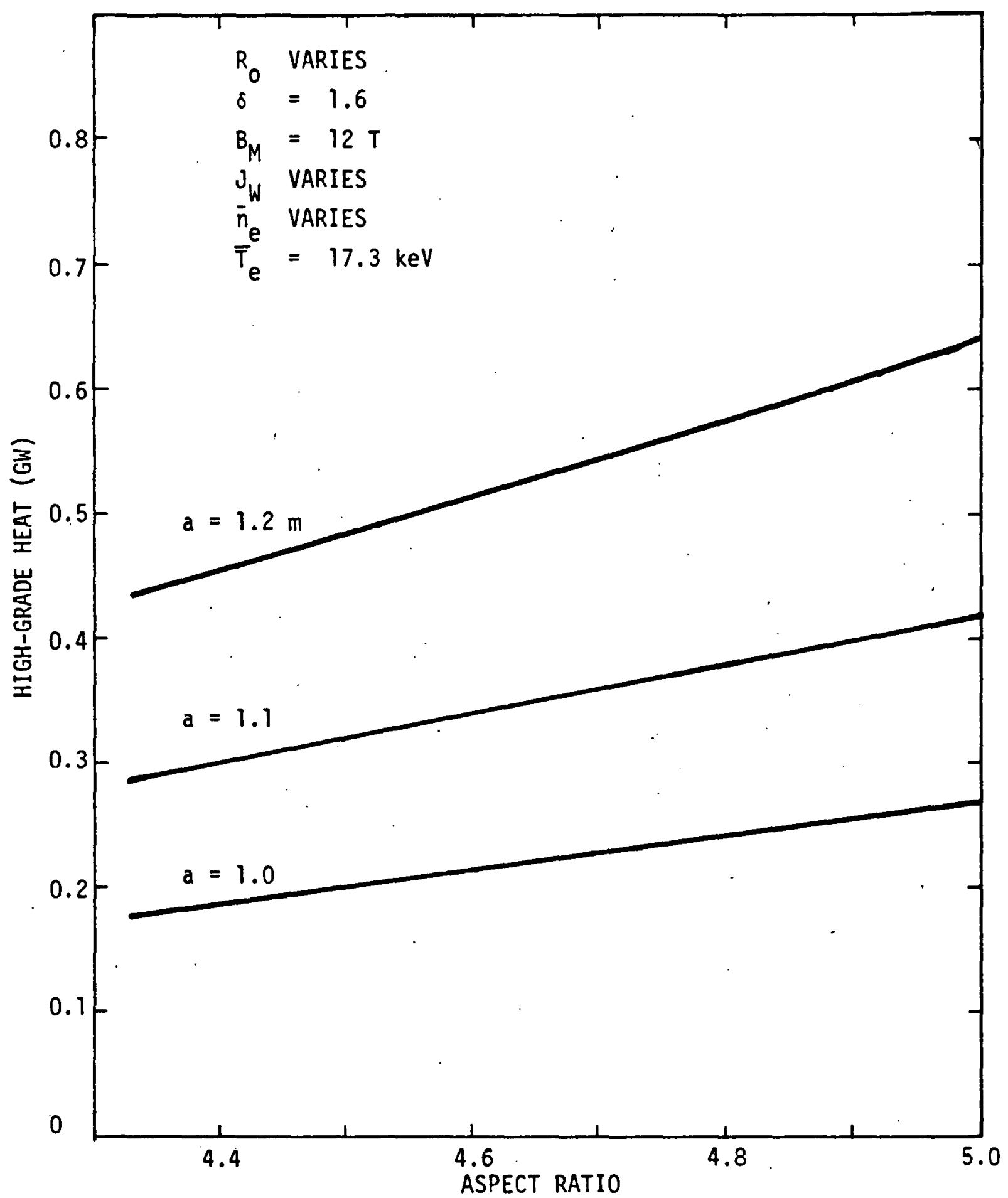

Figure 5-3. High-Grade Heat Production as a Function of Aspect Ratio for Various Minor Radii, a. 


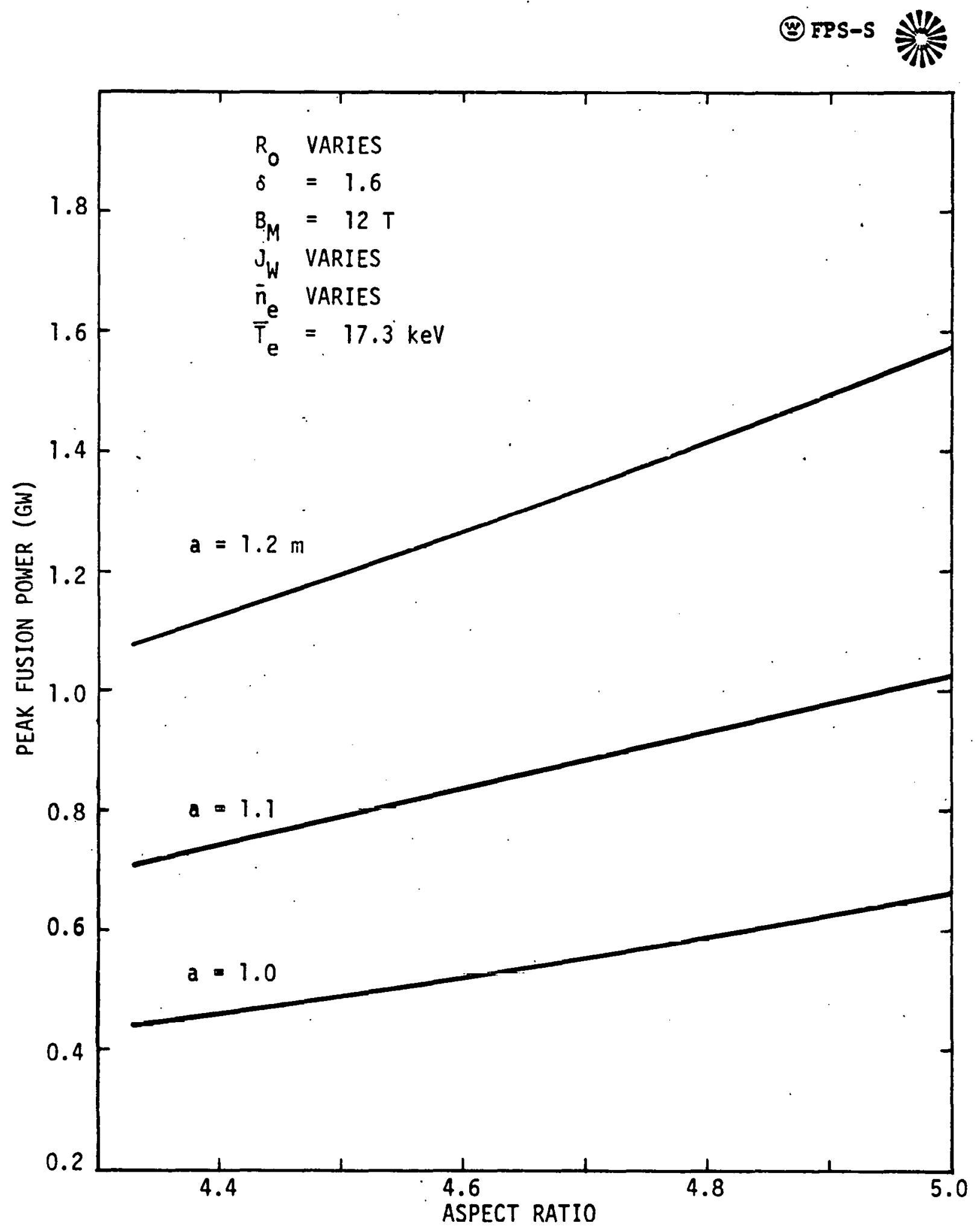

Figure 5-4. Peak Fusion Power as a Function of Aspect Ratio for Various Minor Radii, a. 
(아 FPS-S

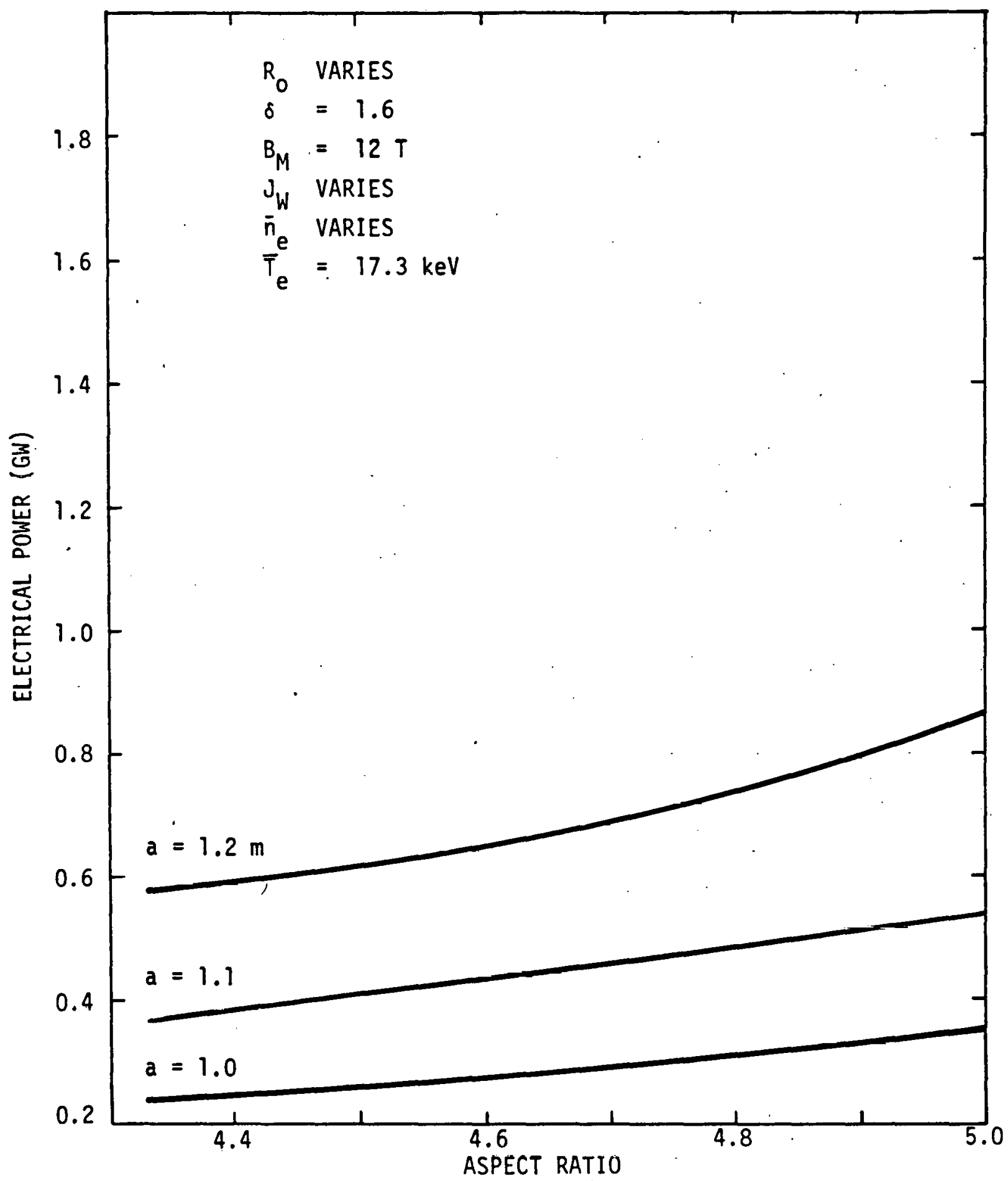

Figure 5-5. Electrical Power Consumed as a Function of Aspect Ratio for Various Minor Radii, a. 
(40) FPS-S

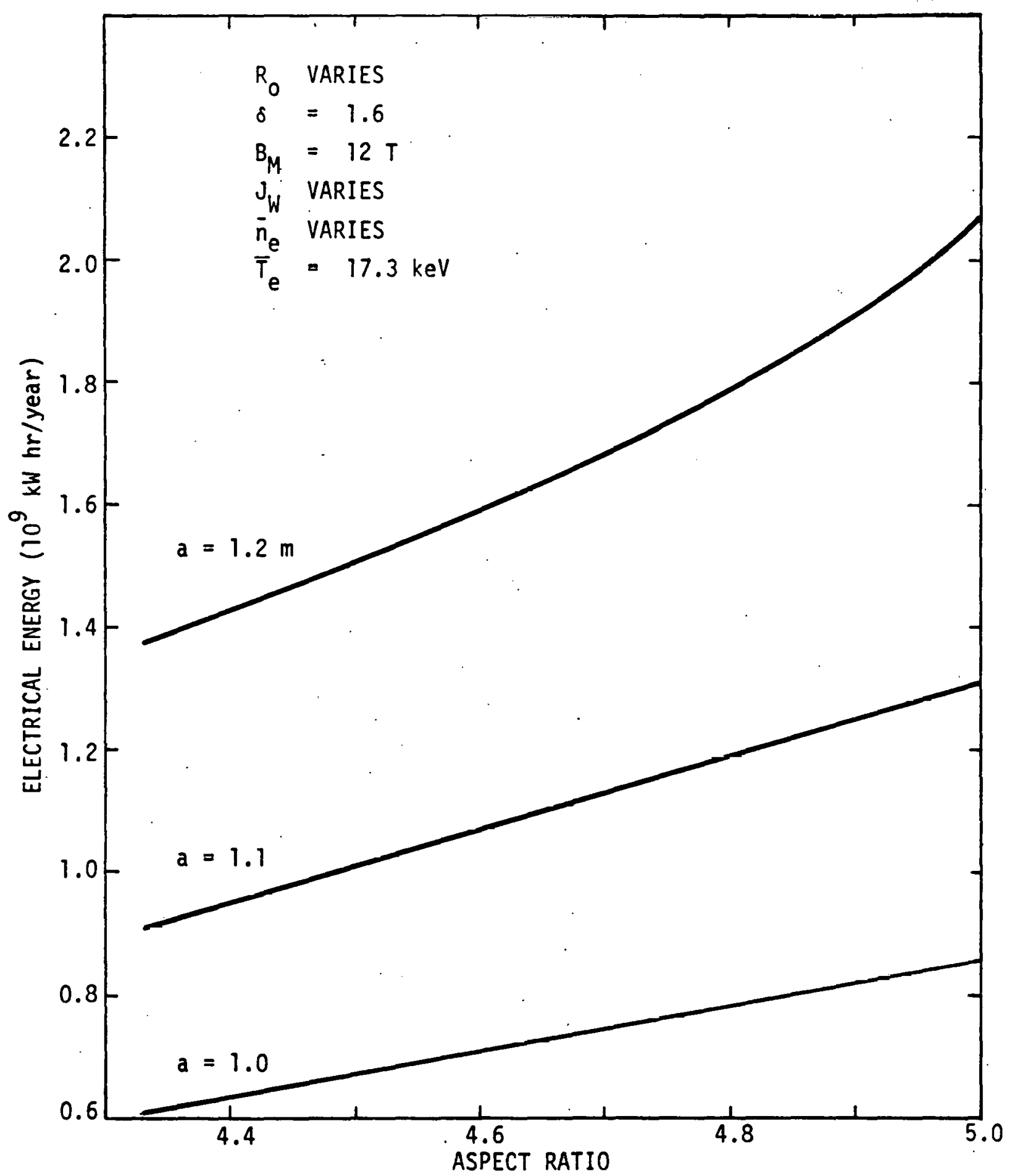

Figure 5-6. Electrical Energy Consumption as a Function of Aspect Ratio for Various Minor Radii, a. 


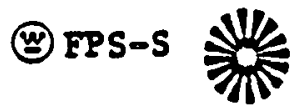

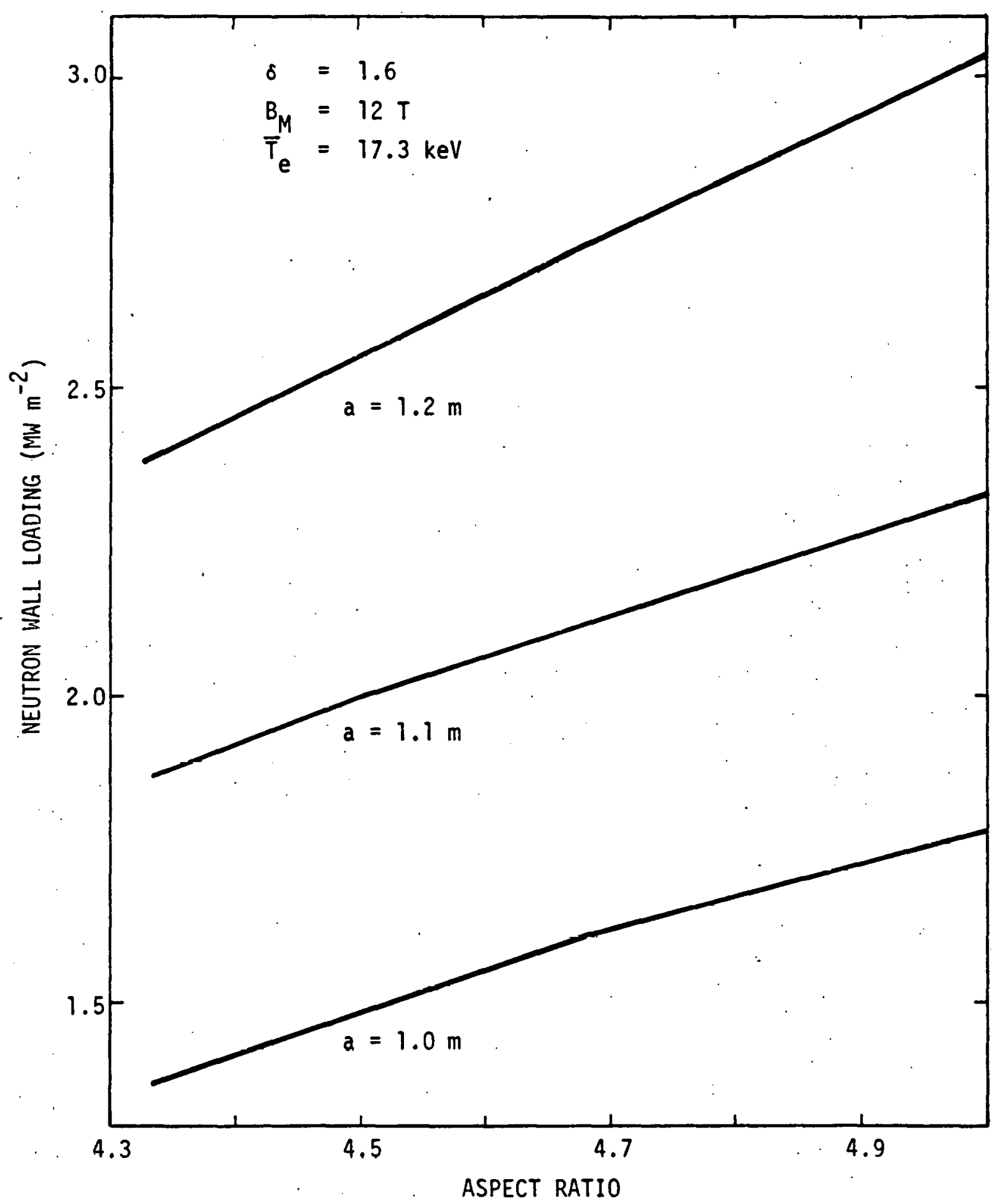

Figure 5-7. Neutron Wall Loading as a Function of Aspect Ratio for Various Minor Radii. 
important in sizing the heat dissipation systems as well as in evaluating the potential electrical power production capabilities of DTHR. The high-grade heat level is low ( $200 \mathrm{MW}$ ) for the smaller devices, but approaches. $700 \mathrm{MW}$ for the largest devices. The fusion power is greater than 1 GW for all values of $a=1.2 \mathrm{~m}$ and can be as high as $600 \mathrm{MW}$ for $\mathrm{a}=1.0 \mathrm{~m}$. Since the blanket wall coverage is only a small fraction $(\sim 0.36)$. of the outer half of the toroidal vacuum vessel, the power generation capacity in the blanket is relatively low. With a coverage fraction of $\sim 0.8$ (space for a divertor and neutral beam injection must be made available) the blanket could produce three times the thermal power.

The electrical requirements for operating DTHR are shown in Figures 5-5 and 5-6. The power levels are modest at $a=1.0 \mathrm{~m}$, but become large for the $a=$ $1.2 \mathrm{~m}$ devices. The main users of power $(80-90 \%)$ are the neutral beam injectors which operate the plasma drivers during the burn and which are very inefficient in converting electrical power to beam power. The conversion efficiencies defined by the ratio of input power to the plasma by the high energy component of the beam to the net input power to the neutral beam system are shown in Figure 5-8. Also shown are the efficiencies under the assumption that a direct energy recovery system is available for DTHR (not assumed for the COAST calculations presented in this report).

As a final calculation in the study of the effects of the aspect ratio on DTHR, a set of data was generated for which the following parameters were fixed: $a=1.2 \mathrm{~m}, \delta=1.6, \bar{n}_{e} \approx 1 \times 10^{20} \mathrm{~m}^{-3}, E_{b}=179 \mathrm{keV}$, and $B_{M}=11.4 \mathrm{~m}$. These parameters are associated with the DTHR point design $(2)$. The variation of cost, fissile fuel production, and wall loading as a function of $A$ (or $R_{0}$ ) is shown in Figure 5-9. The range of $A$ is roughly 3.8 to 5.3: For the assumption used to generate the date, it can be seen that the wall loading varies by only $10 \%$ about $2 \mathrm{MW} \mathrm{m}^{-2}$. The fuel production capabilities roughly doubles over this range in aspect ratio, while the direct capital cost increases by only a third, but does approach $800 \mathrm{M} \$$. The results displayed in Figure 5-9, as well as the remaining data in this section, indicate and quantify important trends associated with sizing trade-offs for DTHR. Such data will provide an important basis for later sensitivity studies as DTHR becomes better defined and optimized. 
(20) FPS-S
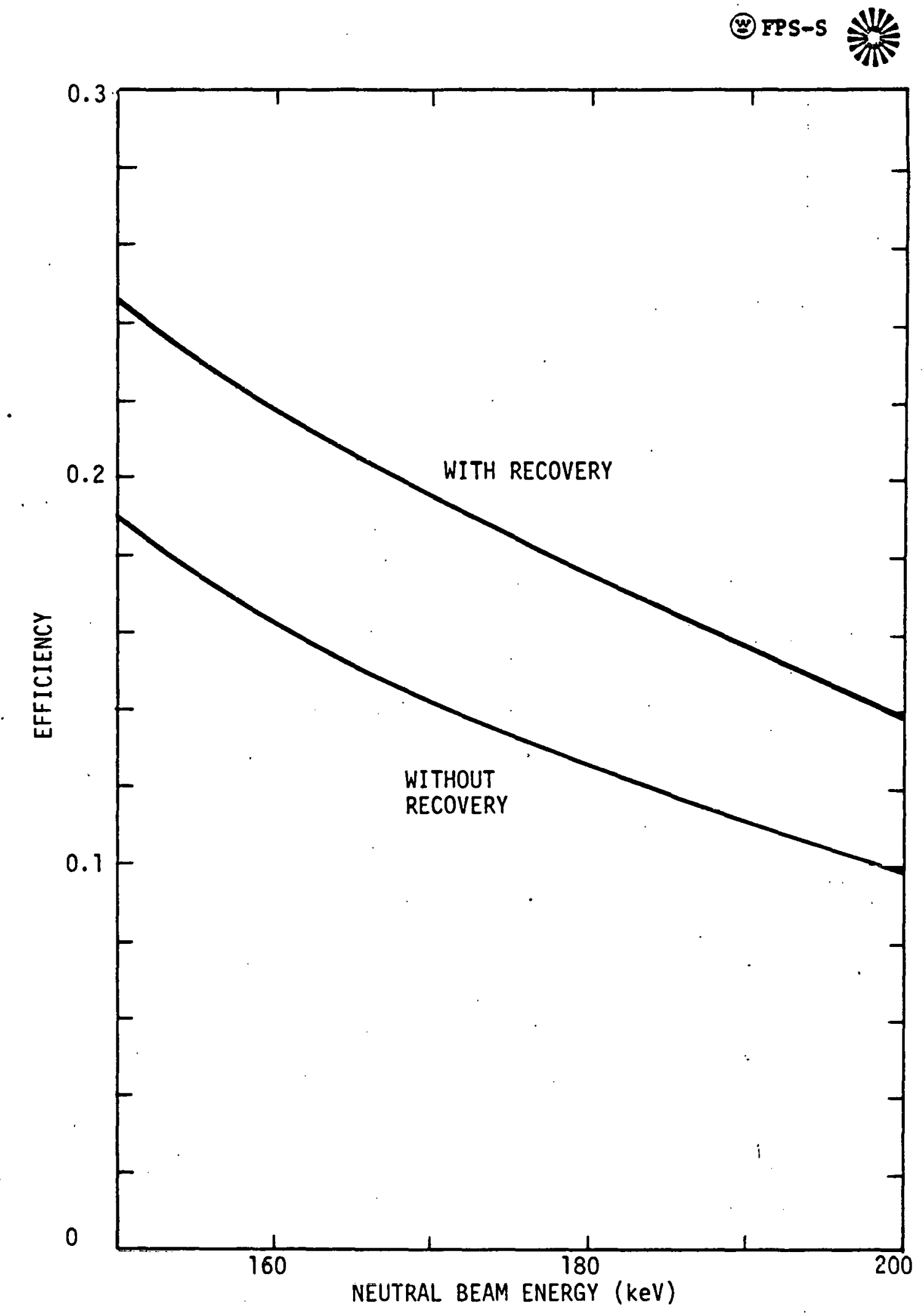

Figure 5-8. Neutral Beam Power Efficiency for Positive Ion Based Injection. 


\section{(0) FPS-S 粚}

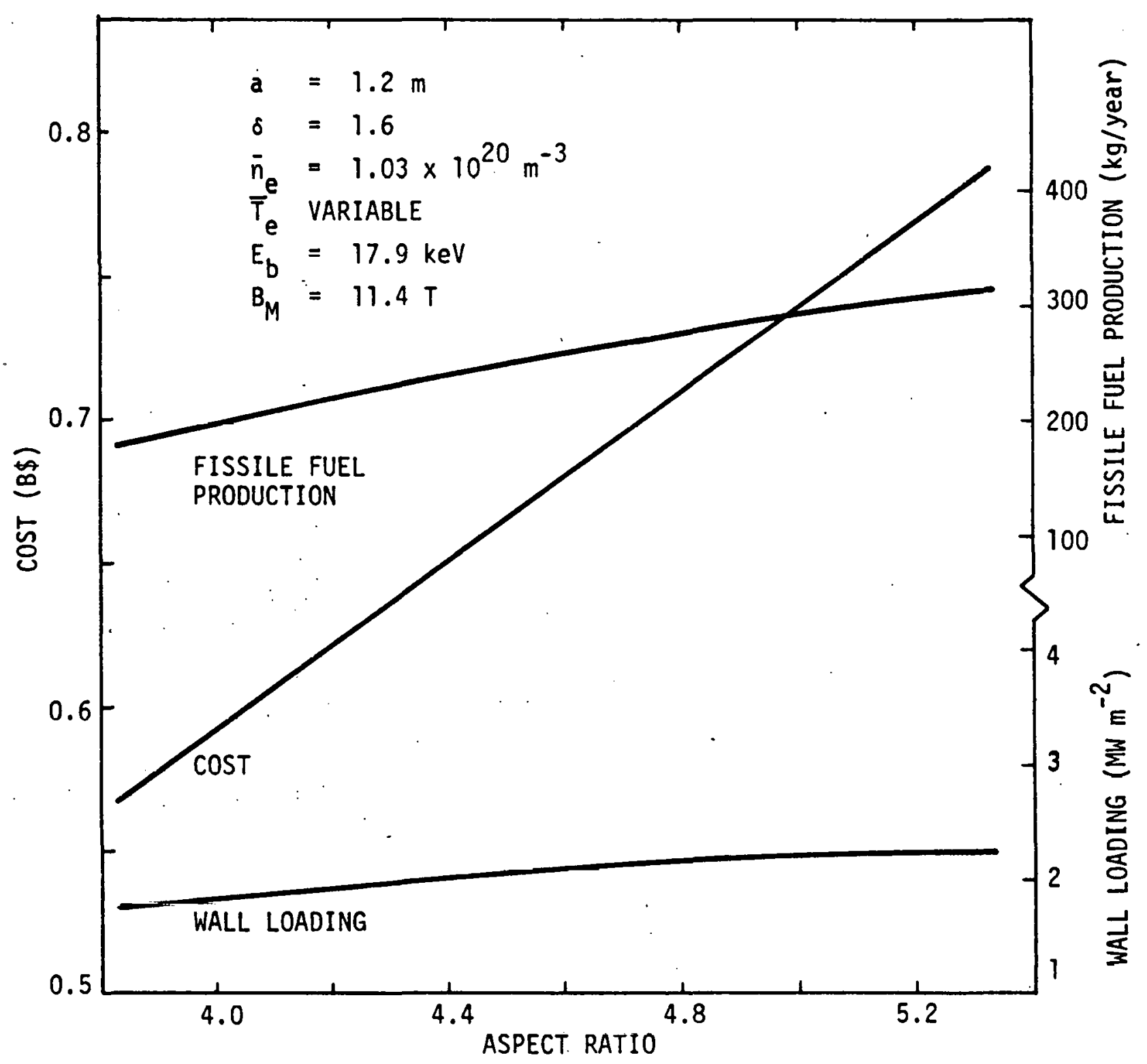

Figure 5-9. Cost and Annual Fissile Fuel Production as a Function of Aspect Ratio for $a=1.2 \mathrm{~m}$. 


\subsection{SENSITIVITY STUDIES}

The DTHR trade study results discussed and shown graphically in Sections 3.0, 4.0, and 5.0 were based on a point design for which a number of arbitrary assumptions were made in order to begin the design of DTHR. An optimization of plasma and engineering ground rules was not conducted as an important or main part of the study. The selection process for the parameters on which the optimization is based as well as the parameters to be optimized requires careful consideration. The results in this report provide a quantifiable base in terms of magnitudes and trends for such considerations. The next step following the trade studies is the identification and selection of parameters for the optimization process. Toward this end, additional COAST calculations were made in which a number of parameters were varied so as to quantify their affect on the cost and operation of DTHR. The parameters were limited and. include those which are clearly important in the determination of the DTHR characteristics. Since the plasma core, the TF coils, and the neutral beam systems are the key components in a demonstration reactor, the following parameters were studied as part of a preliminary sensitivity consideration: the plasma elongation, $\delta$; the plasma minor radius, a; the maximum TF required, $B_{M}$; and the steady state beam power required, $P_{B}$. The results of the calculations are shown in Figures $6-1$ through $6-5$ and are for the beam-driven case only.

Cost, fuel production, and wall loading $J_{W}$ as a function of the plasma minor radius a is shown in Figure $6-1$. The data could have been included in the previous section which shows results as a function of aspect ratio. The data in Figure $6-1$ is presented differently in that $R_{0}$ is fixed (as well as $B_{M}$ and $E_{b}$ ) as compared to fixing the minor radius a in Section 5.0. The results (Figure 6-1) show the wall loading decreasing with increasing minor radius, and a relatively constant ratio of cost divided by fuel production rate. For these calculations, both $\bar{n}_{e}$ and $\bar{T}_{e}$ were varied such that the beam energy and the maximum field $B_{M}$ were fixed. As a consequence, the density $\bar{n}_{e}$ at the larger values of a was lower than at the smaller a values. The temperature 


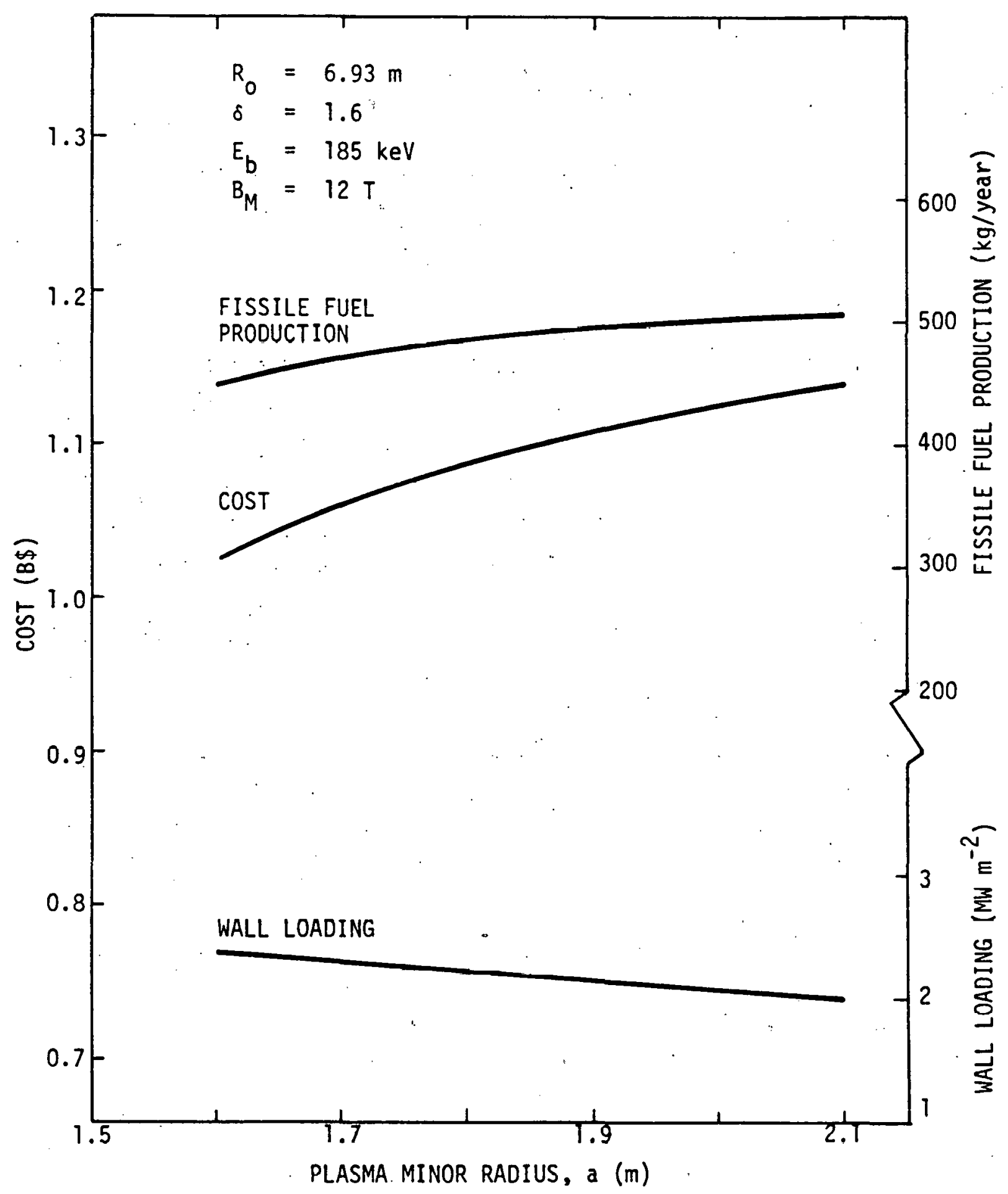

Figure 6-1. Cost and Annual Fissile Fuel Production as a Function of Plasma Minor Radius for $R_{0}=6.93 \mathrm{~m}$. 


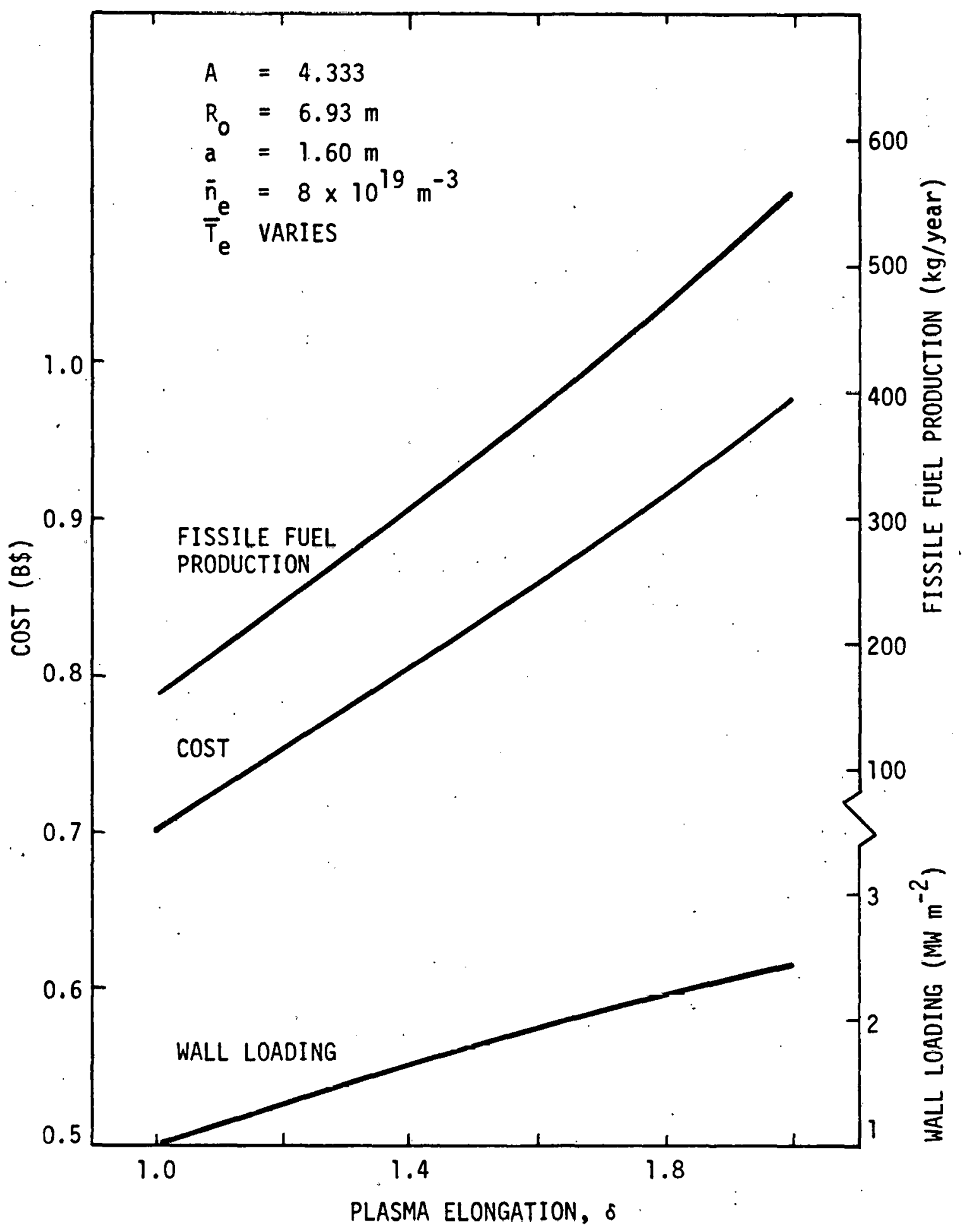

Figure 6-2. Cost and Annual Fissile Fuel Production as a Function of Plasma Elongation for $R_{0}=6.93 \mathrm{~m}$, $E_{b}=185 \mathrm{keV}, B_{M}=9.9 \mathrm{~T}$. 


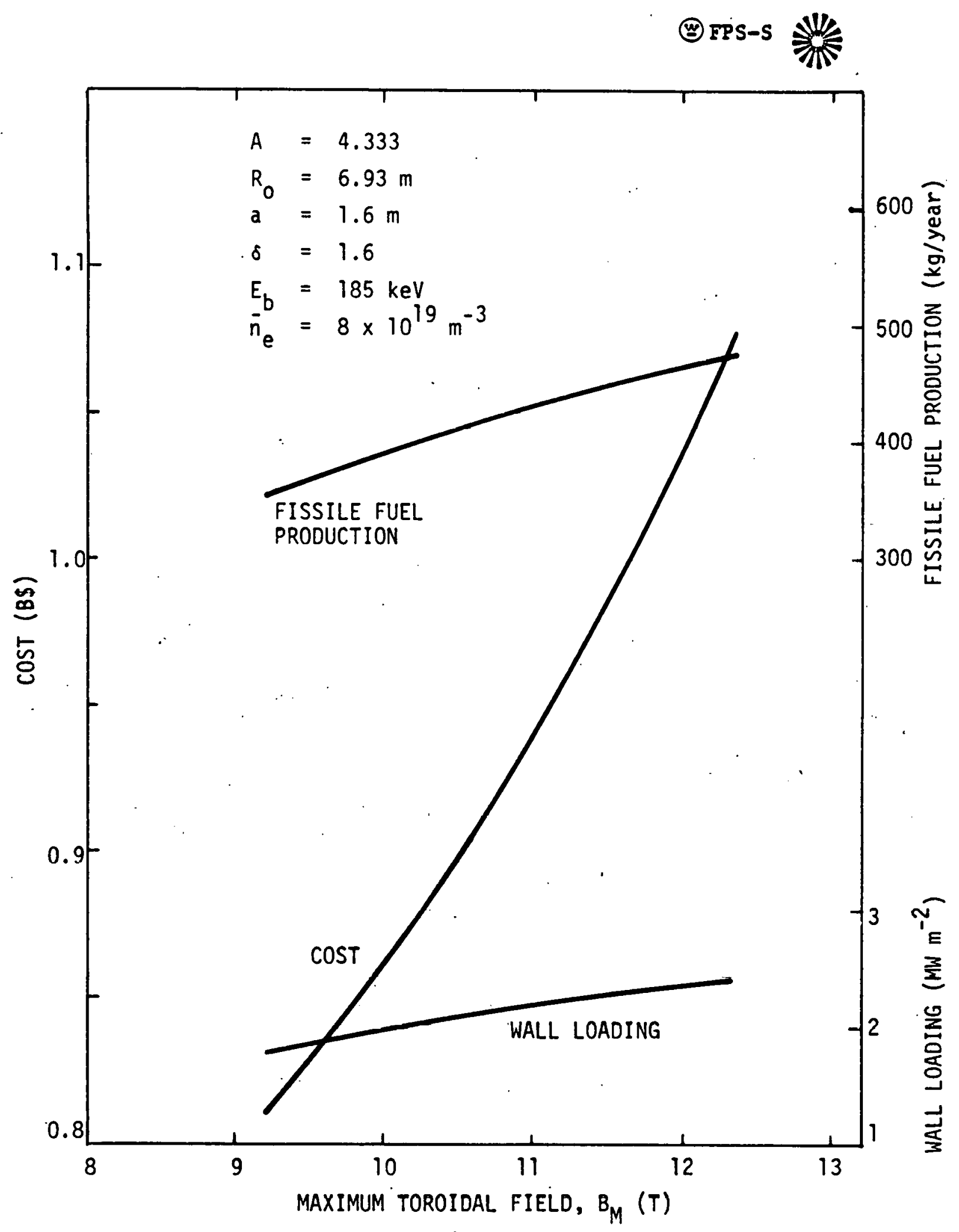

Figure 6-3. Cost and Annual Fissile Fuel Production as a

Function of Maximum . Toroidal Field, $B_{M}$,

$R_{0}=6.93 \mathrm{~m}$. 


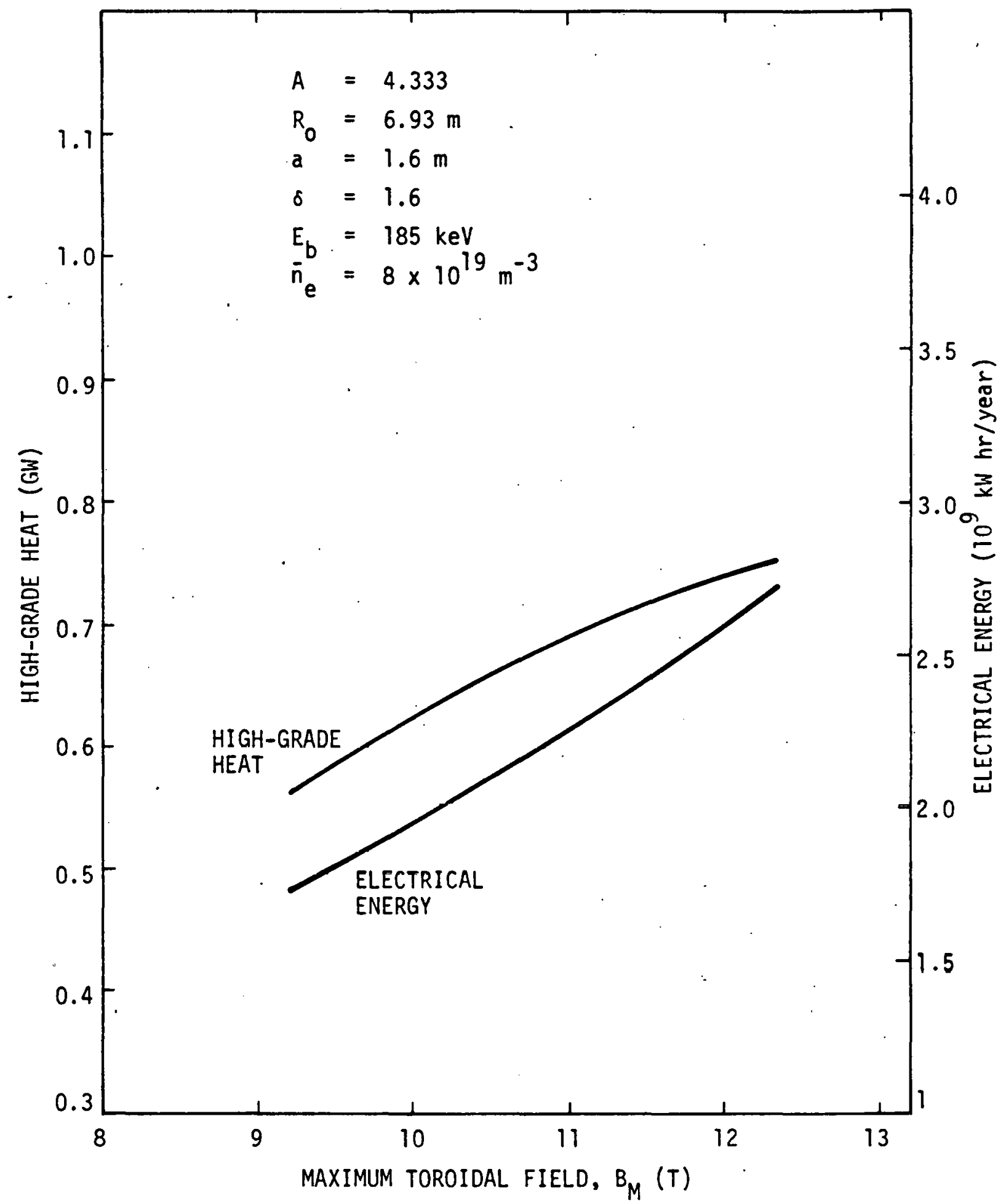

Figure 6-4. High-Grade Heat Production and Electrical Eneray Consumed Per Year as a Function of Maximum Toroidal Field, $B_{M}$. 


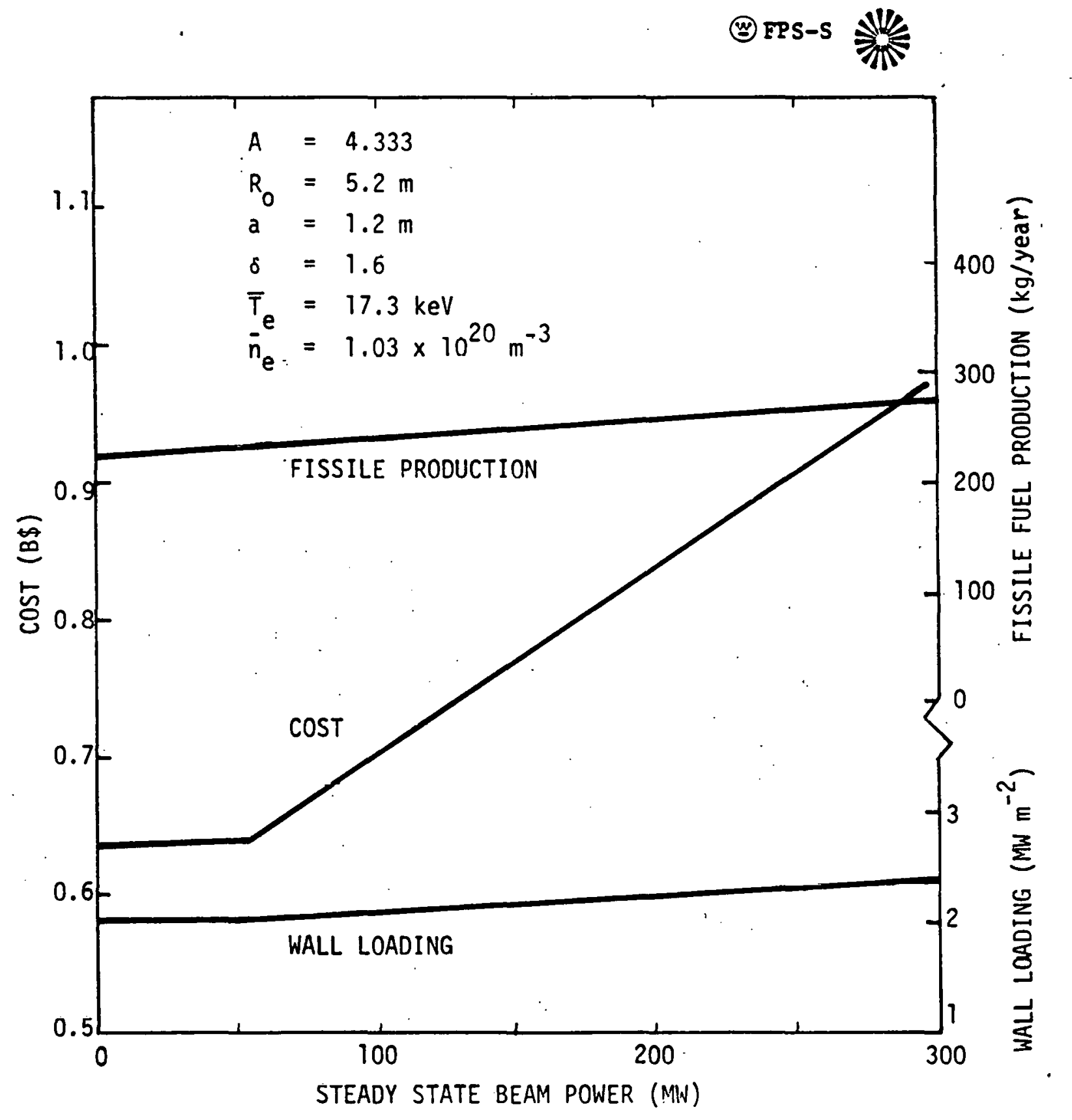

Figure 6-5. Cost and Annual Fissile Fuel Production as a Function of Steady State Neutral Beam Power $\left(P_{N B}=0 \rightarrow\right.$ Ignition $) a=1.2 \mathrm{~m}$. 
$\bar{T}_{e}$ was adjusted to preserve the value of $B_{M}$, but the adjustment was not enough at large a to keep $J_{W}$ from decreasing with increasing $a$.

In Figure 6-2, cost, fuel production, and wall loading were calculated for variations in the plasma elongation $\delta$. For these COAST calculations, $E_{b}=185 \mathrm{keV}$, and $B_{M}=9.9 \mathrm{~T}, \bar{n}_{e}=8 \times 10^{19} \mathrm{~m}^{-3}$, and $\bar{T}_{e}$ was adjusted to maintain $B_{M}$. The results show a strong dependence of wall loading and fuel production on the elongation. The higher the elongation the better, in terms of fuel production. Elongations as high as 2.0 are desirable from the reactor aspects of DTHR, but attaining stable plasmas with $\delta>1.6$ is considered to be difficult, as well as providing the system of equilibrium field (EF) coils. The currents and power requirements for the EF coils increase in both complexity and magnitude as $\delta$ increases. The results indicate that the increase in wall loading and fuel production warrants designing DTHR for the highest feasible elongation.

Cost and performance data as a function of $B_{M}$ (maximum $T F$ at the inner leg) is shown in Figures $6-3$ and $6-4$. The value of $B_{M}$ required is a function of the plasma beta and kinetic pressure. By fixing the plasma density at $8 \times 10^{19} \mathrm{~m}^{-3}$, using the rule $\beta=s^{2} /\left(A q^{2}\right)$, and varying $\bar{T}_{e}$, COAST was employed to generate the data. Fixing $\bar{n}_{e}$ allows $E_{b}$ to be fixed at $185 \mathrm{keV}$. Because $\bar{T}_{e}$ is a variable, the neutral beam power is also a variable such that $P_{B} \propto R_{0} \bar{T}_{e}$. The results show a relatively constant value for the ratio of cost to fuel production. The cost is found to increase by approximately $33 \%$ for. an increase in $B_{M}$ of approximately $33 \%$. The corresponding increases in $J_{W}$ and the high-grade heat are also $33 \%$, while the annual electrical energy comsumption increases by roughly $50 \%$ over the range of $B_{M}$. This $50 \%$ increase is associated with the increase in neutral beam power requirements as $T$ and $B_{M}$ increase.

In the last set of calculations, the steady state neutral beam power was varied over a wide range (from $P_{B}=0$ corresponding to ignition to $P_{B}=300 \mathrm{MW}$ corresponding to $Q=P_{F} / P_{B}=3.6$ ). The resulting costs, fissile fuel production, and neutron wall loading are shown in Figure 6-5. For these calculations, a plasma core with a fixed geometry $\left(R_{0}=5.2 \mathrm{~m}, a=1.2 \mathrm{~m}, \delta=1.6\right)$, density, and 
temperature was assumed. The energy balance within the plasma was assumed to satisfy Equation (11), Section 2.0, and the value of $\tau_{E}$ was that which provided thermal equilibrium for a plasma with parabolic profiles in both temperature and density. For the start-up NB system, $52 \mathrm{MW}$ of $180 \mathrm{keV}$ beams are required to heat the plasma to a burn temperature of $17.3 \mathrm{keV}$ (averaged over plasma volume). Thus, the start-up beams are available for beam-driven operation up to a driving power of $52 \mathrm{MW}$, and the cost remains essentially unchanged from 0 to $52 \mathrm{MW}$ in Figure 6-5. For higher driving powers, additional arms and power supplied (as well as additional heat dissipation) must be included in the design, and the cost curve reflects the associated changes in these beam systems.

Both the wall loading and the fissile fuel production are relatively constant over the range of the calculations. Both quantities are tied to the plasma fusion power $P_{F}(17.6 \mathrm{MeV} /$ event) which has a magnitude of $906 \mathrm{MW}$ for the ignition case and increases to only $1066 \mathrm{MW}$ for a driving power of $300 \mathrm{MW}$. At ignition, all the fusion power is generated by plasma-plasma interactions. By taking charge neutrality into account and by including impurity ions, hot and cold alpha particles, the deuterium/tritium population is $94.5 \%$ of the electron density for the ignition case. For the case in which the plasma is driven with $300 \mathrm{MW}$ of beams, the bulk deuterium/tritium ions are reduced to $88.3 \%$ of the electron density due to the addition during burn of the hot beam particles. As a result, the plasma-plasma fusion power is reduced from $906 \mathrm{MW}$ to $738 \mathrm{MW}$. The beam-plasma interactions add $328 \mathrm{MW}$ of power so that the total fusion power is $1066 \mathrm{MW}$. Thus, the addition of beam power during the burn reduces the bulk fusion power with only a relatively small increase in the total fusion power. The beam-plasma $Q$ is $\sim 1.1\left(P_{F} / P_{B}\right)$, but due to the reduction in the plasmaplasma fusion, the beam-plasma $Q$ should be more appropriately calculated as $Q=(1066-906) \mathrm{MW} / 300 \mathrm{MW}=0.53$.

The COAST calculations on which the above discussion is based assume a value of $\tau_{E}$ required for balance (in plasma energy content) without using any scaling laws. A comparison with the scaling laws introduced in Section 2.0 (Equation (8) and (9)) allows some insight into the assumptions required in the sizing 
of the DTHR neutral beam system. Of the two scaling laws considered in Section 2.0, the first $\left(\tau_{E} \propto \bar{n}_{e} a^{2}\right)$ is more optimistic and predicts longer confinement times for the OTHR plasmas than that calculated using the second $\left(\tau_{E} \propto \tilde{n}_{e} 0.6\right.$ $\left.a^{1.6}\right)$. For the plasma conditions assumed in the calculations presented in Figure 6-5, Equation (8) predicts $\tau_{E}=1.27 \mathrm{~s}$ and Equation (9) predicts $\tau_{E}=$ $0.95 \mathrm{~s}$. The required $\tau_{E}$ for ignition is $1.27 \mathrm{~s}$ in exact agreement with the results using Equation (8); the required $\tau_{E}$ for the $52 \mathrm{MW}$ beam-driven case is $0.93 \mathrm{~s}$ in good agreement with the results from Equation (9). One interpretation of these results is that DTHR should be an ignition device if the better confinement conditions are realistic or a beam-driven device if $\tau_{E} \leq 0.93 \mathrm{~s}$. The magnitude of the injected power would be based on a realistic evaluation of ${ }^{\top} E^{\prime}$ ' Clearly, in terms of cost per unit of fuel production, the ignited and the $52 \mathrm{MW}$ beam-driven cases are the most favorable. If ${ }^{\tau} E$ is less favorable, DTHR, with $52 \mathrm{MW}$ of neutral beam power, would require additional beams to achieve the levels of performance indicated in Figure 6-5. Depending on the actual ${ }^{2} E$, DTHR with $P_{B}=52 \mathrm{MW}$ could be operated at a lower plasma temperature and with a reduced level of fissile fuel production on an annual basis.

For all the calculations presented in this section (as well as in all other sections), the $Z_{\text {eff }}$ of the plasma was set at a value of 1.2 . With long pulse, high duty operation, in which a bundle divertor is providing a plasma exhaust. system during burn, $z_{\text {eff }} \approx 1$ may actually be realized in DTHR (even though the design would be for $Z_{\text {eff }} \approx 1.2$ ). Assuming $200 \mathrm{keV}$ neutral beams at a power level of $150 \mathrm{MW}$, COAST calculations using $Z_{\text {eff }}=1$, predict that the $R_{0}=5.2$ $\mathrm{m}, \mathrm{a}=1.2 \mathrm{~m}, \delta=1.6$ DTHR design would be capable of developing a neutron wal1 loading of $2.7 \mathrm{MW} \mathrm{m} \mathrm{m}^{-2}$ and the fissile fuel product rate would increase from 250 $\mathrm{kg} / \mathrm{yr}$ to $310 \mathrm{~kg} / \mathrm{yr}$. This particular calculation was based on $\mathrm{T}_{\mathrm{e}}=13 \mathrm{keV}$ and $\bar{n}_{e}=1.38 \times 10^{20} \mathrm{~m}^{-3}$, and the resulting fusion power is $\sim 1220 \mathrm{MW}$. From these and other results discussed above, it is clear that an optimization of the present DTHR design would yield important information, as well as an improved design basis. 


\subsection{SUMMARY AND CONCLUSIONS}

In this report, the results from parametric trade studies have been presented in order to quantitatively evaluate the costs and performance of a near-term demonstration fusion-fission hybrid reactor (DTHR) over a wide range of tokamak plasma sizes. The results are especially important in providing trends in both cost and performance as a function of the main parameters associated with the DTHR device. Based on a device consisting of $\mathrm{S} / \mathrm{C}$ forced flow cooled $\mathrm{Nb}_{3} \mathrm{Sn}$ magnetic field coils, a zircaloy-clad $\mathrm{ThO}_{2}$ boiling water-cooled blanket, neutral beam injectors operated in both the start-up for ignition and beam-driven modes, an elongated plasma with a moderately high beta, and a bundle divertor plasma exhaust system, results show the potential for achieving the successful demonstration of fissile fuel production in the 1980's from a tokamak hybrid. The results and discussions presented in Section 2.0 through 6.0 are summarized below. The results are not for an optimized design, but represent numerical data which can be used in further design iterations leading to a fully optimized DTHR in terms of device performance. In Section 2.0, the scientific and engineering ground rules used in the calculational results are discussed. The plasmas for each of the various DTHR sizes are based on assuming the poloidal beta is equal to the aspect ratio for an elongation of 1.6. The resulting total betas are approximately $6 \%$ over the ranges studied. The plasma is assumed to have parabolic profiles in both temperature and density, and both beam-driven and ignition operation are considered. The fission blanket covers only a fraction of the outer half of the vacuum vessel and $i$ ts parameters are obtained by the ground rules shown in Table 2-3, which characterizes the device for a single point in time realizing the blanket behavior changes with time. The selection of blanket parameters yields results that represent average performance over the lifetime of the blanket or performance under equilibrium conditions. The neutral beam power and particle energy is a function of the plasma size and an upper limit of $200 \mathrm{keV}$ is assumed for a realistic design of the positive-ion based system. If it is assumed that ripple injection or programmed start-up are demonstrated to work so that moderate energy ( $150 \mathrm{keV}$ ) 
neutral beams may be employed independent of plasma density, plasma radius, and $Z_{\text {eff }}$, the constraints on the neutral beam energy can be removed. The effect on the conclusions of this study can easily be ascertained. TF coil design is based on a compact D-shaped geometry as well as a $12 \mathrm{~T} 1$ imit on the maximum field at the coil.

In Section 3.0, an extensive set of calculational data is presented for DTHR devices for which $A=4.333, B=6.2 \%$, and $4.33 \leq R_{0}(m) \leq 6.93$, and the neutron wall loading $\mathrm{J}_{\mathrm{W}} \geq 2.0 \mathrm{MW} \mathrm{m}^{-2}$. Three sets of code calculations are discussed: 1) plasma operated at $\bar{T}=17 \mathrm{keV}$ in the beam-driven mode for which $J_{W}=2 M W m^{-2}$ and $B_{M}$ and $E_{b}$ vary with $R_{0} ; 2$ ) an ignited plasma at $\bar{T}=17 \mathrm{keV}$ for which $\mathrm{J}_{W}=2 \mathrm{MW} \mathrm{m}^{-2}$ and $B_{M}$ and $E_{b}$ vary with $R_{0}$; and 3 ) an ignited plasma for which $J_{W} \geq 2 \mathrm{MW} \mathrm{m}^{-2}, B_{M} \approx 12 \mathrm{~T}, E_{b} \approx 200 \mathrm{keV}$, and $T$ varies with $R_{0}$. In the first two series of calculations, $\tau_{E}$ was assumed to be that time constant required for energy balance (Eq. 10, Section 2.0), and in the last series, ${ }^{\tau_{E}}$ was assumed to be the empirical time constant given by Eq. (8). The third set of calculations is considered as a limiting case in which the parameters are set at their upper limits (but. not necessarily the optimized limit). With a few exceptions, the results of varying $R_{0}$ over the range of $\sim 4 \mathrm{~m}$ to $7 \mathrm{~m}$ for DTHR show device (and facility) costs in the range from $600 \mathrm{M} \$$ to $800 \mathrm{M} \$, E_{b} \geq 160 \mathrm{keV}, \mathrm{P}_{\mathrm{B}} \geq 40 \mathrm{MW}$, and TF coil bore dimensions of approximately $6 \mathrm{~m} \times 8.5 \mathrm{~m}$ and larger. For $R_{0} \geq 4.9 \mathrm{~m}$, the fissile fuel $\left({ }^{233} \mathrm{U}\right)$ production is greater than $200 \mathrm{~kg} / \mathrm{yr}$ which is considered important for the successful demonstration of fissile fuel production in a fusion-fission device. For the assumptions (ground rules) used in the study, an $R_{0}=4.9 \mathrm{~m}$ device is the minimum beam-driven size for which $200 \mathrm{~kg} / \mathrm{yr}$ of fuel is produced and for which $B_{m} \leq$ 12 T. At $R_{0}=4.9 \mathrm{~m}, E_{b} \approx 50 \mathrm{MW}$, and approximately $300 \mathrm{MW}$ of high-grade heat is removed from the blanket. The direct capital cost of the device is $\sim 610$ $M \$$ and the average electrical power consumption during pulsing is $400 \mathrm{MW}_{\mathrm{e}}$. In general, the $E_{b}=200 \mathrm{keV}$ limit is important at the larger values of $R_{0}$, while the $B_{M}=12 T$ limit becomes important as $R_{0}$ decreases in magnitude. All of the results take the low plant avallabililiy $(0.2)$ and wall coverage fraction (0.36) into account. The electrical power consumption is based on the operation of the NB injectors which consume up to $90 \%$ of the power and the 
heat dissipation systems which consume most of the remainder of the electrical power.

The results in Section 3.0 for the ignited plasma in which $J_{W}=2 \mathrm{MW} \mathrm{m}^{-2}$ indicate the reduction in operating power required when the NB injectors can be turned off during the burn. The consumption under ignition conditions is in the range of $100 \mathrm{MW}_{e}$ or less and with the appropriate thermal-to-electrical conversion equipment is low enough to allow for the possibility of energy selfsufficiency in DTHR operation. For all radii such that $R_{0} \geq 5.2 \mathrm{~m}$ ignition conditions are consistent with $\tau_{E} \propto \bar{n}_{e} a^{2}$ (Eq. 8), so that ignition operation of DTHR is potentially possible. For the ignition case in which $B_{M}=12 \mathrm{~T}$, $E_{B} \approx 200 \mathrm{keV}$, DTHR operations at extremely attractive levels of performance have been obtained for all values of $R_{0}$. Wall loadings up to $2.5 \mathrm{MW} \mathrm{m}^{-2}$ are calculated, but require $R_{0} \geq 6.5 \mathrm{~m}$. Fissile fuel production rates at $R_{0}=$ $6.93 \mathrm{~m}$ exceed $500 \mathrm{~kg} / \mathrm{yr}$, but the cost is at the $1 \mathrm{~B} \$$ level. These larger sizes are of interest only for future commercial reactors where performance would be further enhanced by higher plant availability and blanket wall coverage.

In Section 4.0, two DTHR devices, one at $R_{0}=5.2 \mathrm{~m}$, and the other at $R_{0}=$ $6.93 \mathrm{~m}$, are examined as a function of neutron wall loading $\mathrm{J}_{\mathrm{W}}$ for the beamdriven option. For the $R_{0}=5.2 \mathrm{~m}$ case, the limiting values of $E_{b}=200 \mathrm{keV}$ and $B_{M}=12 \mathrm{~T}$ occur at the same value of $\mathrm{J}_{W}$. The value is $2.5 \mathrm{MW} \mathrm{m}^{-2}$ resulting in the production of $300 \mathrm{~kg} / \mathrm{yr}$ of fuel and a direct capital cost of $680 \mathrm{M} \$$. If the DTHR design is fixed such that $200 \mathrm{~kg} / \mathrm{yr}$ of fissile fuel is produced, the wall loading, NB energy, and maximum fleld at the TF coil could be reduced to the following values: $1.75 \mathrm{MW} \mathrm{m}^{-2}, 175 \mathrm{keV}$, and $11 \mathrm{~T}$, respectively. The direct capital cost for the $R_{0}=6.93 \mathrm{~m}$ device is considerably increased over that for $R_{0}=5.2 \mathrm{~m}$, i.e., 650 M\$ at $5.2 \mathrm{~m}$ compared to $~ 900 \mathrm{M} \$$ at $6.93 \mathrm{~m}$, but the data exhibits an economy-of-scale in terms of cost per unit of fuel production which provides some motivation for considering the larger sized devices for commercial applications. The main weakness at the larger DTHR sizes is the very high requirement on $E_{b}\left(200 \leq E_{b}(k e V) \leq 250\right)$. 
In Section 5.0, the cost and performance of DTHR as a function of the aspect ratio is discussed for three radii, $a=1.0,1.1$, and $1.2 \mathrm{~m}$. The calculations were performed maintaining $B_{M}=12 \cdot T, \bar{T}=17 \mathrm{keV}$. The results indicate that at $a=1.0 \mathrm{~m}$, the fissile fuel production rate is below the desired $200 \mathrm{~kg} / \mathrm{yr}$ level, while it is roughly at the desired level for a $=1.1 \mathrm{~m}$, and exceeds $200 \mathrm{~kg} / \mathrm{yr}$ for $\mathrm{a}=1.2 \mathrm{~m}$. Unfortunately, only the smaller aspect ratios at $a=1.2 \mathrm{~m}$ are associated with NB energies below $200 \mathrm{keV}$. The results displayed in Section 5.0 indicate and quantify trends associated with the sizing of DTHR, and thus form an important basis for later sensitivity studies for the optimization of DTHR.

In Section 6.0, a number of preliminary sensitivity studies on the DTHR design are discussed. Considered in the calculations were the plasma elongation, $\delta$, the minor radius, $a$, the TF coil peak field, and the neutral beam power injected into the plasma. The results indicate that for fixed values of $R_{0}, \delta, E_{b}$, and $B_{M}$ the smaller values of minor radius result in larger wall loadings, lower costs, and comparable costs per unit of fuel production with the large radi $i$ devices. The wall loading, cost, and fissile fuel production are strongly dependent on the elongation $\delta$. The data clearly indicates the advantages in higher wall loadings, and the need to design DTHR for the highest feasible elongation. For the data presented as a function of the maximum field $B_{M}$, the fuel production, wall loading, and high-grade heat produced in the blanket were found to increase in proportion to the increases in $B_{M}$. The annual electrical energy consumption increases faster than $B_{M}$ due to the increases in neutral beam power requirements at the higher values of $T$ associated with larger values of $B_{M}$. In the last set. of preliminary sensitivity calculations with $R_{0}=5.2 \mathrm{~m}, a=1.2 \mathrm{~m}, \delta=1.6$, the neutral beam power $P_{B}$ during the burn was varied from 0 to $300 \mathrm{MW}$. The range of the calculation represents plasma conditions from a strongly beam-driven option for which $Q \sim 3.0$ through ignition. The device cost increases by $50 \%$ over this range of $P_{B}$, while the fissile fuel production increase only 18\%. For the densities, temperatures, and plasma volumes considered for DTHR, the bulk plasma-plasma fusions represent the major contribution to the fusion power production. Even at $P_{B}=300 \mathrm{MW}$, the plasma-plasma $Q$ is 2.5 while the beam-plasma $Q$ is only 1.1 . Thus, the results indicate the attractiveness of operating DTHR in either an ignited or a near- 
ignited mode. Of course, the energy confinement time will dictate the operation mode, and if $\tau_{E} \propto \bar{n}_{e} a^{2}$ is realized for DTHR plasma conditions, ignition is possible.

Throughout the discussion of the DTHR trade study results, it was indicated that the results were based on a plasma $z_{\text {eff }}=1.2$. In the final discussion of Section 6.0, calculations for which $Z_{\text {eff }} \sim 1.0$ were presented. To summarize, the $5.2 \mathrm{~m}, 1.2 \mathrm{~m}$ DTHR design would be capable of a wall loading of $2.7 \mathrm{MW} \mathrm{m}^{-2}$ and a fuel production rate of $310 \mathrm{~kg} / \mathrm{yr}$ at $Z_{\text {eff }} \sim 1.0$. This calculation cleariy indicates the need for a DTHR design in which impurities can be prevented from entering the bulk plasma. In addition, the calculations indicate the need to examine the complete set of assumptions and ground rules for DTHR in order to provide a more optimized design, as well as to provide more input into the plasma and engineering requirements allowing for the highest degree of performance in DTHR. 


\subsection{REFERENCES}

1. "Status Report on the Preliminary Conceptual Design of a Demonstration Tokamak Hybrid Reactor (DTHR) January 1978-March 1978," Westinghouse Electric Corp. Report No. WFPS-TME-086 (June 1978); see also, D. L. Chapin, J. W. H. Chi, and J. L. Kelly, Proceedings of the Third Topical Meeting of the Technology of Controlled Nuclear Fusion, Santa Fe NM, CONF-780508 (May 1978) p 230.

2. J. L. Kelly, et al., "Conceptual Design of a Demonstration Tokamak Hybrid Reactor (DTHR) September 1978," Westinghouse Electric Corp. Report No. WFPS-TME-107 (December 1978).

3. "Four Ignition TNS Tokamak Reactor Systems - Design Summary," Westinghouse Report No. WFPS-TME-071 (October 1977); al so see the Proceedings of the Seventh Symposium on Engineering Problems of Fusion Research, Knoxville TN (October 1977) where several contributions were made related to TNS/ COAST results.

4. G. Gibson, et al., "A Preliminary Scoping Analysis of SLPX-III, A D-T Burning Version of the Superconducting Long-Pulse Experiment," Westinghouse Electric Corp. Report No. WFPS-TN-132 (November 1978).

5. D. A. Sink, E. M. Iwinski, D. L. Chapin, and G. Gibson, "The COAST Code for the Costing and Sizing of D-T Burning Tokamaks, Supplement to Nuclear Fusion on the Conference and Workshop on Fusion Reactor Design Concepts, University of Wisconsin (October 1977) p 701.

6. D. L. Chapin, H. J. Garber, G. Gibson, E. M. Iwinski, and D. A. Sink, Trans. American Nuclear Society 17, 24 (1977) "Reactor System Size and cost Trends for TNS Tokamaks."

7. W. C. Brenner, "A New Constant Tension Toroidal Field Coil Design," to be published in the Proceedings of the 1978 Intcrnational Conference on Plasma Science, Monterey CA (May 1978).

8. T. F. Yang, G. W. Ruck, A. Y. Lee, G. Smeltzer, and T. Prevenslik, "Reactor Application of an Improved Bundle Divertor," Westinghouse Electric Corp. Report No. WFPS-TME-104 (November 1978).

9. J. W. H. Chi, et al., "Demonstration Tokamak Hybrid Reactor (DTHR) Blanket Design Study," Westinghouse Electric Corp. Report No. WFPS-TME-106 (December 1978).

10. DIVA Group, "Divertor Experiment in DIVA," Nuclear Fusion 18 (1978) p 1619. 
11. D. L. Chapin and H. R. Howland, "Plasma Scaling Relationships for Preparation of Input to COAST," Westinghouse Electric Corp. Report No. WFPS-TN-069 (September 1977).

12. W. Pfeiffer and R. E. Waltz, "Empirical Scaling Laws for Energy Confinement in Ohmically-Heated Tokamaks," Nuclear Fusion 19 (1979) p 51.

13. "MIT/W HFCTR Final Report," MIT Report, to be published.

14. D. Steiner, et al., "ORNL Fusion Power Demonstration Study:Interim Report," Oak Ridge National Laboratory, ORNL/TM-5813 (March 1977).

15. D. L. Jassby, R. J. Goldston, "Enhanced Penetration of Neutral-Beam-Injected Ions by Vertically Asymmetric Toroidal-Field Ripple," Nuclear Fusion 16 (1976) p. 613.

16. "TFTR Final Conceptual Design Report," Westinghouse Report TFTR-TR-001 (October 1975). 


\section{APPENDIX A}

\section{COAST CODE UPGRADE DESCRIPTION}

SCOPE AND PURPOSE OF THE COAST CODE

The FORTRAN code for the costing And Sizing of Iokamaks (COAST) was written by Westinghouse Fusion Power Systems Department to conduct detailed analyses on the engineering features of a tokamak fusion device and facility, and to estimate the costs associated with such a facility. A generalized description of $D-T$ burning tokamaks is coded. This provides for the self-consistent modeling of approximately 50 subsystems. The models allow for the sizing and costing of a wide range of device sizes and features including TFTR, TNS (The Next Step), Fusion/Fission Hybrids, demonstration reactors, commercial reactors, beam-driven devices, and ignition devices. The code has been used to establish the features of various reference designs including TNS and the Demonstration Tokamak Hybrid Reactor (DTHR), and to conduct trade studies for the effects of device options and sizing on the device performance and cost. The models for the various subsystems are generalized where possible, and include considerable engineering detail. The extent of the detail is related to the impact each system has on the sizing of the device and its relative contribution to the cost of the device. The more detailed systems are the toroidal field coils, poloidal field coils, neutral beams, blankets, divertor, fuel handling, and heat dissipation and power conversion systems. The version of COAST presently in operation is the fourth, and has evolved out of engineering studies of tokamak systems conducted over the last two years by the Westinghouse Fusion Power Systems Department.

THE COAST CODE LOGIC.

The logic system for COAST includes both a main program which consists of sections dedicated to specific subsystems and linked in a sequential manner as well as of subroutines each of which relates to a single subsystem. In each COAST section or subroutine, all the data which specifies a subsystem is gen- 
erated including both the data relevant to a self-consistent description of that system and the data required to allow the system to be sized consistently with each of the other tokamak systems components. The sequence of calculations coded in COAST are organized as if one were "building" the tokamak and facility around the plasma core with the components nearest the core modeled first. As each subsystem is specified, data is generated which allows the next subsystem to be described consistently with previous calculations in a given computer run. The COAST logic and components are shown in the detailed flow diagram in Figure $A-1$.

\section{PLASMA ENGINEERING IN COAST}

The models for calculating plasma parameters during the steady state operation of the pulse have been developed to provide the data necessary to size the systems required for such operations. These systems include magnetic field coils, neutral beams, nuclear shielding; fuel supply, exhaust systems, and heat dissipation. The following is a list of features which have been incorporated into the plasma model:

- Calculates both energy and particle balance conditions for either an ignited plasma or a beam-driven plasma;

- Computes the effects on the bulk plasma particle density and the plasma beta of alpha-particle production;

- Incorporates the results from slowing-down theory in obtaining fast particle populations of alpha-particles and hot ions created by neutral beam injection;

- Calculates fusion reaction rates from both plasma-plasma and beam-plasma interactions;

- Includes impurity effects and energy losses due to radiation;

- Assumes the plasma is comfosed of seven particle groups: 1) bulk electrons; 2) bulk deuterium ions; 3) bulk tritium ions; 4) impurity ions; 5) bulk alpha-particles; 6) fast alphaparticles; and 7) fast deuterons from neutral beams (if in beam-driven mode);

- Establishes both the toroidal beta and the poloidal beta as a function of particle pressure due to all particle groups, plasma stability, and plasma aspect ratio; 


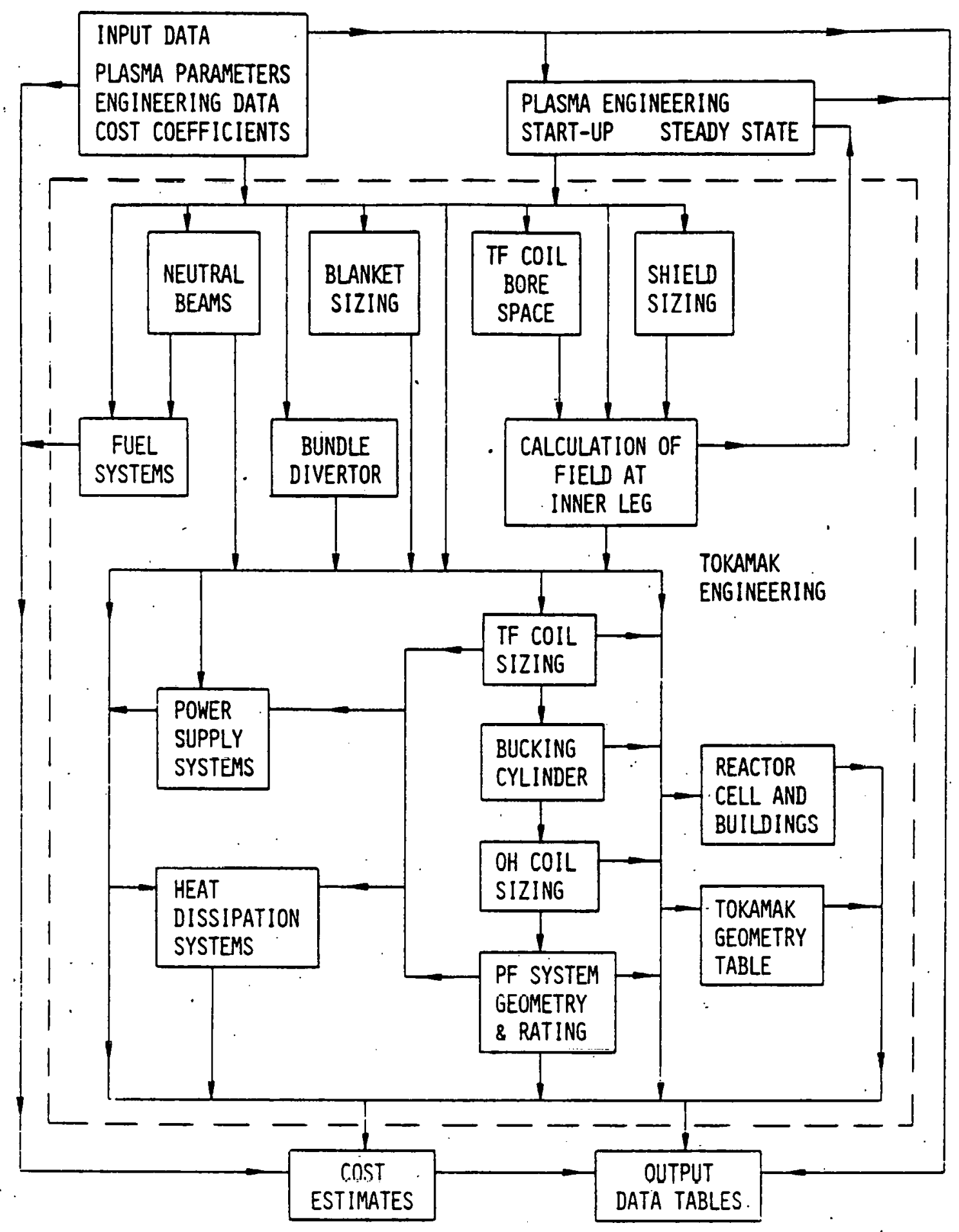

COAST FIOW Diagram 
- Estimates fusion reaction rates, beta values, and $\bar{n}_{\mathrm{e}}{ }^{\tau} \mathrm{E}$ values assuming profile effects;

- Scales the product $\bar{n}_{e} \tau_{E}$ in a generalized manner as a function of plasma density, radius, stability factor, field-on-axis, aspect ratio, and/or plasma temperature.

The above features are incorporated self-consistently in COAST, and the results are obtained through iteration. From the results, one obtains magnetic field requirements, particle fueling rates, plasma power and wall loading levels, magnitude of the plasma current, and neutral beam power and energy requirements.

To complete the modeling of the plasma, calculations allowing a description of the plasma initiation and start-up are also carried out in COAST. The model provides an estimate of the time profiles for the plasma current, inductance, resistance, and voltage, and predicts the volt seconds associated with the plasma resistive losses. From these results, the current and voltage requirements for the various poloidal field coils can be calculated so that the ratings on power supplies can be obtained.

\section{TOKAMAK ENGINEERING IN COAST}

The engineering models for the tokamak and facility are incorporated into the coding in the logic system indicated in Figure A-1. Each block in that diagram represents a subsystem (or set of subsystems) which is coded as a COAST section or subroutine. A very brief description of several of the blocks follows.

The TF coil bore space and shield sizing models provide the basis for establishing the space requirements within the TF coil bore. The vacuum vessel, radiation shielding, equilibrium field (EF) coil, access and maintenance, and TF coil dewar (if superconducting), as well as the plasma and limiter/liner/ scrape-off space requirements are calculated. For the shield sizing, both nuclear heating limits and fluence limitation to conductor insulation are taken into account.

The neutral beam model is coded as a subroutine and involves detailed calculations for sizing the beam arms, estimating the operating parameters, and eval- 
uating the power supplies for either direct energy recovery or for operating without a recovery system. Charged particle source geometry, gas-channel neutralizer sizing, ion collector plates, and vacuum pumping are taken into account in the model. Electrical, heat, and vacuum pumping loads are estimated for the engineering parameters supplied via the input data. The models provide a detailed description of the neutral beam systems, as well as privide access requirements to size TF coils, heat dissipation and power consumption requirements, and size requirements for the reactor cell model.

The blanket sizing model is in the form of a subroutine and allows for the engineering of a blanket assembly covering the outer half of the vacuum vessel, as well as a power conversion system to produce electricity from the blanket thermal power. The assembly is modeled as consisting of up to six zones where each zone is made up of six volume fractions of any desired material. Production of power, tritium, and fissile fuel are modeled. The power production systems include heat exchangers, generators, cooling, and energy storage.

The section indicated by Field at Inner Leg is a branch point in COAST which represents a calculation critical to both the plasma engineering and the tokamak engineering. The maximum B field at the inner leg of the TF coil is constrained by the mechanical/thermal design of the coil as well as by the requirements for a given field on the plasma axis. This section evaluates these constraints and calculates the field taking any ripple in the TF into consideration. As a result of the calculation, the coding allows the calculation to continue, to adjust the plasma field conditions, or to terminate due to a violation of engineering ground rules set by the input.

The TF coil sizing section of the code is the central link in the "building" of the tokamak system. All the above models (except for the fuel systems) communicate at this point, and all the subsequent calculations are impacted by the results from the TF coil sizing. The TF coil bore space dimensions are calculated on the basis of constraints established by: 1) the component and plasma space requirements within the TF bore; 2) the plasma ripple requirements at the outer plasma surface; 3 ) the access requirements for neutral beam injection; and 4) access requirements for the divertor (if sized). The engineering 
models allow for the sizing of coils for four different technologies:

- Copper (room temperature or liquid-nitrogen cooled)

- Superconducting NbTi

- Superconducting $\mathrm{Nb}_{3} \mathrm{Sn}$

- Cu/NbTi hybrid

In the sizing of the assemblies, the models allow coil shapes which are either constant-tension $D$, circular, or compact $D$. The mechanical design of the coils is accomplished through generalized descriptions which account for strain limits, cooling requirements, construction (bolted or welded), and allowable current density in the conductors. The coil assembly sizing results impact the design of the poloidal field (PF) coils, the heat dissipation systems, the power supply ratings, the reactor coil size, and is the major element in the resulting tokamak geometry. The TF coil centering forces are assumed to be handled by wedging unless a bucking cylinder is specified. The bucking cylinder sections sizes this structure to handle a part or all the centering forces for D-shaped coils and to be stable both compression and buckling modes of failure.

The final set of model equations for the tokamak engineering are for the reactor cell and buildings. In this model, the reactor cell sizing is obtained by. taking into account the tokamak dimensions as well as the neutral beam arm sizing. The reactor cell is a cylindrical dome-top structure of concrete with a basement for the containment of the tokamak support systems. The remaining buildings are not explicitly sized, but the costing input data should include estimates for the complete facility including all buildings.

\section{COST ESTIMATES FROM COAST}

The COAST code was designed as a tool for tokamak engineering studies (detail design studies and engineering trade studies) and for the costing of any resulting design. The modeling system incorporated in the cost estimates sections of COAST has been carefully constructed to allow for the wide variety of resulting designs, as well as to allow costing data to be applied in a form which is essentially device independent. To accomplish this feature, a system 
of costing equations was developed which required two types of data: 1) costing data on the materials and components; and 2) sizing results on the amount of material required or on a component rating.

The costing data is supplied as input data in COAST. The data consists of the following:

- Unit cost coefficients

- Economy-of-scale parameters

- Indirect costing parameters

- Escalation

- Operating cost

The unit cost coefficients are in the form of cost per unit size or rating, and in the case of studies by the Westinghouse Fusion Power Systems Department, are the results of a bottoms-up estimate of the materials and manufacturing costs. In estimating the costs of several systems, it was found necessary to establish an economy-of-scale, and the scaling parameters (exponents and reference ratings) are supplied as input allowing data changes without requiring coding changes. Indirect costs are handled as percentages of the direct capital costs, and includes shipping and hendling, installation, EDIA and contingency. Escalation is handled component-by-component, and is a single rate provided as input, for all components. Operating costs include utility and tritium costs. Electrical production and tritium production are calculated, and for a selling price (input data) are subtracted from operating expense. If costs are negative in value, the facility is a producer and not a consumer as would be the case of a commercial plant.

In the second type of data required for the costing equations, i.e., sizing results, the tokamak engineering models provide all the essential data. The models take into account the type of data required so that such data is available at that point in the COAST calculation when the costing begins. For example, masses of magnetic coil assemblies (conductor as well as structural), volumes of radiation shielding, stainless steel, power supply ratings, thermal loads are sizing results required in the cost estimation. The sizing results 
are strongly device dependent whereas the costing data are, in general, device independent and are obtained as input data from a separate costing procedure.

\section{APPLICATIONS OF COAST - TO DESIGN STUDIES}

COAST was developed as a tool for application to the TNS trade studies conducted by the ORNL/Westinghouse study team.:Version 3 of the code was used in the final stages of the study. For the TNS work, four ignition tokamak point designs were developed, and an extensive series of parametric trade studies were performed to consistently evaluate the relative costs and performance parameters of various designs over a wide range of plasma sizes. From this study, it was concluded that the superconducting option was more attractive than copper, and of the superconducting technologies, the $\mathrm{Nb}_{3} \mathrm{Sn}$ is more attractive than both the NbTi and the hybrid $\mathrm{Cu} / \mathrm{NbTi}$ optjons.

During the final stages of coding, COAST 3 was applied to the sizing and costing of the conceptual design of TFTR. The code produced the main features of that device and estimated that capital costs to within $5 \%$ of the costs determined during the conceptual design study. In addition, the GA/ANL TNS reactor system was examined. The GA/ANL reactor involved a doublet plasma which the COAST code could not model in detail, but the code calculations were consistent with both the sizing and costing results reported by that study team.

COAST 4 development began following the designation by DOE of the study of fusion/fission hybrids by the Westinghouse team. All the features of COAST 3 were maintained or upgraded during COAST 4 development, such that all the TNS options and TFTR could be modeled. In fact, the new version of COAST sizes TFTR with more accuracy since upgraded models were added to account for beamdriven operation, as well as ignition operation. As COAST 4 was being completed, the code was applied to the results of the design study of a fusion-driven tokamak hybrid reactor for fissile fuel production conducted for EPRI by Westinghouse. This study was carried out by a team of Westinghouse engineers, who, for the most part, were different from the team who provided the cost models employed in COAST 4. Thus, the EPRI study provided an excellent check of the models incorporated. The code results were very compatible with the 
EPRI design in that the main features and operating parameters of the hybrid device were similar and the capital cost estimates were in good agreement. Considerable effort was applied to the study of any differences arising between the code results and the study design. In every case, the basic models were found to be correct, and provide accurate predictions of sizing and costing results. Any differences were found to be more closely associated with engineering assumptions and ground rules. 
APPENDIX B

COAST RESULTS FOR TFTR

In developing the COAST code to size and cost TNS (The Next Step) devices several iterations and upgrades of the models for various components were required. After the final code iteration (COAST 3) a series of test and verification runs were conducted in which the goal was to size and cost the conceptual design for TFTR. The COAST 3 models were based on an ignition tokamak, so that the results for TFTR required careful examination before one could utilize them. For the most part, the final set of runs allowed for a size and cost parameterization of TFTR which was reasonably accurate. The total cost for TFTR hardware was found to agree to within $5 \%$ of that estimated during the conceptual design study (after taking escalation into account when comparing the 1975 estimates with the 1977 COAST costing data).

After the COAST code was again upgraded to model beam-driven plasmas as well as to model various systems (e.g., PF coils and NB injectors) in more detail and with more alternative design considerations, the code (COAST 4) was applied to TFTR. Those results are discussed below. In general, the sizing results are in good agreement with the conceptual design parameters and the total hardware costs are within $1 \%$ of the earlier estimate. The Final Conceptual Design Report ${ }^{(16)}$ (FCDR) data was used in the following discussion and tables when comparisons with COAST 4 data are indicated.

The assumptions (COAST INPUT) concerning the plasma which were made in sizing and costing TFTR are summarized in Table B-1. The engineering data for the vacuum vessel, radiation shielding, TF coils, PF coils, neutral beam injectors; water-cooling systems, and the reactor cell were obtained from the FCDR (TFTRTR-001, October 1975). The code calculated the plasma performance parameters which are listed in Table B-2. These results are in excellent agreement with the expected plasma behavior as indicated in the FCDR. The confinement time of $0.23 \mathrm{~s}$ is required for energy balance assuming this value for both particle 
TABLE B-1

ASSUMPTIONS FOR TFTR PLASMA

(Used as Input for COAST-4)

PARAMETER (UNIT)

MAJOR RADIUS (m)

MINOR RADIUS (m)

AVERAGE DENSITY, $\bar{n}_{\mathrm{e}}\left(\mathrm{m}^{-3}\right)$

AVERAGE TEMPERATURe, $\overline{\mathrm{T}}_{\mathrm{e}}(\mathrm{keV})$

FIELD-ON-AXIS (T)

STABILITY FACTOR (q)

$Z_{\text {eff }}$

NEUTRAL BEAM ENERGY (keV)

NEUTRAL BEAM POWER (MW)
VALUE

2.48

0.85

$0.5 \times 10^{20}$

6.7

5.2

3.0

2.0

125

20 
TABLE B-2

CALCULATED RESULTS FOR THE TFTR PLASMA

(Based on COAST -4 )

\begin{tabular}{|c|c|}
\hline PARAMETER (UNIT) & VALUE \\
\hline CONFINEMENT TIME (s) & 0.23 \\
\hline TOTAL BETA $(\%)$ & 1.4 \\
\hline POLOIDAL BETA $(-)$ & 1.1 \\
\hline PLASMA CURRENT (MA) & 2.52 \\
\hline PLASMA INDUCTANCT $(\mu H)$ & 4.53 \\
\hline RESISTIVE VOLT-SECONDS & 1.9 \\
\hline Q-VALUE & 0.94 \\
\hline NEUTRON WALL LOADING $\left(\mathrm{MW} \mathrm{m}^{-2}\right)$ & 0.17 \\
\hline FUSION POWER (MW) & 18.8 \\
\hline $\bar{n}_{D} / \bar{n}_{e}$ RATIO & 0.129 \\
\hline $\bar{n}_{T} / \bar{n}_{e}$ RATIO & 0.721 \\
\hline $\bar{n}_{H} / \bar{n}_{e} \operatorname{RATIO}$ & 0.105 \\
\hline $\bar{n}_{a} / \bar{n}_{e} \operatorname{RATIO}$ & 0.002 \\
\hline $\bar{n}_{Z} / \bar{n}_{e}$ RATIO & 0.002 \\
\hline
\end{tabular}


and energy transport losses. The value expected using empirical scaling $\left(n_{e^{\tau} E}^{\infty} n_{e}^{2} a^{2} q^{1 / 2}\right)$ is $0.20 \mathrm{~s}$ which is in good agreement with the required value.

The sizing results for the COAST 4 calculations parameterizing the TF coil systems are shown in Table B-3. Also shown is the percent difference between those values listed and the values obtained during the conceptual design study. All values are generally within 10\% difference for a wide variety of parameters. The TF coil assembly, cooling system, power supplies, and operating parameters were involved in the code calculations. A set of parameters for the PF coil systems are shown in Table B-4. Again, differences are generally less than $10 \%$. The greatest percentage differences are associated with the $\mathrm{OH} C O \mathrm{Cl}$ assembly, and are related to the simplifying assumptions made in sizing that coil. In particular, the $\mathrm{OH}$ coil is assumed to consist only of a central solenoidal column and the large radii coils spaced around the TF coils are not modelled. Even with such an assumption the results are in good agreement with the FCDR.

For the neutral beam injectors on TFTR, operating parameters calculated by COAST and listed in FCDR are shown in Table B-5. Electrical and power loads, gas loads and pressures, and the cryopanel regeneration period are shown. Excellent agreement exists between the two sets of data. From the results listed in Table B-5, as well as Tables $B-3$ and $B-4$, it is concluded that the TFTR-COAST 4 sizing results are in agreement with the TFTR Conceptual Design Study and represents a confirming reference point on the ability of the code calculations to size tokamak reactors.

In addition, the code was applied to providing a cost estimate of the TFTR hardware and facility. The results are compared to the estimate given in the FCDR (+ $10 \%$ escalation) and are shown in Table B-6. The total cost estimates were essentially identical in magnitude with percent differences as large as $25 \%$ showing up in a comparison of the various system costs. For the TOKAMAK system the main difference was a result of estimates of the TF coil, assembly (12.3 M\$ from COAST-4 and $7.1 \mathrm{M} \$$ from the FCDR). Since the sizing calculations estimating the mass of the TF coil assembly was lower by $\sim 15 \%$ from that given 
TABLE B-3

CALCULATED PARAMETERS FOR TF SYSTEMS

\begin{tabular}{|c|c|c|}
\hline PARAMETER (UNIT) & $\begin{array}{l}\text { COAST }-4 \\
\text { VALUE } \\
\end{array}$ & $\begin{array}{r}\text { PERCENT* } \\
\text { DIFFERENCE }\end{array}$ \\
\hline MAXIMUM FIELD AT CONDUCTOR (T) & 9.59 & +0.5 \\
\hline STORED ENERGY (MJ) & 1340 & -2.1 \\
\hline ENERGY PER PULSE (MJ) & 3080 & -16.7 \\
\hline ENERGY RATING OF FLYWHEEL (MJ) & $9700^{\circ}$ & +7.5 \\
\hline COIL RESISTANCE $\left(\mu \Omega / T^{2}\right)$ & 0.082 & 0.0 \\
\hline COIL INDUCTANCE $\left(\mu H / T^{2}\right)$ & 0.642 & -2.6 \\
\hline$I^{2} R$ AT FULL CURRENT (MW) & 344 & +1.2 \\
\hline V-A DC POWER RATING (MVA) & 423 & -3.9 \\
\hline TOTAL TF CONDUCTOR VOLUME $\left(\mathrm{m}^{3}\right)$ & 25.8 & -10.3 \\
\hline AVERAGE COOLING LOAD (MW) & 10.1 & +14.8 \\
\hline
\end{tabular}


TABLE B-4

CALCULATED PARAMETERS FOR PF SYSTEMS

$\begin{array}{llc}\text { PARAMETER (UNIT) } & \text { VALUE } & \begin{array}{c}\text { PERCENT } \\ \text { DIFFERENCE }\end{array} \\ \text { EF COIL INDUCT }\left(\mu H / T^{2}\right) & 2.0 & 0 \\ \text { EF COIL RESIST }\left(\mu \Omega / T^{2}\right) & 2.2 & -8.8 \\ \text { OH COIL INDUCT }\left(\mu H / T^{2}\right) & 0.59 & -11.5 \\ \text { OH COIL RESIST }\left(\mu \Omega / T^{2}\right) & 0.36 & -45.9 \\ \text { OH COIL CURRENT }(M A-T) & 8.32 & -1.0 \\ \text { EF-PLASMA MUTUAL }(\mu H / T) & 0.95 & 0 \\ \text { OH-PLASMA MUTUAL }(\mu H / T) & 0.59 & -12.7 \\ \text { EF VOLT SECONDS (V S) } & 4.3 & +7.2 \\ \text { OH VOLT SECONDS (V S } \mathrm{S}) & 9.8 & -6.0 \\ \text { ENERGY DELIVERED TO EF (MJ) } & 54 & -8.8 .\end{array}$


TABLE B-5

CALCULATED NB INJECTOR PARAMETERS FOR A SINGLE INJECTOR ARM (4 INJECTORS REQUIRED FOR TFTR)

PARAMETER (UNIT)

NB POWER TO PLASMA (MW)

ACCEL POWER TO SOURCES (MW)

ION POWER FROM SOURCES (MW)

GAS THROUGHPUT TO SOURCES (TORR- $\ell / \mathrm{s}$ )

PRESSURE IN NEUTRALIZER(TORR)

PRESSURE IN DUMP REGION (TORR)

PRESSURE IN DRIFT REGION (TORR)

CRYOPANEL REGENERATION PERIOD (DAY)

FRACTIONAL-ENERGY BEAM TO PLASMA (MW) $\underline{\text { COAST } 4}$ TFTR FCDR

$5.0 \quad 5.0$

$28.0 \quad 29.3$

$21.0 \quad 20.0$

100 . $75-100$

$5 \times 10^{-3} \quad 3 \times 10^{-3}$

$3 \times 10^{-5} \quad 5 \times 10^{-5}$

$1 \times 10^{-6} 5 \times 10^{-5}$.

$60 \quad 66$

$2.8 \quad 3.0-3.8$ 
TABLE B-6

COSTS IN M\$ OF TFTR HARDWARE FROM COAST-4 AND THE FCDR

\begin{tabular}{|c|c|c|}
\hline SYSTEM & COAST -4 & TFTR FCDR \\
\hline TOKAMAK & 23.39 & 18.84 \\
\hline ELECTRICAL ANO CONTROL & 33.70 & 43.34 \\
\hline TOKAMAK SUPPORT & 13.09 & 11.51 \\
\hline BUILDINGS & 31.21 & 30.53 \\
\hline NEUTRAL BEAMS & 25.82 & 22.05 \\
\hline TOTAL & 127.21 & 126.27 \\
\hline
\end{tabular}


in the FCDR, the difference in cost represents a difference in the per unit costing rates for materials. For the ELECTRICAL AND CONTROL system a difference of $9.1 \mathrm{M} \$$ showed up in the estimates for the magnetic field coil power supplies (rectifiers, capacitors, switches, etc.). This difference came about for two reasons. First, recent advances in the manufacturing and production of power supplies have allowed for a reduction in per unit costs since the FCDR. Secondly, the circuitry and circuit elements costed out in COAST-4 are different from those used in the FCDR. The costing of the PF coil power supplies for TNS and DTHR have been under recent study by the Fusion Power Systems Department, and the results obtained for the TFTR design may require further study to firmly fix the estimate for the ELECTRICAL AND CONTROL system.

The estimates for the TOKAMAK SUPPORT systems are within $12 \%$, and the estimates for the BUILDINGS are roughiy $2 \%$ different. The NEUTRAL BEAMS system costs differ by $\sim 16 \%$ where the COAST-4 estimate includes a $2.5 \mathrm{M} \$$ cost for the NB cooling system which is not included as part of the costs for the FCDR. An addition difference of roughly $2 \mathrm{M} \$$ shows up in the estimate of power supply costs where the COAST -4 results are higher.

Accumulating all the various system cost estimates to form a total TFTR hardware cost results in a total cost of $127 \mathrm{M \$}$. The differences between the COAST-4 calculations and the FCDR data (127 M\$) are extremely small. As an estimate of the uncertainty associated with that value, the following procedure was applied. If one accumulates the maximum cost (taking both the COAST4 and the FCDR data) for each system, a total hardware cost of 137 M\$ results. Similarly, if the minimum cost for each system is accumulated, a value of 117 $M \$$ results. Thus, an estimate of $127 \pm 10 \mathrm{M} \$$ represents TFTR costs and indicates a $10 \mathrm{M} \$$ uncertainty in that value. 

G. Haas
D. Beard
J. E. Baublitz
F. E. Coffman
J. F. Clarke
R. C. Davidson
N. A. Davies
E. E. Kintner
J. Murphy
K. Zwilsky
C. R. Head
U.S. Department of Energy (G-234)
Office of Fusion Energy
Washington DC 20545

Dr. E. Rossi

U.S. Department of Energy

Office of Laser Fusion

Washington DC 20545

U. S. Department of Energy

(2 reproducible copies)

Technical Information Center

P. 0. Box 62

Oak Ridge TN 37830

0. B. Morgan

D. Steiner

Oak Ridge National Laboratory

P. O. Box $Y$

Dak Ridge TN 37830

D. M. Meade

M. B. Gottlieb

E. Frieman

Princeton University

Plasma Physics Laboratory

P. 0. Box 451

Princeton NJ 08540

Dr. F. R. Scott

Dr. N. A. Amherd

Piet Bos

Electric Power Research Institute

3412 Hillview Avenue

P. 0. Box 10412

Palo Alto CA 94304

K. R. Schultz

S. C. Burnett

General Atomic Company

P. 0. Box 81608

San Diego CA 92138
W. C. Gough

DoE Office

Electric Power Research Institute

Palo Alto CA 94304

B. K. Jensen

Research and Development

Public. Service Electric \& Gas Company

80 Park Place

Newark NJ 07101

E. J. Kohier

E. S. Halfmann

Philadelphia Electric Company

2301 Market Street

Philadelphia PA 19101

J. Luoma

W. Hirst

R. Williams

General Public Utilities Service Corp.

260 Cherry Hill Road

Parsippany NJ 07054

James L. Mulloy

J. A. Vaughn

Los Angeles Department of Water \& Power

P. 0. Box 111

Los Angeles CA 90051

C. C. Baker

S. D. Harkness

Argonne National Laboratory

9700 S. Cass Avenue

Argonne IL 60439

T. J. Driscoll

John Weissmantle

John Valente

Long Is land Lighting Company

175 E. 0ld Country Road

Hicksville NY 11801

C. E. Taylor $(L-384)$

J. D. Lee

Lawrence Livermore Laboratory

University of California

P. 0. Box 808

Livermore CA 94550

Dr. R. Uhrig

Vice President, Nuclear Affairs

Florida Power \& Light Company

9250 West Flagler. Street

Miami FL 33107 
Dr. George Watkins

Empire State Electric Energy

Research Corporation

1271 Avenue of the Americas

New York NY 10020

\section{J. Powel1}

Brookhaven National Laboratory

Upton, Long Island NY.11973

F. L. Ribe

University of Washington

MS FL-10

Seattle WA 98195

Dr. Heinz Pfeiffer

Pennsylvania Power \& Light Company

2 North Ninth Street

Allentown PA 18101

G. R. Siegel

Tennessee Valley Authority

1360 Commerce Union Bank Building

Chattanooga TN 37041

D. E. Simmons

Houston Lighting \& Power Company

Houston TX 77001

W. B. Bechanan

Kenturky Utilities Company

120 South Limestone

Lexington KY 40507

T. J. Burke

Long Is land Lighting Company

P. 0. Box 618

Wading River NY 11792

S. J. Buchsbaum

Bell Laboratories

Crawford Corner Road

Holmdel NJ 07733

D. R. Cohn

Francis Bitter Laboratory

Massachusetts Institute of Technology

120 Albany Street

Cambridge MA 02139

R. W. Conn

G. Kulcinski

Nuclear Engineering Department

University of Wisconsin

Madison WI 53706
E. C. Creutz

National Science Foundation

1800 G Street, N.W.

Washington DC 20440

Dr. Harold L. Falkenberry

Power Research \& Development Branch

Tennessee Valley Authority

503 Power Building

Chattanooga TN 37401

Dr. V. A. Finlayson

Utah Power \& Light Company

P. 0. Box 899

Salt Lake City UT 84110

S. 0. Dean (Dr.)

Science Applications, Inc. (SAI)

8400 West Park Drive

McLean VA 22104

Mr. E. C. Fiss

Duke Power Company

Design Engineering Department

P. 0. Box 2178

Charlotte NC 28242

C. W. Giesler

Wisconsin Public Service Corp.

P. 0. Box 1200

Green Bay WI 54305

R. Goodrich

Northeast Utilities

P. 0. Box 270

Hartford CT 06101

W. H. Hightower

Electric Plant Board

$101 \mathrm{~N}$. Main Street

Hopkinsville KY 42240

W. C. Wolkenhauer

Washington Public Power Supply System

P. 0. Box 968

300 George Washington Way

Richland WA 99352

H. Yoshikawa

Westinghouse Hanford Company

P. 0. Box 1970

Richland WA 99352 
R. Krakowski.

Los Alamos Scientific Laboratory

P. 0. Box 1663

Los Alamos NM 87544

L. M. Lidsky (Rm 38-174)

Massachusetts Institute of Technology

Department of Nuclear Engineering

Cambridge MA 02139

Dr. Ron Lijkala

Battelle Memorial Institute

Pacific Northwest Laboratory

P. 0. Box 999

Richland WA 99352

Sidney Law

Northeast Utilities

P. 0. Box 270

Hartford CT 06101
R. E. Aronstein

Advanced Nuclear Systems Research

\& Engineering

Bechtel Corporation

P. 0. Box 3965

San Francisco CA 94119

Dr. J. N. Grace

Princeton Area Office

U. S. Department of Energy

James Forrestal Campus

Princeton University

P. 0. Box 451

Princeton NJ 08540 